
SB421

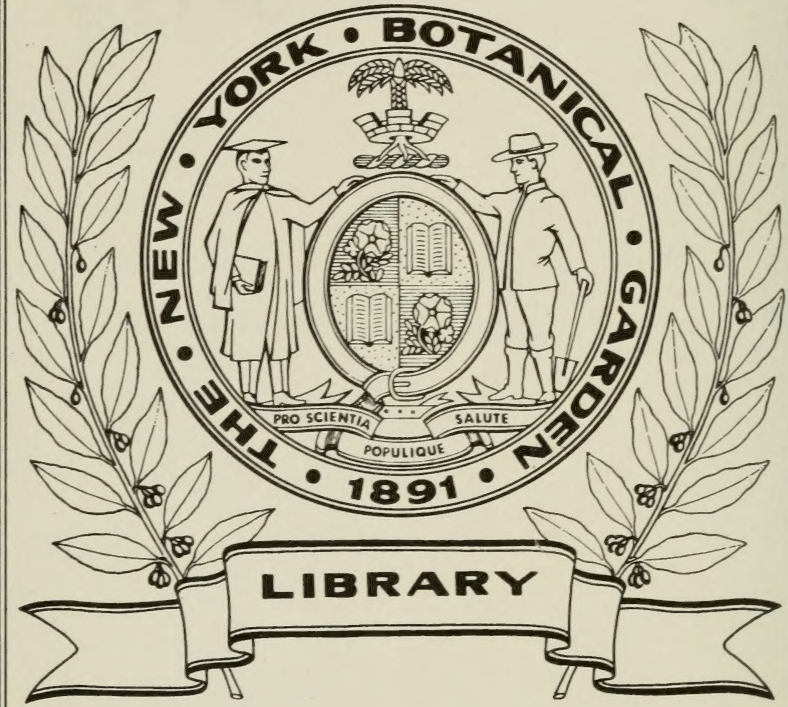




DUPLICATA BE LA BIBLIOTHEिQYZE

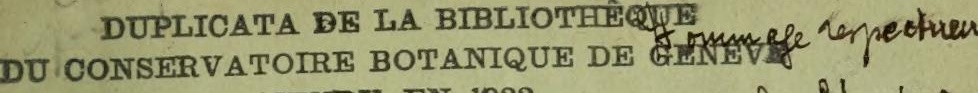
VENDU EN 1922 de l'anteura

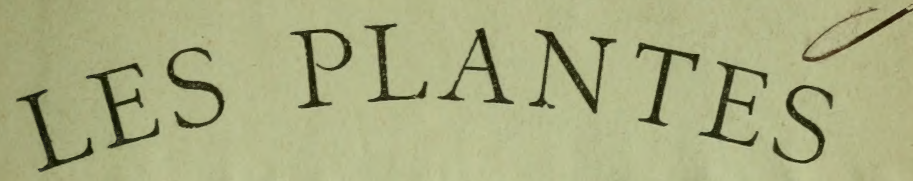

\section{DES ALPES}

PAR

\section{H C ORRE V O N}

DIRECTEUR DU JARDIN D'ACCLIMATATION

GENÈVE

Terrestria sidera, flores.

GENÈVE

IMPRIMERIE JULES CAREY, 3, RUE DU VIEUX-COLLÈGE

I 885 
- Livres provenant de la bibliothèque De Candolle, acquise par la Ville de Genève en 1921, insérés la mème année dans la bibliothèque du Conservatoire botanique de Genève. 


\section{LES}

\section{PLANTES DES ALPES}

PAR

\section{HENRY CORREVON}

Directeur du Jardin alpin d'acclimatation

GEN È V E

Terrestria sidera, flores.

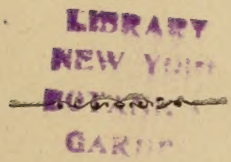

GENÈVE

IMPRIMERIE JULES CAREY, 3 , RUE DU VIEUX-COLLÈGE 


$$
\begin{aligned}
& S B 421 \\
& . C 63
\end{aligned}
$$




\section{A MES COLLÉGUES ET AMIS}

les membres du Club alpin Suisse, et à tous les alpinistes. 



\section{PREFACE}

Il n'est pas en Europe de pays aussi farorisé de la nature que l'est notre petite Suisse. Nulle part ailleurs on ne retrouve, renfermés dans un territoire aussi restreint, une pareille variété de phenomènes intéressants, de beautés pittoresques, une telle masse de matériaux propres à guider et à éclairer le naturaliste dans ses recher. ches. On ne connaît pas de contrée où, comme chez nous, le monde civilisé côtoie d’aussi près une nature indomptable et sauvage Cette nature alpine, si différente de celle qui se déroule dans nos plaines, offre, à elle seule, un champ d'études si vaste, qu'il est encore à peine exploré. G'est un domaine immense, qu'aucun homme ne peut étudier dans toutes ses parties et que 8 les savants abordent en travaillant chacun dans Til la sphère qui lui est propre. Les Horace-Bénédict i de Saussure, les Necker-de Saussure, les Buffon, Jes Escher, les Charles Bonnet, les Conrad Gessner, 
les Oswald Heer, les de Candolle, les Berlepsch, les Tyndall, les Agassiz, ont, chacun à un point de vue particulier, étudié les Alpes et leur nature. De nos jours, le nombre de ces pionniers de la science, qui ont choisi le monde des Alpes comme champ d'action pour leurs travaux, a beaucoup augmenté. Chacun travaille dans un domaine spécial et apporte ensuite sur un terrain commun le résultat de ses recherches et de ses expériences. Des sociétés se sont fondées dans le but de réunir toutes ces données, d'encourager les nombreux naturalistes qui s'occupent des Alpes et de travailler avec eux à l'avancement de la science. Puis sont venus les Clubs alpins qui, dans cette sphère-là, ont déployé pendant ces dernières années, une activité des plus utiles.

Mais laissons les savants et les naturalistes alpins à leur noble besogne et n'essayons point d'empiéter sur leurs droits. Ce que nous voulons faire ici, ce n'est point de la science, c'est de la pratique. Ce que nous allons passer en revue, ce sont les résultats d'études et d'expériences faites dans le domaine de la flore alpine par l'un de ses plus humbles, mais aussi de ses plus sincères admirateurs. La flore alpine! Qui peut rester insensible à ses charmes? Qui peut ne pas vous aimer, fleurs admirables de nos Alpes, vous, les 
bijoux du Créateur, qui brillez comme autant de perles sur les pentes veloutées de nos montagnes. comme autant d'étoiles sur le fond noir du ciel? Qui peut résister à la tentation de vous enlever, de vous emporter avec soi et de vous posséder? Délicats et gracieux joyaux, qui rayonnez au sein de la plus belle, de la plus grande des natures, comment vous dépeindre, comment décrire vos charmes? Pardonnez le peu d'élégance d'un style si peu en harmonie avec vos corolles que balance le souffle du zéphir. Quelle est la langue humaine qui pourrait rendre ces charmes et exprimer la grâce de vos contours? Il est si doux de parler de ceux qu'on aime! Mais on le fait avec d'autant plus de plaisir qu'on peut s'exprimer plus librement, sans recherche, et qu'on laisse son cœur parler tout seul. Ce plaisir reste entier alors même que l'objet de son amour est éloigné; aussi m'est-il bien doux dans un moment où vous êtes ensevelies là-haut sous des milliers de quintaux de neige, de penser à vous et de m'occuper de vous.

Qu'il me soit donc permis, humble enfant de la belle Helvétie, d'apporter mon faible tribut à l'édifice qu'ont élevé et qu'élèvent encore tant d'amis des arts et de la nature, tant de littérateurs et de poëtes, dans le but de faire connaitre, 
aimer et fréquenter les Alpes. A Genève, mieux que partout ailleurs, on aime et l'on connaît cette nature sauvage. C'est de notre patrie romande, et de Genève particulièrement, qu'est parti ce mouvement qui a fait apprécier la flore alpine et l'a a mise à la mode ", suivant une expression consacrée. Depuis quelques années, on semble avoir pris à cœur de faire descendre la flore des Alpes dans nos plaines et d'en répandre le goût dans le public, soit en la faisant connaître par le crayon ou le pinceau, soit en la répandant par le moyen de la culture.

Le moment semble donc favorable pour publier quelques renseignements au sujet de l'acclimatation de cette flore dans nos jardins. Peutêtre eût-il été plus sage de laisser ce soin à de plus savants ou d'attendre d'avoir acquis une plus forte dose d'expérience dans ce domaine. C'eût été mon intention si je n'avais été stimulé à cette entreprise par le zèle de quelques amis qui estiment que le besoin d'un ouvrage en français traitant de la culture des plantes alpines, se fait impérieusement sentir.

J'ai donc réuni à mes notes particulières, prises dans chaque occasion au fur et à mesure de mes expériences, les quelques matériaux que j'avais compulsés depuis une douzaine d'années 


\section{$-9-$}

et les renseignements divers qui ont pu m'être fournis par des personnes s'étant spécialement occupées de ce sujet. J'espère que plusieurs trouveront dans la lecture de ce petit ouvrage des renseignements utiles et des encouragements dans bien des cas. C'est là mon désir et mon vœu; puisse-t-il se réaliser !

Janvier 1884. 



\section{LES ALPES ET LEUR NATURE}

Les différentes régions. - Le printemps dans les Alpes. - Le föhn. - Les avalanches. - Les éboulements Les glaciers. - L'influence de ces différents phénomènes sur la végétation alpine.

La chaîne de montagnes qui traverse la partie méridionale de notre continent, et qu'on appelle les Alpes, est un monde à part, qui possède une vie à lui, une nature qui lui est propre et chez lequel se produisent des phénomènes particuliers que nous ne rencontrons nulle part ailleurs. Cette nature offre un cachet tout-à-fait original et n'a aucun rapport avec celle qui se déroule autour de nos cités. Tandis que, chez nous, la végétation ne se modifie qu'à de grandes distances, sur les hauteurs, au contraire, ces modifications portent sur un espace très restreint. C'est ainsi qu'un voyageur qui gravit les Alpes peut, en quelques heures, passer de la nature italienne et méridionale qui caractérise notre Valais et le Tessin, aux régions glacées des zones supérieures. La Suisse possède presque tous les climats de l'Europe et Haller écrivait déjà en 1768: 
- L'Helvétie renferme presque toutes les ré- " " gions de l'Europe, telles qu"elles se rencontrent D " des extrémités de la Laponie et du Spitzberg " - jusqu'à l'Espagne. o

En une seule journée un botaniste peut dans certaines contrées de la Suisse, récolter des plantes appartenant aux flores les plus diverses, depuis celles qui renferment le Cactus Opuntia, le Grenadier, l'Amandier, la Rue et l'Hysope, jusqu'à celles des régions arctiques.

On a divisé le monde des Alpes en différentes régions, suivant les modifications qu'offre leur nature. Tandis que certains naturalistes en multiplient le nombre, d'autres, tels que Tschudi, classent le monde alpin en trois zones différentes qui sont:

1. La région montagneuse ou boisée, laquelle s'élève, suivant les contrées, jusqu'à 1000 ou 1500 mètres. Elle comprend toute la base de la chaine alpine, la plupart des collines qui lui servent d'avant-postes et la chaine du Jura jus. qu'à la limite supérieure de ses forêts.

$2^{0}$ La région alpine, qui s'élève jusqu'à 2000 à 2500 mètres et qui comprend la grande ceinture de pâturages qui entoure les Alpes de tous côtés et sépare la région des forêts des vastes étendues de rocs qui les dominent. 


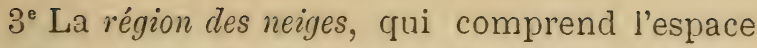
situé au-dessus des pâturages. Dans cette dernière zone, la vie organique est pauvrement représentée; là l'effrayant se mêle au sublime, l'horrible au grandiose.

C'est de la flore qui se rencontre dans les deux régions supérieures que nous nous entretiendrons ici, celle des régions boisées sacclimatant dans le plupart des cas sans aucune difficulté dans nos cultures et ne demandant pas de traitement spécial. Les espèces qui s'y rencontrent croissent dans des conditions souvent analogues à celles de nos plaines et peuvent ètre traitées dans nos jardins, comme de simples plantes vivaces.

La vie organique, dans les Alpes, est soumise à des lois qui sont absolument différentes de celles qui régissent la nature qui nous environne. Les conditions d'existence des plantes $\epsilon t$ des animaux se rapprochent un peu de celles des régions polaires, sans toutefois être identiques à celles-ci. Tandis que, dans nos plaines, la neige commence à disparaître en février et qu'aux premiers jours de mars on peut déjà voir le laboureur dans les champs, les pâturages alpins restent couverts de leur manteau blanc jusqu'en mai, juin, juillet. Les grands sommets ne se découvrent jamais et c'est à peine si, dans la 
région subalpine; quelques arêtes exposées au midi et balayées par les vents, parviennent à se débarrasser de glace pour quelques semaines pendant lesquelles une végétation cryptogamique opère son développement.

Dans la région montagneuse la neige commence à disparaître au commencement de maj. C'est à cette époqne seulement que les habitants des grands et riches villages qui peuplent ces régions commencent leurs travaux agricoles. Ceci nous explique pourquoi, dans ces contrées où l'hiver est fort long, on s'occupe de tant d'industries diverses qui ont amené l'aisance et la prospérité dans ces vallées. Les mois de mai et de juin sont pour la végétation de ces contrées là les plus beaux de l'année. Partout la vie brille, la nature s'anime et se réjouit. La bleue Gcntiane étale ses brillants pétales à côté de la Potentille dorée, la Primevère farineuse côtoie les pâles Renoncules à feuilles d'aconit. Tout s'éveille, tout vit et se réjouit; c'est un printemps radieux et lumineux, plein de douces espérances et de chants joyeux. Il n'en est point ainsi dans les régions supérieures; là tout est encore immobile et glacé. Ce n'est guère que six ou huit semaines plus tard que le pâturage apparaîtra, dépourvu de son manteau glacé et revêtu de sa 
riante robe estivale. La période de vie et d'animation chez la végétation de ces régions est souvent très-courte. Dans certaines vallées supérieures l'été ne dure que quelques semaines. Il est même, dans les hautes Alpes, plus d'un vallon encaissé qui, par le fait d'une succession de mauvaises années, passe plusieurs étés sous la neige. On comprend dès lors combien les conditions d'existence pour la végétation sont différentes de celles que les plantes rencontrent dans nos plaines. Avant de faire une étude plus particulière de ces conditions, cherchons à nous familiariser un peu a vec cette grande nature alpine ainsi qu'avec la flore qui la caractérise.

Nous sommes à la fin de juin et nous nous trouvons dans la région alpine. Le soleil brille de tout son éclat et l'ardeur de ses rayons a déjà fait disparaître une grande partie de la nappe blanche qui nous environne. Mais combien sont terribles les résistances qu'il a à vaincre pour obtenir le dessus! Quelle lutte pénible et quelle ténacité de la part de l'élément glacé! Les gels de ces nuits longues et froides qui caractérisent cette époque de l'année sur ces hauteur's durcissent la surface de la neige au point que le soleil pourra darder ses rayons pendant plusieurs heures sur cette couche de glace avant de 


\section{$-16-$}

l'amollir. Il néige souvent encore et il arrive fréquemnient que la couche de neige, diminuée par l'influence de quelques jours de soleil, augmente de nouveau d'une manière plus ou moins sensible.

Cette lutte serait bien plus longue et bien plus terrible encore sans l'existence d'un puissant auxiliaire qui, s'il faisait défaut une seule anrée, causerait les plus grands malheurs pour tout le pays. C'est le föhn, le grand bienfaiteur des Alpes et celui de tous nos vents qui est le plus favorable à la végétation. Sous son action la couche de neige s'amollit, fond et disparait avec une étonnante rapidité. Le föhn est l'une des conditions les plus essentielles du développement de la vie organique dans les hautes Alpes; il excerce une influence considérable sur la végétation alpine, qu'il active et stimule. Il ne se fait sentir que là où il y a de la neige et seulement lorsqu'il y en a. Son action deviendrait préjudiciable à la végétation s'il se maintenait après la disparition de la grande humidité. Il semble rechercher les endroits où il exerce une heureuse influence; lorsque le soleil a réchauffé le fond des vallées, ce vent bienfaisant se contente de balayer les hauteurs où il y a encore de la neige. Il recherche les lieux glacés et souffle avec plus 
de violence pendant la nuit que pendant le jour, sans doute parce que les couches d'air chaud déplacent avec d'autant plus de rapidité que celles-là sont plus froides les couches d'air avec lesquelles elles sont en contact. Le föhn est le signe certain du printemps; il commence souvent à souffler en janvier et s'annonce non seulement par le bruit qu'il fait mais aussi par la chaleur de l'atmosphère, la densité de l'air et la crue rapide des eaux qui deviennent grondantes et boueuses. Pendant trois hivers successifs, j'ai étudié dans la Suisse orientale les effets du föhn sur la végétation et j'ai été frappé de l'importance de son rôle. Son influence se fait sentir en hiver sur le sommet des collines et des montagnes peu élevées et c'est ainsi que dans les environs de Zurich on trouve quelquefois sur l'Utliberg ou les montagnes environnantes, une flore vernale tout épanouie alors que dans les plaines règne le froid le plus interıse ou le brouillard le plus épais.

Le föhn exerce en outre, d'après le $\mathrm{D}^{\mathrm{r}}$ Christ, une certaine influence sur la flore de nos Alpes, parmi laquelle il introduit nombre d'espèces d'origine méridionale. L'illustre botaniste a présenté à l'exposition nationale de Zurich, dans la section du Club Alpin, un herbier composé de 
quarante espèces dont la présence sur les Alpes est due à ce vent. C'est ce qu'il a nommé «la flore du föhn ».

Le föhn provoque en outre la formation des avalanches, ces puissants phénomènes qui, s'ils causent parfois des désastres, n'en sont pas moins l'un des plus puissants moyens de déblaiement dans certaines parties de nos Alpes. Ecoutez Tschudi :

* Ce phénomène naturel par lequel les hau- teurs se déchargent de millions incalculables " de quintaux de neige est une des circonstances - qui contribuent le plus efficacement à y rendre " possible la végétation printanière. Si toutes ces " masses, dont il est impossible de calculer le * volume, ne devaient se fondre que lentement, " la durée de ce travail de dissolution s'étendrait " jusque bien avant dans l'été. Il est beaucoup " d'expositions à l'ombre où la neige ne disparaît " jamais. Des champs de neige et des glaciers ( se formeraient et s'accroittraient sans cesse dans * les endroits mêmes où le montagnard vient " aujourd'hui, grâce aux avalanches, charger - sur ses épaules son lourd fardeau de fuin - odoriférant. Si l'avalanche vient à faire des" cendre un champ de neige d'un pâturage élevé, a l'action du soleil et de la pluie est doublée sur 
a le terrain déblayé; le sol se réchauffe, les a champs de neige voisins, minés par dessous, a dévorés par la pluie et par le föhn, suivent à - leur tour la même route, ou disparaissent sur - place. s ( $\left.{ }^{1}\right)$

La neige n'a pas plutôt disparu que le paysage s'anime, verdoie et s'émaille des plus vives couleurs. En un clin d'œil, comme par enchantement, la vie se manifeste de tous les côtés et l'été apparaît sans qu'il y ait, en quelque sorte, de transition ou de printemps. La neige qui fond partout, provoque souvent la formation de terribles catastrophes telles que les éboulements, les glissements de terrain. Le souvenir de l'éboulement d'Elm est encore trop vivant au milieu de nous pour qu'il soit nécessaire d'insister sur le danger de ces chutes de rochers qui couvrent de leurs décombres les vallées les plus riches et les réduisent d'un moment à l'autre en un champ de désolation. Au point de vue de la végétation, ces effroyables descentes de rochers. offrent cette particularité qu'elles transportent dans des régions inférieures des espèces appartenant à une zone plus élevée. C'est ainsi qu'on trouve dans les débris de l'éboulement des Dia-

(1) Tschudi : Le Monde des Alpes, pag. 320. 


\section{$-20-$}

blerets une certaine quantité de plantes telles que la Saxifraga oppositifolia, l'Androsace Helvetica qui sont descendues des hauteurs lors de la catastrophe.

Puisque nous en sommes à parcourir les Alpes afin de nous initier à leur grande et sauvage nature, il est bon de nous arrêter devant le phénomène le plus important et le plus intéressant de ces hauteurs, c'est-à-dire devant les glaciers. Ces vastes étendues de glace qui alimentent les plus grands fleuves et les plus fortes rivières ont été pendant longtemps la frayeur du pâtre qui n'osait s'y aventurer. Au premier abord, le glacier semble être un séjour de mort et de désolation. Aucune vie organique ne s'y présente et, sauf quelques algues et de petits infusoires, les êtres organisés le fuient comme un séjour dangereux. Cette influence négative du glacier se borne cependant au terrain qu'il occupe, car il est, pour la végétation qui l'entoure, une source de vie et de développement. Sur la limite immédiate du glacier et ce que nous pourrions appeler son rivage nous trouvons une foule de plantes intéressantes et prospères. La moraine de chaque glacier est comme un jardin botanique réunissant sur un espace plus ou moins restreint une grande variété de fleurs et d'espèces. C'est un 


\section{$-21-$}

endroit privilégié, où le botaniste fera rapidement une riche récolte; cette atmosphère char. gée d'humidité semble convenir tout particulièrement à la brillante flore des Alpes. C'est le terrain de la moraine que recherche avec préférence le Pin d'Arole qui, nulle part, n'est aussi beau ni aussi prospère. Le $\mathrm{D}^{\mathrm{r}}$ Hooker a constaté en Syrie ce fait curieux, que lors de la prospérité des forêts du Liban, dont il ne reste plus que quelques dernier's vestiges, le célèbre Cèdre qui en faisait la gloire croissait sur les moraines de glaciers aujourd'hui disparus.

L'humidité de l'air est l'une des conditions les plus importantes de la vie des plantes dans les Alpes. Sans ces vapeurs répandues dans l'atmosphère, l'insolation, si forte sur ces hauteurs, serait préjudiciable à la végétation. L'humiđité de l'air est une sorte de parasol, qui amortitl'effet des rayons solaires sans diminuer la dose de lumière. La lumière la plus vive et la plus intense est prodiguée à cette régétation dans une mesure qu'il n'est pas possible de lui rendre dans nos plaines. C'est ce qui fait que nous la voyons se développer avec une si grande rapidité. La nature alpine a ceci de particulier qu'elle manifeste sa vie et la développe en beaucoup moins de temps qu'il n'en faut dans les plaines 
aux mêmes espèces. C'est le propre de la vie alpine d'accomplir le cycle de son existence annuelle en un temps beaucoup plus court que ce n'est le cas pour la vie organique de nos plaines.

\section{FORÊTS ET DÉBOISEMENT}

Importance de l'entretien des forèts au point de vue de l'exploitation et de leur bienfaisante influence sur le pays. - Nouvement descendant de la limite supérieure des forêts. - Les conséquences.

Chacun sait combien sont nombreux et divers les fléaux qui ravagent nos régions alpines. Les inondations, les glissements de terrain, les torrents de boue, les descentes de glaciers, etc., produisent parfois des effets terribles. Des désastres. sans cesse renouvelés plongent dans la misère et l'effroi des populations entières dont l'énergie ne peut lutter contre les éléments qui semblent se conjurer pour sa ruine. Ces phénomènes dangereux se produisent avec d'autant plus d intensité que la contrée est plus anciennement habitée et ils sont dus, dans le plupart des cas, à l'incurie et à l'imprévoyance de l'homme. Ils pourraient être grandement atténués, sinon absolument empêchés, par la présence d'une régétation arborescente sur les pentes élevées 


\section{$-23-$}

des montagnes; les contrées boisées souffrent généralement peu de ces sortes de calamités. Mais il est un fait certain et redoutable à constater, c'est que la limite des forêts s'abaisse de plus en plus dans nos Alpes. Il n'est pas possible d'aborder ce sujet, si important au point de vue de la végétation alpine, sans s'y arrêter un peu et sans l'approfondir. Puissent les efforts que font en ce moment les alpinistes de toutes les contrées, aboutir à un résultat avant que le mal devienne tellement grand qu'il ne soit plus possible d'y porter remède.

La vaste ceinture de forêts qui entoure et recouvre la base de nos Alpes a, plus qu'aucune autre végétation, sa raison d'être à l'endroit même où l'a placée le Créateur. La forêt exerce son influence bienfaisante non seulement sur le pays même qu'elle domine et protège, mais plus loin et souvent dans les contrées tributaires des montagnes dont elles reçoivent les eaux. Les inondations terribles dont nous entendons parfois les récits soit en France, soit en Allemagne, soit en Hongrie ou ailleurs, proviennent généralement du manque de forêts sur les montagnes de ces différents pays. L'existence de forêts dans les hautes montagnes est de toute importance pour la prospérité de toutes les régions in. 
férieures. Le bois, dans les zones supérieures, ne devrait pas être exploité autrement que par les bergers pour les besoins de l'industrie laitière. Le chevalier de Gutenberg, dans un article très intéressant à ce sujet( ( $\left.{ }^{1}\right)$, combat l'idée, accréditée dans certains milieux, que la protection des forêts a pour résultat une diminution dans le commerce des bois. Il démontre que l'entretien des forêts est, au contraire, le meilleur moyen de dérelopper ce commerce. Les parties du Tyrol dont les vallées sont les plus riches et les plus prospères sont précisément celles dont le nombre des forêts protectrices est le plus considérable. Il y a des districts dont plus la moitié des forêls sont "Schutzwald ": or c'est là qu'on exploite le plus de bois dans les régions inférieures. M. de Gutenberg assure que, dans les Carpathes, où la moitié des forêts sont inexploitées, elles ne sont pas entretenues et sont en voie de destruction, tandis qu'en Saxe, en Bohême, en Alsace, l'exploitation des bois force les habitants à entretenir leurs forêts et à en augmenter le nombre. A cette action protectrice de l'homme, l'auteur applique les paroles de Schiller :

( ${ }^{1}$ Ueber Wald- und Waldwirthschaft im Hochgebirge. Zeitschrift des Deutsch.- u. Oest. Alpen-Vereins, 1883. 
"Ihr Forstleute erscheint mir wahrhaft gross; D " frei von des Egoismus Tyrannei, wirkt Ihr in s " euren dunkeln Wäldern und eures stillen " "Fleisses Früchte, reifen der späten Nachvelt zu.»

L'imprévoyance de l'homme, dans certaines contrées de nos Alpes, est telle que malgré les lois édictées par les gouvernements cantonaux, le déboisement poursuit son cours sans que personne songe à replanter. Ce sont parfois les communes qui veulent agrandir leurs pâturages et qui, dans ce but, sacrifient les quelques hectáres de forêts restées debout dans la montagne, lesquelles protégeaient encore contre les éboulements et les inondations, le pâturage qu'on veut étendre. Ou bien ce sont les particuliers qui, peu soucieux du bien-être du pays et de l'intérêt général, arrachent, coupent, détruisent pour des raisons souvent très futiles. $\mathrm{Ou}$ bien encore ce sont les bergers et les troupeaux surtout ceux de chèvres, qui commettent des déprédations d'autant plus funestes à la formation et à l'entretien des forêts qu'elles ont lieu à des altitudes plus élevées. J’ai vu dans les Alpes pennines des exemples frappants de cette incurie de la gent bergère qui, dans son incroyable égoïsme, assiste impassible et insouciante à la destruction des plus importants éléments protecteurs des pâturages. Un souffle de mort semble envahir les 
régions élevées de nos montagnes et rouloir refouler toute vie organique vers les régions inférieures. " De même " dit Tschudi a que le $\mathrm{Li}$ - ban, autrefois si richement boisé, ne présente " plus aujourd'hui que quelques-uns des cèdres - qui lui ont valu sa célébrité, ainsi les forèts se " sont retirées de nos Alpes et, même dans les * parties moyennes, ont fait place en beaucoup - d'endroits à des glaciers et à des déserts de " cailloux. " Il existe, dans plusieurs vallées supérieures des Alpes valaisannes, des contrées actuellement arides et absolument découvertes, mais qui, il y a une trentaine d'années, étaient encore protégées par des Mélèzes et des Aroles. Que dire de l'Engadine supérieure, du Rheinwald, et de tant d'autres parties de nos Alpes orientales, autre. fois très boisées et qui ne contiennent plus d'arbres actuellement? Dans certaines parties de nos Alpes, les paysans en sont réduits à brûler le fumier desséché de leurs moutons et de leurs chèvres, et l'on cite plus d'un pâturage élevé qui a dû être abandonné par suite de l'impossibilité où s'y trouvent actuellement les bergers d'y amener du bois. Notre industrie laitière s'en ressent grandement car elle ne peut se passer de combustible. Dans le haut de la vallée de Bagnes où se trouvent les riches pâturages de 


\section{$-27-$}

Chanrion, de Boussine et de Tzermontana, les pâtres sont obligés de descendre à trois ou quatre lieues dans la vallée pour s'approvisionner de bois. Il est nombre de contrées dans nos Alpes qui, autrefois riches et abondamment boisées, sont actuellement arides et envahies par les glaces. A mesure que descend la limite des forêts, le désert et la mort envahissent le paysage. Petit à petit les orages, les inondations, les avalanches balaient le sol et emportent dans des régions inférieures la terre végétale que rien n'attache plus au sol. Il arrive alors un moment où le roc est mis à découvert et ne contient plus de terre que dans les parties abritées. Là pourtant nous pourrons voir encore prospérer quelque maigre végétation arborescente sous la forme de pins rabougris, qui, si on les laisse vivre en paix, pourront opposer une barrière aux fléaux dévastateurs. Lorsque toute végétation arborescente, c'est-à-dire tout obstacle, a disparu, il n'est plus étonnant de voir des masses de glace, de neige ou de rocs se précipiter avec fracas dans les vallès. Non seulement le forêt constitue un obstacle et forme une barrière contre ces fléaux dévastateurs, mais encore le sol qu'elle recouvre agit à la manière d'une éponge, absorbant l'eau et la retenant lors des grosses pluies ou de la fonte des neiges et la laissant écouler petit à petit dans 


\section{$-28$}

la suite. La couche de mousse qui recouvre généralement le sol augmente encore ses propriétés spongieuses. En outre, il est prouvé que les. arbres exercent une influence salutaire sur la végétation qui les entoure; ils tempèrent les climats, provoquent la formation de pluies douces et bienfaisantes. Il est certain que si la partie inférieure de notre Valais était plus boisée qu'elle ne l'est, ce canton aurait moins à souffrir de la sécheresse. On a remarqué, chose curieuse, qu'il ne grêlait que dans les contrées peu boisées et que le fléau dévastateur ne se produisait jamais dans les forêts. Qui s'étonnera dès lors que, par suite des déboisements pratiqués sur les sommités qui nous environnent, nous voyions souvent le retour du terrible visiteur? On sait que le Salève, les Pitons, le Vuache et le Jura étaient autrefois recouverts d'un riche végétation arborescente et que les pentes arides et sèches du Jura français n'ont pris l'aspect sauvage et désolé qui les caractérise que depuis qu'on a déboisé ces montagnes

Il existe en Valais, non loin de Martigny, sur la rive droite du Rhòne, une pente sèche et aride dont l'œil se détourne avec horreur. Pas un buisson, pas une place gazonnée, ne coupe l'effrayante monotonie de ce paysage brûlé. Sur trois ou quatre lillomètres de longueur on n'aper- 
coit que des débris de rocs et de graviers provenant du sommet de la montagne. Tout est aride, morne et sinistre dans cet emplacement sur lequel semble reposer une éternelle malédiction. Et cependant il n'y a pas 80 ans que le voyageur parcourant ces contrées recherchait l'ombrage de la superbe forêt de châtaigniers qui dominait le riche petit village du Rozet, aujour.d'hui détruit et enseveli sous les décombres de la montagne! On devine ce qui s'est passé. Un jour un misérable spéculateur convoita la forêt; il offrit au Conseil municipal du Rozet la somme de 30,000 francs pour le bois. L'or étranger tenta le Conseil municipal qui, en vendant les châtaigniers, vendit le bonheur du pays. Avec les arbres abattus disparut le village et, au bout de peu d'années, les éboulements successifs qui ensevelirent les champs et les terrains des environs, forcèrent les habitants du lieu, à quitter leurs demeures, qui sont aujourd'hui ensevelies sous des monceaux de pierres. Or, d'après estimation faite plus tard par un expert, il se trouva que la forêt avait.comme bois à brûler, une valeur de plus de 200,000 francs $\left({ }^{1}\right)$.

(1) Il existe encore aujourd'hui, parmi les habitants des bourgs voisins, trois ou quatre vétérans d'entre ceux qui ont aidé à abattre la forêt protectrice de leurs anciennes demeures. Ceci n'est donc point un récit légenclaire, mais de l'histoire facile à contròler. 
On le voit, les conséquences du déboisement sont terribles; il était temps que la Confédération prît la chose en mains et s'occupât de cette ques. tion, afin de protéger les forêts qui nous restent. Mais il serait grand temps aussi que certains gouvernements cantonaux prissent la chose à cœur et aidassent d'une manière plus énergique à la conservation et à la reconstitution des forêts.

En Amérique, en Australie, en Algérie, on a vu se former des ligues pour la protection des forêts; c'est un signe bien certain que la question est d'une importance capitale pour le bien-ètre d'un peuple agricole. Et si nous voulions encore soulever le côté esthétique et artistique de la question, combien n'y aurait-il pas à dire en faveur du maintien de ces belles forêts, dont la verdure donne à nos paysages al pestres et à nos contrées boisées un aspect si agréable et si gracieux! Qu'on compare l'aspect que présentent les flancs arides du Jura français avec ceux de la même chaine de montagnes dans les cantons de Vaud et de Neuchâtel! Qui n'aime mieux l'ombre des sapins sur les Voirons que les broussailles arides du Salève! Conservons les arbres de nos montagnes et nous maintiendrons la prospérité, la richesse et la vie de notre pays. 


\section{LA VÉGÉTATION DANS LES ALPES}

Végétation arborescente. - Sous-arbrisseaux. - Caractères de la flore alpine. - Arrachages intempestifs. Jardin alpin d'arclimatation. - Limites supérieures de la végétation dans les Alpes.

Si, de la région des espèces arborescentes, nous passons à l'étude de la végétation qui garnit les régions supérieures des Alpes, nous nous trouvons en présence d'une flore toute particulière et qui diffère sensiblement de celle que nous rencontrons dans les plaines. Les formes de la végétation se rabougrissent de plus en plus; après les forêts de sapins viennent les arbrisseaux, puis les petits buissons rampants et enfin les pâturages gazonnés. Le $R$ Rhododendron, les différentes Vacciniées, le Bouleau nain, sont les derniers vestiges de végétation ligneuse, sauf toutefois les Saules, qui atteignent les dernières limites de la végétation phanérogamique, mais ne s'y rencontrent plus qu'â l'état de frêles touffes rampantes, rasant le sol.Deux espèces arborescentes appartiennent cependant à la zone alpine; ce sont l'Arole et le Mélèze.

L'Arole (Pinus Cembra L.) est le plus majestueux, le plus imposant et le plus célèbre d'en- 
tre les arbres de notre pays. Bien que n'appartenant pas exclusivement à la chaîne alpine, puisqu'il se rencontre abondamment dans les Car. pathes, l'Altaï et la Sibérie, cet arbre est considéré comme le Cèdre de nos Alpes. Sa forme en candélabre, l'odeur pénétrante qu'il répand dans l'air à l'époque de sa croissance, la couleur de sa verdure, les superbes cônes qui garnissent ses branches et renferment les précieuses amandes si recherchées des pâtres et aussi des écureuils, tout cela donne à l'Arole un cachet particulier que nous ne trouvons chez aucune autre espèce de nos forêts. Le seul fait que cet arbre peut croître dans des hauteurs aussi élevées, côtoyant souvent le bord du glacier dont il anime et décore les moraines, ajoute encore à sa valeur et à son importance. Il s'acclimate du reste fort bien dans nos plaines, où il demande une position fraîche et un sol léger. Il s'en trouve un superbe dans la propriété Naville à Villette, et un autre, également fort beau, quoique plus jeune, chez $\mathrm{M}^{\mathrm{m}}$ la baronne de Rothschild, à Pregny.

Quant au Mélèze (Larix europæa L.) c'est certainement l'arbre le plus caractéristique de notre pays. C'est une espèce appartenant en propre à notre chaîne alpine; l'espèce septentrionale (Larix 
sibirica Ledeb.), qu'on avait longtemps regardée comme identique à la nôtre, a été reconnue pour être différente. Le Mélèze de nos Alpes est bien l'un des enfants de notre chaîne de montagnes, et d'entre les plus glorieux.

Quoi de plus beau, de plus majestueux que ces vénérables Mélèzes, isolés au milieu des pâturages alpins, qui ont vu à leurs pieds se suc. céder tant de générations humaines, qui ont assisté à tant de révolutions parmi la race à laquelle nous appartenons et qui, semblables au phare que n'ébranlent pas les tempêtes, élèvent leur front vers le ciel comme pour braver la foudre et l'orage! Le bois du Mélèze est l'un des des plus précieux que nous fournisse la famille Conifères. Jl est recherché pour un grand nombre d'usages et forme un excellent combustible.

Tandis que l'Arole demande de la fraîcheur et l'ombre, le Mélèze, au contraire, recherche le soleil et le sec. Dans une groupe d'Aroles et de Mélèzes, on a remarqué que ces derniers sont généralement orientés de façon à recevoir le soleil et qu'à leur ombre croissent les Aroles.

Le Rhododendron est, parmi les arbustes alpins, l'espèce la plus recherchée et la plus populaire. C'est la fleur des Alpes par excellence, notre fleur nationale; elle est la fille de notre 
chaîne de montagnes, dont elle constitue le plus bel ornement. Le genre Rhododendron, très répandu sur les montagnes de l'Asie centrale, est représenté en Suisse par deux espèces, le $R$. hirsutum L. et le $R$. ferrugineum L. Le Tyrol possède dans le $R$. chamcecistus $\mathrm{L}$. une espèce particulièrement belle et très différente des nôtres. Le nord de la Russie et les plaines de la Sibérie contiennent quelques espèces qui se rapprochent de la nôtre sans ètre exactement semblables.

Le Rhododendron, est-il nécessaire de le rappeler, est connu sous le nom glorieux de Rose des Alpes ou de Rosage. Il y a quelquefois confusion avec le Rosa alpina L. qu'il conviendrait mieux de nommer l'Eglantine des Alpes. Ce que Henri Durand a chanté n'est évidemment pas le Rosa alpina mais bien le Rhododendron, alors même qu'il s'écrie, emporté par son élan poétique:

Ne l'ôtez pas du sol de ces hauteurs
Pour la transplanter dans les plaines;
Là-bas l'épine aussi bien qu'à ses sœurs,
Viendrait bientôt tromper vos peines.

La Rose des Alpes est notre plante nationale; le mot d'Alpenrose se trouve dans la plupart des chants patriotiques de nos confédérés de la Suisse allemande. Se figure-t-on les Alpes sans Rhododendron! Ce serait Nice sans les orangers, Gênes 
sans sa Riviera, l'Italie sans son ciel bleu. Alpinistes et touristes, qui que vous soyiez, que vous. aimiez les fleurs ou que celles-ci vous soient indifférentes, dites, que serait la nature alpine sans cette ceinture de roses qui enveloppe les flancs. de nos montagnes ainsi qu'une rivière de diamants relève l'éclat de la beauté du jour? Qu'il est heureux, le grimpeur haletant, fatigué, lorsqu'il aperçoit leurs joyeuses fleurs qui, du sein d'une verdure tenant du myrte et du laurier, lui envoie les premiers parfums de la nature alpine. Avec quel enthousiasme ne les place t-il pas au ruban de son chapeau! Et combien il sera heureux à sa descente des hauteurs, d'en cueillir des gerbes aussi grosses que possible, dont il cherchera à maintenir la fraîcheur, s'ingéniant à trouver des trucs pour y parvenir. Comme nous comprenons bien, nous autres coureurs de montagnes, ces vers qui terminent la pièce déjà citée. de notre cher Durand:

Que je voudrais, maitre de mon destin, Sur les grands monts choisir ma rose ; Là je viendrais m'établir un matin Sans nul souci pour autre chose; Je dresserais ma tente près du ciel, $\mathrm{A} u$ vent des haleines divines, Et je vivrais de parfums et de miel Près de ma rose saris épines. 
Mais laissons là l'Alpenrose que nous devrions appeler Rosage mais que nous continuerons à nommer de son nom populaire, et voyons plus loin. Plus nous nous élevons, plus la végétation se ratatine et se rabougrit. Arrivés à 2000 mètres, nous ne trouvons plus guère que des plantes vivaces herbacées, étalées sur le sol. Les genres qui dans la plaine sont représentés par des arbres ou des arbustes, tels que le Saule, le Bouleau, l'Azalée, se rencontrent ici sous la forme d'espèces naines et rampantes. Dans ces régions les plantes, au lieu de se développer en hauteur, s'élargissent et s'étalent sur le sol à la protection duquel elles semblent vouloir en appeler. E!les fuient la fraîcheur de l'atmosphère et s'attachent au terrain, qui conserve plus longtemps la chaleur des rayons solaires. En général ces plantes sont vivaces, stolonifères, cespiteuses: il y a fort peu d'espèces annuelles parmi les plantes alpines. La plupart sont sans parfum; seule la Nigritelle répand dans l'air l'odeur aromatique de sa corolle. Il n'y a pas de champignons dans les Alpes; la lumière vive et intense qui règne sur ces hauteurs, n'en permet pas le développement. Par contre, la couleur des fleurs est vive et brillante et leur corolle est généralement très grande. Les insectes, ces puissants auxilia- 
res de la fécondation, n'ayant sur ces hauteurs qu'un court espace de temps pour vivre et pour accornplir leur œuvre, sont guidés par l'éclat des couleurs dans le choix qu'ils ont à faire. L'Oeillet des Alpes qui se rencontre dans la Suisse orientale, possède une fleur dont la corolle est plus grande et plus large que chez l'Oeillet de nos plaines, quoique sa tige soit à peu près nulle. Aussi, lorsque cette plante est en fleur, les pétales tiennent-ils tellement de place et recouvrent-ils tellement la touffe qu'on ne voit pas la verdure. La Pensée des Alpes nous présente une fleur grande, d'un lilas vif et foncé; cette fleur est portée sur une tige courte et sa corolle est cependant beaucoup plus large et plus développée que chez la Pensée de nos champs ou la Violette de nos bois. On pourrait multiplier les exemples.

Le docteur Christ, parlant de la flore alpine, dit :

a L'action puissante du soleil n'a pas manqué " d'imprimer à la forme extérieure et à l'organi" sation des plantes alpines un cachet particu" lier. Leurs feuilles sont d'une texture serrée. - épaisse et, grâce à un épiderme très solide, - elles sont capables de résister au dessèchement " auquel les expose par moments l'intensité des 
" rayons solaires. Souvent aussi, elles sont pré-

- servées de ce dessèchement par une pubescence * serrée qui se compose presque toujours de " poils étoilés, surtout chez les crucifères, dont " l'épiderme est d'ordinaire très délicat. Le poil - se partage dès la base en une série de rameaux " étalés en rayons, et il forme ainsi sur tous les - organes une couche qui empêche l'épiderme a de se dessécher. Le duvet grisâtre, sorte de " feutre épais, qui recouvre d'autres plantes al"pines, surtout chez les composées, a le même a but. Dans les stations exposées au soleil, sur "les hauteurs découvertes et les pentes. on rea marque que les plantes ont presque toutes des - feuilles coriaces ou une pubescence serrée tan" dis que dans les ravins ombragés et abrités, a dans les gorges et les couloirs qui servent de - lits aux torrents, les plantes ont les feuilles " plus vertes et plus délicates $\left.{ }^{1}{ }^{1}\right)$

Il est en effet facile de constater sur les Alpes, que dans les parties rocailleuses et exposées aux rayons desséchants du soleil la végétation est velue, souvent grisâtre et argentée (l'Edelweiss, les Artémises, les Sénę̧ons, en sont des exemples), tandis que dans les couloirs frais et humides c'est le contraire qui a lieu.

(1) La flore de la Suisse et ses origines, page 30 . 
- L'anatomie des plantes alpines s continue le Dr Christ a prouve que les cellules de leurs feuilles " sont plus petites, qu'elles ont des parois plus " épaisses et un contenu plus concentré que dans " les plantes de plaine; de sorte qu'en gelant et " dégelant après, les tissus ne se déchirent pas, a même à des températures auxquelles succoma beraient infailliblement les plantes de la plaine * dont les cellules sont munies de parois plus " minces et renferment plus d'eau. Le port plus a ramassé des plantes alpines et leurs feuilles ( imbriquées contribuent également à les gaa rantir contre les courants atmosphériques " qui passent sur le sol.

( Et ce sont précisement ces gelées qui se re" nouvellent toutes les nuits qui expliquent " pourquoi ces plantes restent si basses. Les " recherches physiologiques les plus récentes " ont prouvé que c'est pendant la nuit que les " plantes croissent le plus rapidement; de jour " elles croissent d'autant moins que l'insolation a est plus considérable. Pour ces plantes des - hautes Alpes il n'est pas question de croissance * nocturne; elle est empèchée par le gel. Ce n'est " que pendant les heures du jour où la chaleur " du soleil est assez forte pour chauffer considé" rablement le sol qu'il leur est permis de croître, 
" ce qui explique la brièveté de leurs entre-nœuds.

" G'est pour la même raison que les plantes gaa zonnantes des hautes Alpes changent si facilea ment d'aspect quand on les transporte dans nos - plaines; les nuits étant chaudes, elles continuent a de croître et s'épuisent; toutes leurs parties (" s'allongent bientôt et s'étiolent rapidement. * ( $\left.{ }^{1}\right)$ Ces touffes gazonnantes, ces mousses fleuries, comme on est tenté de les appeler, sont les plus ravissantes d'entre les apparitions végétales. Aucune langue ne saurait les décrire, aucun pinceau les reproduire: ce sont bien les bijoux du Créateur et ses favoris dans le monde des plantes. Nous les aimons, nous les alpinistes non point seulement parce qu'elles sont alpines, qu'elles nous rappellent de doux souvenirs, mais aussi parce qu'elles sont jolies, gracieuses, ravissantes. Elles ont la fraîcheur que n'ont aucune de leurs sœurs de la plaine; elles sont fines et légères; ce sont de vraies enchanteresses. Qui peut résister au désir de les emporter avec soi et de les cultiver? La chose n'est-elle pas toute naturelle! Ce n'est du reste pas une nouveauté que cet enthousiasme qui s'empare maintenant de beaucoup d'amateurs de cultures alpines. De Candolle, en fondant notre jardin botanique, (1) La flore de la Suisse et ses origines, page 30 4. 
avait déjà réservé certaines plates-bandes pour la culture des plantes des Alpes et déjà avant lui, Necker-de Saussure et Vaucher avaient fait des essais d'acclimatation au Jardin du Calabri.

Eh! qui donc s'en étonnera? Les fleurs alpines ont bien des avantages sur leurs sœurs de la plaine. Elles ont surtout celui-ci qu'elles tiennent peu ile place, garnissent les grottes et rocailles en y étalant leurs touffes et qu'elles fleurissent généralement de bonne heure au printemps. Ces cultures sont en outre intéressantes et demandent peu de soins en dehors de ceux qu'on donne à toute plante vivace. Les plantes alpines ont done leur place marquée dans l'horticulture actuelle et ne peuvent manquer d'y jouer un rôle important par la suite.

L'arrachage des plantes alpines et leur transplantation dans les jardins de la plaine a pris une telle extension, depuis quelques années, qu'il a eu pour conséquence l'extirpation de certaines espèces dans plus d'un territoire. On peut traiter d'exagérée la crainte manifestée par les naturalistes de voir certaines espèces de plantes rares disparaître des localités où elles existent; il n'est pas moins vrai que ce cas s'est présenté plus d'une fois en Suisse 


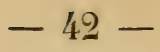

pour ne parler que de ce qui se passe chez nous. Loin d'être chimériques, ces craintes sont pleinement justifiées; preuve en soit le mouvement qui se produit aujourd'hui en faveur de la conservation dans leurs domaines respectifs et de la protection des plantes sauvages. Les deux premiers bulletins de l'association protectrice des plantes renferment d'utiles et intéressants renseignements à ce sujet. Le dernier numéro de cette publication contient un travail, dû à la plume de M. Fischer-Siegwart, pharmacien à Zofingue et naturaliste distingué. L'auteur donne la liste des localités de plantes rares qui sont en voie de disparaître et parle des essais qu'il a faits pour acclimater des plantes sauvages aux environs de Zofingue.

M. Fischer cherche à établir une statistique des espèces qui,en Suisse, sont sur leur déclin et de celles qu'il s'agit de protéger; il a la conviction qu'il faut lutter contre les sociétés d'échange, qui, à ses yeux, ne sont pas des sociétés scientifiques, parce que celui qui se livre aux échanges ne peut guère s'occuper d'autre chose que de collectionner et de récolter pour ses aboutissants. M. René Guisan, ingénieur à Lausanne, a également traité ce sujet dans une brochure qu'il a envoyée aux alpinistes. Il pense qu'il est surtout nécessaire 
de lutter contre les personnes qui arrachent les plantes dans un but purement spéculatif et cite le fait que des maisons horticoles de l'étranger ont, dans nos Alpes, des collectionneur's et des correspondants leur fournissant par milliers les plantes rares de nos sommets glacés.

Le 29 janvier 1883 s'est fondée à Genève une société sous le titre de "Association pour la pro. tection des plantes " dans le but de réagir contre ce fléau qui ravage la flore suisse. Les membres ont pour principe de combattre le commerce des plantes arrachées dans les montagnes et de recommander l'élevage de ces plantes par semis ou leur acclimatation d'une manière raisonnée. Loin d'entraver les cultures de plantes alpines, cette société a pour but de les encourager en dirigeant les amateurs dans leurs essais d'acclimatation et de cultures. Il arrive souvent qu'on détruit une grande quantité de plantes pour arriver à n'en réussir que fort peu. Toutes ces plantes sacrifiées sont autant de sujets qui, s'ils fussent restés dans leur patrie, eussent donné des graines et contribué à la reproduction de l'espèce. Pour les plantes rares, cet argument est d'une certaine importance; or, comme c'est précisément sur ces plantes là qu'on s'acharne de préférence, il en résulte nécessairement des 
dommages dans le domaine de la flore. Qui n'a éprouvé un sentiment d'indignation à la vue de ces centaines et de ces milliers de plantes alpines qui viennent deux fois par semaine joncher le sol de notre marché et dont celles qui ne se vendent pas, desséchées par le soleil, sont jetées avec les balayures de la place!

Il est cependant bien naturel que les grimpeurs de montagnes rapportent de leurs courses alpestres les plantes qui les ont émerveillés làhaut et qu'ils cherchent à les transplanter dans leurs jardins. Qui peut résister à cette tentation? Mais hélas, combien de déceptions, que d'essais manqués, par quels déboires se terminent souvent ces tentatives d'acclimatation sur lesquelles on avait fondé de si douces espérances! Aussi combien d'amateurs découragés n'ont-ils pas renoncé à ces cultures et déclaré que les plantes des Alpes étaient inacclimatables! Ce qui ne les empêchera pas de rapporter de leur prochaine course une nouvelle cargaison pour tenter un nouvel essai. C'est pour instruire ces amateurs et les empêcher de détruire un grand nombre de pieds pour n'obtenir aucun résultat que l'association protectrice tient des séances dans lesquelles on indique les procédés à employer pour acclimater ces plantes. Nous verrons plus loin 


\section{$-45-$}

quelle est la meilleure époque et la manière dont il faut s'y prendre pour opérer la transplantation des espèces alpines.

La fondation d'un Jardin alpin d'acclimatation répond précisément à un besoin virement senti par tous les amis de cette cause protectrice. Le nouvel établissement horticole a pour but d'élever en masse les plantes recherchées et de les offrir aux amateurs à des prix avantageux. Il espère pouvoir fournir ces plantes élevées de semis aux établissements horticoles de l'étranger, qui n'auront dès lors plus besoin de s'approvisiouner dans les Alpes.

Voici ce qu'en dit, dans son numéro du 24 mai, le Journal de Genève, toujours si réservé et si sobre dans ses appréciations: " Pour la " première fois apparaissait sur le marché le " Jardin alpin, le nouvel établissement fondé a sous les auspices de la Société pour la protec" tion des plantes. Il n'y avait qu'à jeter un coup" d'œil sur ces plantes si variées, d'une santé " exubérante, d'une reprise certaine, d'un prix - très abordable pour être assuré de l'efficacité * du moyen patroné par la Société de Genève. " ainsi que par beaucoup d'esprits distingués au - dehors, pour combattre la plaie du trafic bar" bare qui menaçait de détruire la flore de nos. 
* montagnes. Espérons que dans quelques an-

- nées on ne verra plus sur nos marchés ces a masses de plantes à l'aspect morbide, arrachées

a saus soin, destinées à périr sitôt après être sor-

- ties des mains des marchandes et dont quan" tités, non vendues, se retrouvaient dans le ruis" seau après la fin du marché."

Que les amis des plantes et de la nature alpine farorisent le nouvel établissement en achetant ses produits et en les faisant acheter à d'autres et l'on aura bientôt la preuve que le remède le plus efficace pour combattre le mal est, non pas d'édicter des lois ou de demander l'appui des gouvernements, mais d'agir moralement. L'exemple est toujours le meilleur moyen à employer dans des cas semblables.

- Ces limiles ne peuvent ètre définies en ce qui concerne les cryptogames, qui atteignent les sommets les plus élevés des Alpes. Mais la végétation phanérogame s'arrête à des limites mieux définies. Elle ne dépasse guère 3200 à 3500 mètres dans la chaîne des Alpes. Cependant, on a trouvé sur le Finsteraarhorn, à 4000 mètres d'élévation, des plantes telles que Saxifraga bryoides L., Sax. muscoides Wulf., Achrllea atrata L. Le docteur Christ cite le fait que Calberla a trouvé sur la cime de la même montagne, 
au versant ouest, à 4270 mètres, un exemplaire de Ramunculus glacialis L., portant deux fleurs et paraissant annuel. Sur l'Hymalaya et dans les Andes de l'Amérique du Sud, la végétation s'élève à des altitudes beaucoup plus considérables. Sur le Ghimborazo, la végétation atteint 4600 mètres et Hooker a trouvé sur les cols du Thibet des composées atteignant 18500 pieds anglais et des buissons de Chèvreleuille et de Rhododendron jusquà 17000 pieds. Dans certaines parties du Thibet, la limite supérieure des phanérogames est de 19000 pieds anglais.

Les touffes fleuries ne se bornent pas à émailler nos pâturages et à réjouir les pentes rocheuses de nos montagnes; elles se présentent partout où elles trouvent des territoires libres de neige ou de glace et un sol quelconque pour y plonger leurs racines. Dans la région glacée des neiges, on les voit garnir les moindres fentes de rochers dans lesquelles elles s'abritent. De fines et élégantes graminées, quelques Saxifrages aux formes ténues, l'Androsace glacialis Hoppe, deux ou trois espèces de Crucifères sont les phanérogames qui montent le plus haut dans les Alpes.

Les plantes alpines deviennent souvent fort âgées ; j'ai examiné un jour au sommet de l'Augsborgspass, en Valais, une touffe de Saxitraga 


\section{$-48-$}

opposititolia L. qui devait avoir, pour le moins, 100 années d'existence. On rencontre parfois des plantes alpines dont une partie de la touffe est déjà décomposée et sert de sol à un autre pied, plus vigoureux, tandis que l'extrémité des tiges de la plante-mère est encore pleine de vie et de santé.

\section{ORIGINE DE LA FLORE ALPINE.}

Les travaux du $\mathrm{D}^{r}$ Ghrist. - Réflexions à ce sujet. Opinion de M. John Ball.

D'où vient la flore qui recouvre les Alpes? Quelle est sa patrie d'origine et comment est elle parvenue à s'installer sur les sommets escarpés des montagnes ? Est-elle endémique et peut-on considérer le territoire alpin comme le foyer créateur de cette brillante végétation, ou bien sa présence sur nos monts glacés est-elle due à une immigration ? Ces questions, si intéressantes pour tous ceux qui s'occupent des Alpes et de leur nature, ont été étudiées d'une manière particulière pendant ces dernières années. Nous devons aux travaux du Dr. Christ dans ce domaine, une impulsion nouvelle dans la voie des découvertes. Son * Histoire des plantes de la 
Suisse, est le travail le plus important qui ait paru sur ce sujet. Après une étude très approfondie de la flore des Alpes au point de vue de leur distribution géographique, l'auteur conclut en assignant aux diverses catégoriez d'espèces, des origines différentes. Tandis que les unes, originaires du nord et des zones arctiques, auraient envahi notre centre européen lors de l'époque glaciaire, puis escaladé les plus hautes cimes des Alpes, d'autres, au contraire, auraient une origine méridionale et se seraient modifiées dans leurs formes sous l'influence d'un climat plus froid. Il reconnait cependant que, parmi les 693 espèces de plantes observées dans la chaîne des Alpes, il en est 230 qui lui appartiennent en propre. $\left({ }^{1}\right)$ Mais ces espèces-là se bornent, suivant Christ, à habiter les parties chaudes et sèches des Alpes au lieu que les espèces arctiques vont plus haut et occupent tous les territoires exposés à l'humidité et à la fraîcheur. Voici ce qu'il dit à ce sujet :

"Un fait bien établi, c'est que la chaîne des - Alpes, dotée d'un climat plus chaud et plus - sec, a donné naissance à des espèces qui, pour - la plus grande partie, ont élu domicile dans - les stations qui ne convenaient pas aux espè(1) La flore de la Suisse et ses origines, p. 325. 
" ces arctiques ; en revanche ces dernières ont

- recherché les lieux humides et abandonné les

" lieux secs à nos plantes endémiques. C'est

* aussi précisément en leur qualité de plantes

- des régions humides qu'elles sont répandues

" sur un aussi vaste territoire.

* A. de Candolle a prouvé que les plantes cos-

a mopolites dansle vraisens du mot sont presque

a exclusivement des espèces aquatiques. On peut

" donc admettre que les espèces arctico-alpines

" qui ont trouvé un sol suffisamment imprégné

" d'eau, ont été victorieuses dans la lutte avec

" leurs rivales, et qu'elles se sont répandues

" de leur foyer central du nord de l'Asie et de

" l'Amérique dans toute la région circumpolaire

" et dans toutes les chaînes de la zone tempérée,

" jusqu'à l'Himalaya, et s'y sont maintenues

- alors que la plaine était depuis longtemps cou-

a verte d'une flore composée des lieux secs et

a chauds.

- Il n'en est pas ainsi de nos plantes alpines

- endémiques : elles se sont arrêtées à la limite

" de la zone qui a le même climat que celui des

"Alpes; au delà de la grande chaîne que for-

- ment ensemble les Carpathes, les Alpes et les

- Pyrénées, elles ne se sont a vancées vers le nord

- que jusqu'aux montagnes de l'intérieur de 
" l'Allemagne, vers le sud jusqu'aux presqu'îles " de la Méditerranée et vers l'est jusqu'au Cau- case. A de plus grandes distances, on n'en re" trouve que 70 espèces qui sont au nombre des a plantes rares et disséminées de la Norwège, - de la grande Bretagne, de l'Islande ou de l'Oua ral. Deux espèces ont pénétré jusqu'à l'Hima- laya,ce sont les Pedicularis asplenifolia et l'Oxy- tropis lapponica. Malgré sa dénomination, cette " dernière espèce est alpine et ne se retrouve a qu'en Norwège, où elle est très disséminée. "Ce n'est pas seulement dans les stations hua mides, mais aussi dans les stations les plus " élevées, dans la zone subnivale et nivale que " se révèle la nature plus robuste, la force d'a- daptation plus considérable du groupe arctique. “ Des 287 plantes croissant dans cette région et ( appartenant à toute la chaîne, la moitié, soit a 125, , sont arctiques. Des 172 espèces alpines - qui peuvent être envisagées comme les plus " répandues et en même temps celles qui - forment par la quantité des individus la a partie la plus considérable de la végétation, a il n'y en a pas plus de 93 qui soient non arc. " tiques.

- L'élément endémique de notre flore alpine a n'arrive donc à avoir la prépondérance que 
" lorsqu'il est soutenu par la douceur du climat

* méridional ; quand l'humidité et le froid des

* hauteurs se fait sentir d'une manière hostile

- à la végétation, ces espèces cèdent la place aux

* espèces du nord plus résistantes.

"Quoi de plus remarquable! Ce n'est pas seu-

- lement dans la population humaine de nos

"Alpes que l'on peut distinguer une race indi-

* gène-celtique, une race germanique plus apa-

" thique et plus froide et une race romaine plus

* vive; la flore elle-même se compose d'un mé-

" lange tout semblable; on $\mathrm{y}$ trouve en effet

* un élément endémique, un élément arctique

* et un élément méditerranéen. $\left.\quad{ }^{1}\right)$

L'auteur insiste sur la durée et l'importance des deux époques glaciaires qui ont couvert notre pays. La flore alpine aurait alors occupé tous les territoires qui, dans nos plaines et sur les plateaux, n'étaient pas occupés par les glaces. Puis lorsque la limite des glaciers et des neiges éternelles, sous l'influence d'un climat plus chaud, peut-ôtre de l'apparition du fœhn, commença à remonter, la flore suivit aussi ce mouvement ascensionnel et gagna les hauteurs où elle retrouvait ses conditions antérieures d'existence. Elle en redescendra peut-ètre un jour si, chose

(1) La flore de la Suisse et ses origines. p. 335. 


\section{$-53-$}

fort possible, la température de notre pays s'abaissait au point de permettre aux glaciers des Alpes de recouvrir encore une fois nos plaines.

La théorie du Dr. Christ est basée sur les données des plus grands naturalistes, des Cuvier, des Ostvald Heer, des Agassiz. L'auteur a, du reste, étudé la question fort à fond; il a travaillé lui-même et s'est entouré des renseignements les plus exacts. Malgré cela, cette théorie est loin de satisfaire entièrement ceux qui observent les Nlpes et ce qui s'y passe dans le domaine de la flore. On peut se demander entre autres, quelles sont les lois qui poussent la flore alpine dans une marche ascendante et qui lui permet d'envahir les sommités de bas en haut en escaladant les parois les plus abruptes, vierges de toutes traces de glaciers. D'après les données du Dr. Kerner d'Innsbrück ( $\left.{ }^{1}\right)$ qui a fait de sérieuses études et de longues expériences à ce sujet, il n'existe dans les Alpes qu'un nombre fort restreint d'espèces dont les graines sont sujettes à ètre transportées par les vents. Il divise les graines des végétaux alpins en plusieurs séries: Les unes, et c'est le plus grand nombre, sont absolument nues, sans aspérités et destinées à rester en place ou à être en-

$\left({ }^{1}\right)$ Der Einfluss der Winde auf die Alpenvegetation. Zeitschrift der O. u. D. Alpenvereine, B. II, S. 141. 
trainnées par les eaux dans les régions inférieures. Les autres, munies d'aigrettes ou d'ailes, sont emportées par le vent dans toutes les directions et voltigent dans les airs ainsi qu'on peut facilement le constater à l'œil nu par un beau soir d'été, quand l'air est pur et que le soleil est sur son déclin. La flore qui garnit les gorges des montagnes et les lits des torrents alpins, est presque entièrement composée d'espèces appartenant à cette catégorie de graines. Mais le nombre de ces espèces est fort restreint relativement à la richesse de la flore alpine. D'autres enfin sont sans aucun appendice mais possèdent une structure contournée, chagrinée, qui offre aux vents une faible prise laquelle ne peut être de longue durée. Ces espèces-là ne s'écartent jamais beaucoup de la plante-mère et sont généralement emportées dans un sens horizontal: ce sont elles qui, avec les plantes de la première série, garnissent les pâturages et les arêtes des Alpes. Or, on ne trouve dans les régions élevées les plus richement dotées en espèces, qu'un nombre trés restreint de plantes appartenant à la série des graines ailées ou subissant linfluence des vents. Le nombre de celles qui pourraient être disséminées par le moyen des animaux est beaucoup plus restreint encore. Aucune loi ne semble donc 
établie pour permettre la marche ascendante de la vie végétale; tout semble au contraire se conjurer pour en abaisser la limite. Examinez les divers phénomènes qui se produisent dans les montagnes et vous serez bientôt convaincu comme moi que loin de permettre ce mouvement ascendant, tout ce qui se passe là haut tend à refouler la végétation de haut en bas et à la répandre dans les plaines. Depuis l'avalanche qui entraîne avec elle des masses plus ou moins considérables de sol, jusqu'au seul grondement du tonnerre, capable d'ébranler les extrémités des montagnes et d'en faire rouler les débris dans les vallées tout contribue à faire descendre la montagne et à en abaisser le sommet. Il ne saurait y avoir d'exception à mes yeux que pour les cryptogames (Lychens) dont les spores ténues et légères remplissent l'atmosphère et transportent l'espèce dans les régions les plus diverses et les plus élevées.

Les plantes des Alpes sont douées d'une étonnante ténacité et d'une certaine force de résistance qui leur permet de se cramponner aux lieux qui les ont vues naitre. Leurs fortes racines, leurs souches épaisses munies souvent de racines adventives, les attachent au sol et leur permettent de résister aux différents courants dévastateurs qui 
les entraîneraient dans les plaines. Mais là se bornent les propriétés de notre flore phanérogame; elle a un caractère résistant, envahissant mais non point ascendant. On a bien signalé la marche ascendante de certaines plantes dans plusieurs régions de nos Alpes. C'est ainsi que Tschudi ( $\left.{ }^{1}\right)$ signale un cas de ce genre sur le sommet du Piz Linard où se trouvent actuellement établies une certaine quantité d'espèces dont Heer avait, 30 ans aupararant, trouvé les dernières traces à quelques centaines de mètres plus bas. Je ne pense pas cependant qu'on puisse se baser sur quelques faits isolés qui peuvent s'être produits dans des circonstances particulières; il est du reste fort possible que les plantes découvertes sur le sommet de la montagne, 30 années après l'ascension de Heer, provenaient de graines déposées dans le sol depuis un grand nombre d'années, de siècles peut-être et qui, comme celles retrouvées dans les pyramides de l'Egypte, y ont conservé leur facultés germinatives. Quelles seraient en effet les causes qui, en 30 ans, pourraient transporter les graines relativement lourdes de l'Androsace glacialis et de la Renoncule des glaciers à 2 ou 300 pieds d'élé-

(1) Le monde des Alpes. p. 689. 


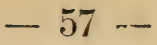

vation, étant données les circonstances locales si peu favorables au rapide développement de la végétation?

J'ai hâte cependant de citer sur ce sujet l'opinion d'un homme éminemment compétent, quoi. que étranger à notre pays, lequel, dans un travail lu à la Société royale de géographie de Londres, expose, au sujet de l'origine de la flore alpine, une opinion absolument différente de celle des autres naturalistes. M. John Ball, qui pendant longtemps a été président du (ilub alpin anglais, a fait, dans le domaine de la flore des Alpes, des étrudes très intéressantes et s'est occupé de cette question à un point de vue très élevé. M. Ball m'annonce qu'il publiera plus tard les résultats complets de ses recherches et de ses travaux. Enattendant, voici en quelques mots la résumé de sa théorie: $\left({ }^{1}\right)$

Au lieu de se baser sur la corrélation qui exis entre la flore des Alpes et celle des régions polaires pour conclure comme les autres naturalistes à une immigration de l'une de ces flores dans le territoire de l'autre, il cherche à démontrer que cette corrélation est tout aussi grande entre les flores qui couvrent une partie des mon-

(1) Proceedings of the royal geographical Society, Londres 1870. 
tagnes de l'hémisphère boréal; que ces montagnes ont dû, à une époque fort reculée, être reliées les unes rux autres et que leur flore était dans une certaine mesure la même sur tous leurs sommets.

Des espèces contenues dans la flore alpine, dit-il, $17 \%$ sont communes aux régions arctiques et $25 \%$ à la chaîne de l'Altaï. Il se demande alors combien il aurait fallu de siècles à ces plantes du Nord pour atteindre les sommets de nos Alpes. Puis il s'agirait de savoir d'où proviendraient les $83 \%$ autres espèces qui ne se trouvent pas dans le Nord. Est-il possible que dans l'intervalle, relativement si court, qui nous sépare de la fin de l'époque glaciaire, des centaines d'espèces parfaitement distinctes et même un certain nombre de genres distincts aient pu prendre naissance dans nos Alpes? Est-il surtout possible que ces espèces et ces genres non arctiques aient pu, dans une époque encore plus rapprochée de la nôtre, être distribuées à de si vastes intervalles sur une chaîne de montagnes de 1500 milles anglais, allant des Pyrénées aux Carpathes, et dont quelques-unes sont séparées des autres par de vastes territoires? Mais là même ne s'arrêterait pas la difficulté; comment s'expliquer le fait qu'une certaine quantité de types non- 


\section{- $59-$}

arctiques se trouvent disséminés dans les montagnes de régions absolument étrangères les unes aux autres et qu'ils y soient représentés par des espèces absolument différentes quoique descendant toutes du même ancêtre? Qu'une espèce de Wulfenia, par exemple, habite les Alpes de la Carinthie tandis qu'une autre espèce voisine mais différente, se retrouvera dans le nord de la Syrie et une troisième sur les monts Himalaya?

M. Ball n'admet pas non plus que des genres très riches en espèces différentes, tels que les Saxifraga, dont les formes et le port sont des plus variés, aient pu se former depuis la fin de l'époque tertiaire, ainsi que l'admet Engler, qui croit qu'à cette époque il n'existait que six types de Saxifrages. Il n'est pas possible que, dans un temps relativement si court, il ait pu se former une pareille quantité d'espèces si diverses et si parfaitement caractérisées descendant toutes d'un seul et même ancêtre. Comment admettre que la Saxifraga oppositifolia L., qui aurait été introduite des régions arctiques dans nos Alpes pendant la période glaciaire, ait pu donner naissance à une espèce très distincte du même groupe, la Saxifraga retusa Gouan, qui ne se rencontre, dans les Alpes, les Pyrénées et les Carpathes, qu'à de très vastes intervalles? 


\section{$-60-$}

Passant à un autre côté de la question, il se demande, dans le cas où une partie de la flore arctique aurait été disséminée sur les montagnes de l'hémisphère boréal depuis le commencement de l'époque glaciaire, où devait être cette flore, avant d'exister dans les régions arctiques. On sait en effet d'une manière très positive qu'à l'époque tertiaire, la flore de l'extrême nord était pareille à nos zones tempérées et que le climat qui régnait alors dans ces contrées n'eût absolument pas convenu à la flore qui s'y trouve actuellement.

A l'époque carbonifère, la vie organique qui convrait la terre était très différente de celle que nous voyons de nos jours. L'atmosphère était alors chargée d'une très forte proportion d'acide carbonique et contenait beaucoup moins d'oxygène que maintenant. D'après les calculs qui ont été faits, on peut supposer que l'atmosphère contenait alors sur la surface de la terre vingt fois plus d'acide carbonique qu'elle n'en renferme aujourd'hui. Mais il est probable que l'équilibre devait être rétabli sur les sommets des montagnes, lesquelles étaient alors beaucoup plusélevées qu'elles ne le sont maintenant. il ressort d'un calcul fait par le comte de Saint-Robert, de Turin, qu'en admettant 100 parties d'acide carbonique 


\section{$-61-$}

à la surface de la terre, il n'en resterait plus que 67 à 5000 mètres et $12 \frac{1}{2}$ à 10,000 . La proportion, encore très grande à 5000 mètres, diminue rapidement depuis lors et devient naturelle au double de la hauteur. Là, des végétaux phanérogames dans le genre de notre flore alpine devaient pouvoir vivre.

En outre les sommets des montagnes, à l'époque tertiaire, étaient dans de tout autres conditions que les bas-fonds et les plaines par le fait de la lumière qui devait les inonder,alors que les plaines, ensevelies sous des masses énormes de vapeurs, étaient plongées dans une sorte de miobscurité. Le récit de Moïse qui nous parle de la lumière comme étant apparue le premier jour sur la terre tandis que le soleil ne fut visible qu'à quatrième époque, s'explique fort bien par ce fait que la lumière n'était alors qu'une lueur diffuse, quelque chose comme celle de nos jours ténébreux et que les vapeurs ne furent dissipées que beaucoup plus tard, à la fin de l'époque houillère. Si, comme je l'ai déjà dit, et comme tout porte à le croire, les sommets des montagnes étaient alors beaucoup plus élevés qu'ils. ne le sont maintenant, il est probable que les flancs de ces sommets étaient revêtus d'une brillante flore phanérogame qui devait contras- 
ter singulièrement avec la végétation cryptogamique et gymnosperme qui couvrait la surface de la terre. Or, c'est là, sur ces hauteurs privilégiées et baignées de lumière, que N. Ball croit décourrir les foyers créateurs, non seulement de la flore alpine, mais encore de toute la végétation phanérogame. Ces plantes se seraient formées avant la fin de l'époque carbonifère. Des vastes sommets des montagnes, car il est a supposer qu'ils étaient très étendus et que les révolutions terrestres ont fait disparaître bien des chaînes importantes, cette flore aurait assisté, impassible et souriante, à tous les bouleversements qui se sont produits sur notre globe Tandis qu'à la surface du globe terrestre l'Esprit créateur faisait surgir la végétation si extraordinaire et si luxuriante dont nous retrouvons les traces dans les couches houillères, en haut, sur les flancs des plus gigantesques montagnes qui émergeaient au-dessus des nuées comme le font en hiver nos sommets au-dessus des brouillards, le soleil brillait et Dieu s'occupait des fleurs. Ces végétaux se sont développés, ont donné naissance à de nouvelles espèces; puis lorsque sous l'influence du soleil, les vapeurs dissipèrent, que l'atmosphère se décomposa et que des masses carbonifères se déposèrent sur le 
sol, alors cette flore descendit des hauteurs. Elle envahit petit à petit tous les territoires libres et se substitua par la suite à la flore de l'époque tertiaire. Les formes se mélangèrent, un grand nombre d'espèces disparurent tandis que d'autres apparaissaient et depuis ce moment la végétation terrestre changea complètement d'aspect. Aux plantes imparfaites, à organes rudimentaires, succédèrent les phanérogames aux tiges plus fermes et portant des fleurs. Les corolles au plus brillant coloris virrent occuper la place des fougères et des prêles et la terre se couvrit d'un grand nombre de plantes. C'est alors seulement que différents climats commencèrent à exister sur la surface de la terre, car auparavant la végétation des pôles était identique à celle des autres parties du globe.

L'idée que la flore ait suivi un mouvement descendant plutôt qu'ascendant me parait juste; les autres arguments que M. Ball emploie en faveur de sa thèse me paraissent également difficiles à réfuter. Pour ma part, je ne crois pas que les régions polaires puissent être en aucune façon des foyers créateurs. Il faudrait pour cela une intensité de lumière qu'ils ne possèdent pas. En effet, les rayons solaires y arrivent obliquement sur le sol, après avoir traversé une couche 
d'atmosphère beaucoup plus considérable quo partout ailleurs. La lumière vive qui régne sur les sommets des montagnes, la chaleur intense qui s'y fait sentir pendant la journée, l'humidité de l'air sont autant de causes capables d'activer la végétation phanérogame et de la modifier; ces causes n'existent plus dans les régions polaires.

La théorie de M. Ball a en outre cet avantage qu'elle résout le problème de la dispersion des mêmes espèces sur des territoires de montagnes très éloignés les uns des autres. Il est à supposer en effet qu'à l'époque carbonifère, la plupart des chaînes de montagnes de notre hémisphère boréal étaient plus ou moins reliées les unes aux autres. Les révolutions qui ont bouleversé la surface de notre globe ne l'ont cependant pas tellement transformé qu'on ne puisse réunir quelques traces prouvant que ces différentes chaines de montagnes n'en formaient qu'une seule à une certaine époque. est parfaitement certain, par exemple, qu’à une époque fort reculée, l'A mérique méridionale était un pays très montagneux. Le Brésil était alors relié au continent africain par un archipel ou même par une chaîne de montagnes qui s'étendait au travers de l'océan Atlantique mais qui a disparu sous l'eau. De là vient sans doute la présence sur les Andes de 


\section{$-65-$}

certains genres de plantes communs aux montagnes des deux continents. Il est facile dès lors de se faire une idée sur les causes premières qui ont aidé à la dissémination des espèces et des genres sur des sommets et dans des pays absolument différents et éloignés les uns des autres. Les montagnes du centre européen sont plus particulièrement riches dans leur partie orientale qu'à l'occident; c'est là, du reste, qu'il faut chercher l'un des principaux foyers créateurs. Les relations entre les flores de ces différentes montagnes sont également plus étroites à l'orient qu'à l'occident des Alpes. C'est ainsi que tandis que les Pyrénées n'ont que la moitié des espèces communes avec nos Alpes, cette proportion monte aux $2 / 3$ pour les Carpathes et descerd à $1 / 6$ pour les régions septentrionales.

Il est impossible de ne pas reconnaître la vraisemblance de la plupart des objections que fait $\mathbf{M}$. Ball aux théories précédemment admises sur l'origine de la flore des Alpes. Les travaux qu'il publiera à ce sujet seront bien accueillis par les naturalistes et contribueront au développement de la science dans ce domaine. L'histoire de la flore alpine et de son apparition sur les montagnes sont des questions qui sont encore loin d'ètre résolues et sur lesquelles on ne peut 
encore se prononcer d'une manière définitive. Il était cependant utile et nécessaire de connaître deux théories qui prévalent en ce moment dans le monde scientifique. C'est ce que j'ai cherché à faire sans parti pris tout en avouant que les idées de M. Ball me paraissent beaucoup plus en accord avec les données que me fournit une étude de quelques années seulement et avec les quelques faits qu'il m'a été possible d'observer dans les Alpes.

\section{RAPPORTS DE LA FLORE ALPINE AVEG GELLE DES AUTRES MQNTAGNES DU GLOBE}

Nous avons vu que la végétation des Alpes offre des caractères particuliers, qu'elle possède un cachet qui lui est propre et n'a que peu de rapports avec celle des plaines. Par contre, elle offre beaucoup d'analogie avec la flore qui recouvre les sommets des hautes montagnes dans n'importe quelle autre partie du monde. Il est vrai que c'est surtout entre les montagnes de l'hémisphère boréal que cette analogie est frappante. Si nous parcourons les her- 


\section{$-67-$}

biers de ces différentes montagnes, que nous prenions par exemple la flore de l'Himalaya com. parée à celle du Caucase, de l'Atlas ou des Alpes voire même des montagnes rocheuses dans l'Amérique septentrionale, nous retrouvons, non seulement un certain nombre de genres com. muns aux différents pays, mais encore, dans bien des cas, un assez grand nombre d'espèces qui sont les mêmes. D'après Christ, on compte dans les montagnes espagnoles et les Pyrénées 126 espèces communes à nos Alpes, 231 dans l'Apennin, 125 sur les Balkans, 23 dans l'Asie mineure, 86 au Caucase, 15 en Angleterre, 59 au Labrador et 2 sur l'Himalaya. Sur les sommités de l'hémisphère austral, la végétation, tout en conservant les mêmes caractères que celles de nos Alpes, s'en éloigne toutefois passablement quant aux espèces. Un certain nombre de genres cependant sont communs aux deux hémisphères et il est même plus d'une espèce qui se rencontre sur nos Alpes et dans les Andes de l'Amérique méridionale.

Partout, les plantes des zones nivales conservent les mêmes propriétés, les mêmes formes, le même cachet, le même habitus. C'ela s'explique par le fait qu'elles se trouvent dans les mêmes conditions d'existence et que les phénomènes 
glaciaires qui se produisent sur nos Alpes, se re. trouvent sur la plupart des hautes sommités du globe. Au Thibet comme sur les Andes du Nord de l'Amérique, sur les montagnes de la Norwège comme sur celles de la Tasmanie, les espèces qui composent la flore des régions glacées conservent leur port nain, rabougri, leurs tiges stolonifères rampant sur le sol ou tapissant le rocher, leurs fleurs à corolle relativement large, portée sur un court pédoncule. On trouve sur les pentes glacées du mont Cook, dans la Nouvelle Zélande, un certain nombre de Gentianes, de Renoncules, de Myosotis et de Viola qui ont beaucoup de rapport avec leurs congénères des Alpes. L'Edelweiss de la Nouvelle Zélande (Gnaphalium grandiceps) figure dans le journal "The Garden o et ressemble à s'y méprendre à notre fleur alpine. Le blanc tomenteux de ses tiges et de ses bractées est le même: cependant ces dernières sont plus courtes, plus obtuses et ses feuilles moins développées que chez notre Edelweiss. Un voyageur qui faisait, en compagnie d'un guide suisse, l'ascension de cette montagne, raconte que son compagnon, croyant découvrir la plante de son pays, ne put retenir un cri de joie. Comparant la fleur en question à une fleur d'Edelweiss quiil portait à son chapeau, ils ne trouvèrent 
presque pas de différence. Le voisinage des grands glaciers et des neiges éternelles, permet le développement d'une flore pareille dans un pays aussi éloigné du nôtre que l'est la Nouvelle Zélande. Le paysage de ces zones-là a du reste beaucoup de rapport avec celui de nos Alpes. La base des montagnes est garnie de forêts d'Eucalyptus, audessus desquelles seetendent de vastes étendues d'arbustes et de sous-arbrisseaux. Puis viennent les pâturages, en tous points semblables à ceux de nos Alpes et dans lesquels on rencontre une brillante flore, sœur de la nôtre. Là s'étalent les plus gracieuses Véroniques, de brillantes Gentianes, des Renoncules, des Ourisia, des Celmisia, des Utriculaires. On m'a montré l'an dernier une fleur d'Edelweiss qu'un missionnaire avait récoltée sur les montagnes du centre de la Chine; cette fleur, à part un duvet tomenteux plus fourni et d'un blanc plus jaunâtre que nos Edelweiss suisses, leur était cependant absolument semblable quant à la forme et aux dimensions. Dans les montagnes de l'Abyssinie, il existe une flore qui a de l'analogie avec celle de nos Alpes et offre un certain nombre de genres communs avec elle. Si nous étudions la flore des montagnes américaines, nous y retrouverons encore les mêmes formes, les mêmes caractères, les mêmes genres. Dans 
les Andes de l'Amérique du Sud, nous retrouvons les Saxifrages et les Gentianes représentées par de très jolies espèces. Des genres qui ailleurs forment des arbres et des arbustes, se trouvent là à l'état de touffes naines et rampantes comme c'est le cas pour les saules dans les Alpes. Nous retrouvons par exemple dans le genre Fuchsia le même phénomène qui se produit dans. nos Alpes avec l'Azalée, c'est-à-dire qu'il y devient absolument nain et rampant. Nous avons déjir vu que l'Amérique du Nord possède un certain nombre d'espèces communes avec nos Alpes; avec le Grcenland les rapports sont encore plus grands.

Maintenant, si, du Noureau monde, nous passons dans l'ancien, la conformité des espèces est beaucoup plus accentuée et va en augmentant plus on s'approche des Alpes. Commençons par l'Asie: en Chine nous retrouvons, en fait de plantes de montagnes, car je ne mentionne que celles là, notre Primula Auricula L. Des espèces telles que Solidayo Virgo aurea L., Artostaphylos alpina Sprengl., A. Uva Ursi Sprengl., Veronica alpina L. Pedicularis versicolor Wahl., $P \in d$. verticillata L, Rhodiolarosea L., Saxifraga cermua L., Sax Hirculus L., Saxifraga stellaris L., Teucrium montanum L., Polygonum viviparum L., Polygonum 
Bistorta L., se retrouvent sur les montagnes qui forment la chaîne de l'Himalaya, particulièrement riche en Primulacées. Sur le Taurus, nous trouvons le Myosot is alpestris Schmidt, la Pinguicula alpina L. L'Altaï contient une forme de la Saxifraga cermu L., une forme de la Saussurea alpina Dl., Campamula latifolia L., Androsace chamajasme Willd., Cortusa Mathioli L., Gentiana tenella Fries, Gentiana cruciata L., plusieurs Pédiculaires, le Myosotis alpestris Schmidt, et des Polygonum. Si nous explorons la Sibérie, nous trouvons dans ses vastes plaines ou sur les flancs et les plateaux. de ses montagnes une flore qui se rapproche considérablement de la nôtre. Là, les forêts sont formées d'aroles (Pinus cembra L.) et de mélèzes; le mélèze de ces régions est le Larix Sibirica, un peu différent du nôtre. Nous y rencontrons entre autres la petite violette jaune de nos Alpes, la Saxifraga cernua L., la Saussurea alpina Dl., la Sibbaldia procumbens L., la Linnaea borealis L., la Pyrola minor L., la primevère farineuse, l'azalée naine et rampante des Alpes, le myosotis alpestre, l'androsace chamajasme Willd., plusieurs pédiculaires et d'autres plantes encore. Une certaine quantité d'espèces alpines se retrouvent en Sibérie en même temps que dans l'Amérique septentrionale dont la flore est également 
anologue à celle des Alpes. Le Kamtschaka et la Daourie en possèdent quelques-unes. Plus nous nous rapprochons du centre européen et plus le nombre des espèces alpines augmente parmi les plantes de montagnes. LiOural et le Caucase en contiennent beaucoup plus que l'Hymalaya et l'Altaï. L'Asie mineure, malgré la température sèche et chaude qui caractériseses montagnes, contient un certain nombre d'espèces qui se retrouvent dans les Alpes. On trouve la Pinguicula vulgaris $\mathrm{L}$. en Bithynie, la Centaurea montana L. un peu partout dans les montagnes; le Petasites albus Gaertn., plusieurs de nos Campanules, l'Androsace villosa L. couvrent les pâturages du Liban et des montagnes de la Cappadoce. On retrouve la Gentiana cruciata L., G. asclepindaea L., Myosotis alpestris Schmidt, Veronica fru. ticulosa L., Teucrium montanum L, sur les monts de la Grèce et de l'Epire.

Si nous prenons l'extrémité occidentale de notre Europe, nous rencontrons dans la Sierra Nevada et les autres montagnes espagnoles un certain nombre de genres et d'espèces qui nous sont familières. La flore des montagnes ibériques contient un fort grand nombre de nos plantes: Astzr alpinus L., Solidago Virgo aurea L., Senecio Doronicum L., Vaccinium uliginosum L., Pinguicula 


\section{$-73-$}

vulgaris L., Pinguicula grandiflora Lam., Primula integrifolia L., Gregoria vitaliana Dub., Gentiana lutea L, G. alpina Griseb., Linaria alpina Mill., Veronica alpina L., Pedicularis verticillata L., Daphne alpina L., etc. Quant aux Pyrénées, nous avons déjà vu que Christ leur attribue 126 espèces communes avec nos Alpes et que ce nombre monte à 231 par la chaîne de l'Apennin.

Il est peu de plantes alpines qui soient cosmopolites ; une seule, un gazon, le Trisetum subspicatum Clairv., se retrouve sur les sommets de toutes les montagnes du monde, depuis la Nouvelle Zélande jusqu'au pôle nord.

Mais si toutes les montagnes du globe, ou pour. mieux dire toutes les contrées nivales, ont une flore qui offre le même cachet, le même port et les mêmes caractères, elles onl aussi chacune leurs espèces qui leur sont propres et qu'on ne retrouve pas ailleurs. Les unes sont plus riches que d'autres mais toutes offrent quelque particularité. Dans les montagnes de l'Océanie c'est le genre Veronica qui domine; sur les Andes il y a un grand nombre d'espèces de Gentiana, de Pentstemon, des Onıbellifères naines, des Fuchsia, des Saxifrages absolument différentes des nôtres. Dans l'Amérique du Nord ce sont les Phlox, les Enothères qui donnent le cachet ; 
sur l'Himalaya ce sont les Primula, les Androsaces, les diverses Potentilles et de curieuses Chomposées. L'Orient est riche en Campanulacées et en Renonculacées, tandis que le Nord nous fournit des Saxifrages, des Crucifères, que les montagnes de l'Europe méridionale nous donnent les Labiées et les Antirrhinées.

Cette flore des zones glacées de notre globe est bien la plus gracieuse, la plus richement colorée de toutes celles qui recouvrent notre enveloppe terrestre ; elle mérite, à tous égards, la préférence dans nos cultures. Mais entre toutes ces flores de montagnes, la plus intéressante et la plus fine est bien celle de nos Alpes et des montagnes du centre européen ; c'est aussi de celle-là surtout que nous nous occuperons pour chercher à l'acclimater dans nos plaines.

\section{GONDITIONS D'EXISTENGE DE LA FLORE ALPINE}

Il est important, pour celui qui veut se livrer à l'acclimatation des plantes alpines, de connaître les conditions dans lesquelles celles-ci se développent dans l'état naturel. Ces conditions 
ne se retrouvent sans doute pas dans nos climats, mais il est possible, dans bien des cas, d'y suppléer par des moyens artificiels. C'est précisément dans la recherche et l'application de ces moyens-là que résident tous les secrets de cette acclimatation. Nous essayerons donc de saisir le mieux possible l'état de ces conditions dans nos Alpes, afin de remédier aux inconvénients que présente pour les cultures alpines un climat très-différent et parfois meurtrier.

La première condition de développement chez les plantes des Alpes est, cornme dans toute autre végétation, la production d'un degré quelconque de chaleur. Si le thermomètre ne s'élevait jamais au-dessus de zéro, le soleil pourrait inonder le paysage de sa clarté sans qu'il se produisît de mouvement dans la vie végétale, à supposer même que le sol fût libre de neige ou de glace. Mais tandis que pour faire croître et fleurir les plantes de nos plaines il faut un certain déploiement de chaleur, il n'en est point de même dans les plantes des Alpes, où le plus minime degré au-dessus du point de congélation appelle les plantes à la vie. La végétation des zones supérieures est soumise à un traitement fort rigide et jouit d'un été si court et si froid 


\section{$-76-$}

qu'il représenterait l'hiver pour les plantes de nos plaines. Cependant ces espèces accomplissent pendant ce court espace de temps le cycle complet de leur existence annuelle. Elles tleurissent et mûrissent leurs graines aussi bien que les plantes de nos plaines. Leur port rabougri, la brièveté de leurs tiges, la petitesse de leurs organes foliacés, contribuent évidemment à activer le réveil et la vie en reportant sur la fleur et les organes reproducteurs toute la sève qu'envoient à la plante les nombreuses racines dont nous avons constaté l'existence, chez les espèces alpines. Il faut cependant reconnaître que dans les conditions où se trouve la flore alpine elle est à même de jouir d'une chaleur vive et intense par le fait que les rayons solaires dardent plus longtemps, d'une manière plus continue sur elle et que la couche d'atmosphère est moins considérable que dans nos plaines. Mais si, pendant la journée et lorsque le soleil exerce son influence, cette végétation jouit d'un degré élevé de chaleur elle a, par contre, à endurer des nuits froides et rigoureuses pendant lesquelles le thermomètre descend quelquefois à 5 ou 6 degrés au-dessous de zéro.

Une seconde condition essentielle à ce développement rapide de la vie végétale, c'est la lu- 
mière. La lumière est, après la chaleur, le principal élément dont cette flore s'abreuve. A cette altitude la nature prodigue la lumière dans des proportions beaucoup plus considérables que dans nos plaines. A l'époque de son réveil, la flore alpine se trouve immédiatement au bénéfice de la même dose de lumière que reçoivent les plantes de nos plaines en plein été. Le printemps, dans les zones supérieures, se trouve retardé de trois ou quatre mois sur le nôtre; pour être plus exact il faut dire qu'il n'y existe pas. En effet, la végétation alpine entre en possession des avantages de l'été immédiatement après la fonte des neiges et sans avoir à passer par une saison intermédiaire. L'époque de la disparition des neiges dans les régions alpines est généralement celle des plus longs jours de l'année et tombe sur les mois de mai et de juin. En peu de temps, souvent en quelques heures, on peut voir le champ de neige transformé en un pâturage verdoyant et émaillé de fleurs. Après sept ou huit mois de sommeil, les plantes se trouvent tout à coup exposées aux conditions les plus favorables à leur croissance et à leur développement. Lumière, chaleur et humidité, tout concourt à achever ce travail, qui n'est interrompu que par des nuits 
très courtes. Les plantes jouissent alors de 12, 14 et même 16 heures de lumière consécutive toujours pure et intense; or, dans nos contrées au contraire la végétation ne jouit au printemps que de jours fort courts et souvent nébuleux. Nos nuits longues et chaudes, nos crépuscules et nos aurores n'existent presque pas là-haut. Le nombre beaucoup plus considérable chez nous, des jours sombres et nébuleux pendant lesquels la lumière du soleil est interceptée par les nuages ou les brouillards diminue encore la dose de lumière ou d'insolation ce qui permet aux organes foliacés et aux tiges de se développer au détriment des fleurs. Plus la lumière est intense et abondante et plus les fleurs seront nombreuses et développées; au contraire si le jour est nébuleux, si la lumière est diffuse et voilée, les organes secondaires des plantes prendront plus d'extension et de développement. C'est ce qui nous explique pourquoi les plantes alpines que nous cultivons chez nous tendent généralement à alionger leurs tiges et à aug. menter le nombre et le volume de leurs feuilles, au détriment des fleurs.

Une forte dose de lumière est nécessaire aux plantes dont on veut obtenir beaucoup de fleurs. Les plantes des Alpes, loin de craindre les 
rayons solaires, exigent au contraire la lumière et l'insolation. Ces végétaux sont a reine Kinder des Lichtes " comme les a appelés un poète allemand; on ne trouve pas de champignons dans les Alpes, ni aucune plante qui n'appartienne franchement au domaine de la lumière. Aussi les espèces de nos plaines qui se trouvent transportées là-haut sont-elles parées de couleurs bien plus vives, bien plus pures qu'elles ne le sont chez nous. Voyez le Myosotis dans les Alpes. Quelle teinte ravissante, quel bleu adorable! Et la Primevère farineuse! Comparez donc la corolle de celles qui croissent dans nos marais avec celle de la plante alpine. On les dirait absolument différentes. Il en est de même de la simple esparcette (Onobrychis sativa Lam.) dont la couleur est tellement plus vive dans les Alpes que quelques botanistes en ont fait une espèce à part. Je pourrais multiplier les exemples. Mais il suffira de rappeler aux cultivateurs de plantes, les nombreuses déceptions qu'ils ont eues lorsqu'ils ont vu dans leur jardin les gra. cieuses fleurs des régions nivales produire des corolles pâles et moins colorées que dans la station naturelle. Ils ont alors compris que la position étant très ombragée, il fallait essayer de placer les plantes au soleil et ont été surpris 
l'année suivante en voyant la couleur vive et brillante de leurs fleurs.

Mais si la chaleur et la lumière sont nécessaires aux plantes alpines pour se développer, jl est une troisième condition qui leur est indispensable et qui ne doit jamais leur faire défaut dans les cultures. Les rayons du soleil auraient bientôt anéanti ces organes délicats, ces fleurs légères, ces corolles si fraîches et si fines s'il ne se trouvait un agent protecteur pour empêcher les dégâts. Cet agent c'est l'eau répandue dans l'air sous forme de vapeurs et qui entoure la plante comme d'une gaze légère, empêchant ainsi les rayons du soleil de brûler ses organes. Pour se rendre compte de l'importance du rôle que joue l'humidité de l'air, on peut faire une petite expérience bien simple et que chacun peut essayer. Prenez, d'une espèce délicate et sortant d'une serre chaude, deux pieds de méme grandeur et ayant crû dans les mêmes conditions; placez-en un au plein midi dans un endroit sec et de manière que les rayons solaires l'atteignent dans le milieu du jour. Vous verrez bientôt votre plante souffrir et ses.feuilles se brûler sous l'influence de la chaleur sèche du soleil. Recommencez le lendemain votre expérience au même endroit avec le second pied 
mais en plaçant celui-ci au-dessus d'un bassin d'eau sans toutefois que le pot trempe dans le milieu ambiant. Le soleil produira l'évaporation de l'eau ; si l'air est tranquille, la vapeur de cette eau se maintiendra pendant un certain temps au dessus du bassin, c'est-à-dire autour de la plante et empêchera le mal. C'est ainsi que dans les Alpes, les plus délicates corolles des fleurs sont préservées contre l'influence pernicieuse des rayons brûlants du soleil par la couche de vapeurs qui plâne pendant une grande partie de la journée sur le sol. Quand l'été s'empare de la nature alpine, le sol nage dans l'eau qu'a produite la fonte des neiges; ce sol spongieux garde cette eau pendant longtemps et la rend à l'atmosphère aussitôt que celui-ci commence à se dessécher. Puis dans les parties dominées par des sommets plus élevés, la neige qui fond pendant tout l'été sur les hauteurs, envoie dans les régions alpines et sous-alpines l'eau qui leur est nécessaire pour maintenir l'humidité de l'air. En outre, les nuits produisent régulièrement, lorsqu'il ne pleut pas, de riches et abondantes rosées dont les effets se font sentir le jour en remplissant l'air de vapeurs. Plus tard, dans les mois d'août et de septembre, l'air est plus sec, les doses de rosées matinales étant moins fortes: 
c'est alors qu'a lieu le travail de maturation des graines pour lequel la trop forte humidité serait préjudiciable. La plante entre alors dans une période de repos relatif; elle a déposé ses brillants attraits et semble inactive. Elle n'en poursuit cependant pas moins un travail incessant et fort intéressant à observer. Pendant cette période de sa vie, les parties extérieures de la plante n'ont aucun besoin d'humidité, car les graines, pour mûrir, doivent être sous l'influence directe des rayons solaires et d'une chaleur sèche. Puis, lorsque l'activité de la sève n'est plus nécessaire à la graine qui, une fois mûre, tombe et se répand autour du pied mère, elle se reporte sur les organes souterrains où s'opère un travail différent. Les racines se gonflent et se remplissent de sucs nourriciers, les bulbes secrètent les aliments qui seront nécessaires à la plante pour le printemps suivant; en un mot la plante pourvoit à ses besoins futurs. C'est l'hiver qui est à la porte; avant cependant d'entrer dans cette période de sommeil, il semble que la végétation alpine tente un dernier et suprème effort de vie et de développement. C'est alors que se forment les boutons à fleurs sur les espèces vernales chez lesquelles tout doit être prèt pour que le premier soleil du printemps 
fasse épanouir les fleurs. Prenez une soldanelle ou une Anemone vernalis $L$. à la veille d'être surprise par l'hiver; examinez attentivement la plante. Vous y trouverez, au centre de la rosace de feuilles, bien cachés dans le cœur de la touffe, les boutons qui fleuriront au printemps. Lorsque la neige vient recouvrir le terrain de la montagne, les boutons des fleurs printanières sont déjà formés et se trouvent dans un état plus ou moins avancé. C'est le même phénomène qui se produit chez les plantes bulbeuses du cap de Bonne-Espérance ainsi que chez les plantes des steppes centrales de l'Asie. Ces boutons tout formés n'auront pas à souffrir des changements de température particuliers aux hivers de nos plaines, car les plantes seront recouvertes de neige pendant tout le temps que durera l'hiver. Aussitôt cette couche disparue et le soleil reprenant ses droits, ces boutons grossissent et la fleur apparaît. Il est même des espèces précoces dont les fleurs, pour se développer, n'attendent pas même que la couche de neige ait entièrement disparu et émergent quelquefois au-dessus de la couche glacée lorsque celle-ci est devenue assez mince pour leur permettre de la percer. J'ai constaté le fait chez les Crocus et les Soldanelles, et au sujet de cette dernière 


\section{$-84-$}

espèce, le $\mathrm{D}^{\mathrm{r}} \mathrm{Christ}\left({ }^{1}\right)$ déclare avoir trouvé des Soldanelles dont les fleurs s'épanouissaient sous la couche de neige dans laquelle elles s'étaient creusé de petites cavités.

Ce dernier effort de développement chez les plantes des Alpes amène quelquefois celles-ci, sous l'influence des pluies qui précèdent l'hiver,

entr'ouvrir leur corolle. Ce phénomène se produit surtout dans les régions inférieures, lorsque l'hiver se fait trop longtemps attendre et qu'au lieu de la neige qui doit la recouvrir, cette végétation est soumise à l'influence des pluies automnales et du soleil. Comme nous l'avons vue prête à se développer au printemps sous la moindre influence de chaleur et de lumière, ainsi nous expliquons-nous facilement les causes qui nous permettent queiquefois de jouir de a flore vernale en plein automne. Qui n'a tressailli de joie à la vue des touffes de bleues gentianes et de potentilles dorées qui garnissent souvent, pendant les mois d'octobre, de novembre et même en plein hiver, les pentes ensoleillées de notre Salève? Il arrive quelquefois que sur les montagnes calcaires, où ce fait semble se produire plus fréquemment que sur les au-

( $\left.{ }^{1}\right)$ La flore de la Suisse et ses origines. Page 3\%i. 


\section{$-85-$}

tres, les plantes vernales fleurissent pendant tout l'hiver lorsqu'il n'y a pas de neige. Nos derniers hivers ont été particulièrement favorables à ce mouvement anticipé de végétation lequel nuit, cela se comprend, à la floraison du printemps.

L'humidité est donc l'une des trois conditions essentielles de la vie chez la végétation alpine. On objecte quelquefois que tel ne peut être le cas chez les espèces saxatiles dont les racines s'enfoncent dans le roc et dont la verdure est exposée aux rayons desséchants du soleil le plus ardent. Cette objection repose sur les idées absolument fausses qu'on se fait parfois de la nature de ces fissures de rochers qui ne sont point sèches comme on le croit. En effet, les racines de ce genre de plantes sont extrêmement développées et s'enfoncent profondément dans le roc; les fentes, souvent très profondes, sont entretenues dans une constante humidité qui suinte tout le long de leurs parois et communique aux racines de la plante l'eau dont celle-ci a besoin. Cette eau s'échappe en vapeurs par le côté extérieur de la fente, c'est-à-dire précisément à l'endroit où se trouvent les organes foliacés de la plante. Celle-ci se trouve donc dans les mêmes conditions atmosphériques que celles 
de leurs sœurs qui se trouvent dans le sol frais. et humide du pâturage. Dans les endroits les plus arides et les plus chauds, les fissures des rochers sont enduites d'humidité. Les cactées et les diverses espèces succulentes qui garnissent les rochers des plateaux du Mexique ou des autres contrées de l'Amérique tropicale, ne sont nullement privées d'eau comme le pensent beaucoup de voyageurs. Les racines de ces plantes s'en vont au loin, au traver's des fentes, chercher la fraîcheur dont leurs organes extérieurs ont besoin. C'est une erreur de croire que les plantes grasses vivent d'air. Un grand praticien dans l'art de cultiver ces plantes me racontait un jour que, se trouvant quelque part aux environs de Naples en conversation avec un amateur non convaincu de ce que je viens de dire, il lui proposa darracher une superbe plante d'Opuntia qui sortait de la fente d'un rocher du voisinage, à l'apparence très aride. On tenta laventure et on trouva que, malgré la grande sécheresse de l"époque et de tout le terrain d'alentour, les racines du dit Opuntia plon. geaient dans un milieu absolument humide et s'enfonçaient dans des fissures où ruisselait l'eau. Ces fissures sont nombreuses dans les rochers calcaires; elles le sont moins sur la 
roche primitive. Au sujet de leurs fonctions, de leur existence et des effets qu'elles produisent, M. A. Brun vient de publier dans l'Echo des $A l$ pes (1), un travail des plus intéressants et des plus dignes d'attention. Ces diaclases qui se forment insensiblement, sous l'influence du gel et du dégel, dans le sein des pierres les plus dures et les moins poreuses, produisent des effets considérables et jouent un très grand rôle dans la destruction des montagnes. L'humidité pénètre dans toutes les sortes de pierre avec plus ou moins de promptitude, suivant la nature de celles ci; mais il n'en est aucune qui ne soit soumise à cette loi. Tandis que les unes la boivent avec autant d'avidité qu'un morceau de sucre, d'autres, au contraire, ne la laissent pénétrer dans leurs interstices microscopiques qu'au bout d'un temps fort long. Les rochers sont donc imprégnés d'humidité et peuvent rendre aux racines des plantes qu'elles contiennent cette fraîcheur dont elles ont un si grand besoin.

Les plantes qui croissent dans les pierriers ou les éboulis sont également entourées de fraîcheur et d'humidité, malgré l'apparence aride de leur

(1) Destruction des arêtes des Alpes, par MI. A. Brun. Echo des Alpes, 1884, n 1. 


\section{$-88-$}

habitation. Leurs racines, leurs stolons et leurs tiges souterraines sont entretenus dans une humidité constante par la présence des pierres qui empêchent l'évaporation. Fouillez dans l'endroit en apparence le plus sec et le plus aride, la couche de matériaux qui recouvre le sol dans l'endroit qui forme un pierrier. Si la couche supérieure exposée à l'air et au soleil est sèche, il en est tout autrement dans les parties inférieures. Plus vous avancez vers le sol et plus vous constatez d'humidité chez les pierres; enfin, vous trouverez que le terrain dans lequel les plantes enfoncent leurs racines est absolument humide, malgré la sécheresse de l'air extérieur. Aussi trouve-t-on en abondance, dans ces amas de pierres qui paraissent si contraires à toute espèce de vie, les plantes les plus jolies, les fleurs les plus délicates et les plus fines qu'il soit possible de rencontrer. C'est là que se plaît la plus fraiche, la plus gracieuse et la plus suave des fleurs de nos Alpes; je veux parler du pavot blanc des pierriers, le Papaver alpinum L. Délicieuse apparition au milieu de la plus désolée des natures, cette plante est aux yeux de bien des alpinistes la plus adorable d'entre les fleurs. Si vous ne la connaissez pas lecteur, oh! vous perdez beaucoup. Impossible de vous la 
décrire; le pinceau, même le plus habile, ne peut rendre ces gracieux contours et sa corolle glacée avec son cœur d'étamines d'or. Elle nest point commune et ne se trouve jamais en grandes quantités au même endroit. On la trouve aux Vergys; allez-y pour l'admirer là-bas et lui rendre votre culte. Mais, de grâce, ne l'arrachez pas cela ne servirait de rien; j'ai commis ce crime un jour et m'en suis amèrement repenti, car aucun des pieds que j'avais emportés n'a réussi à reprendre vie chez moi, malgré les tendres soins qui leur furent prodigués. Par contre, le semis est un moyen sûr et infaillible de se la procurer. La graine est toujours très abondante dans ses capsules, et il est facile de les récolter pendant les courses d'été ou d'automne. Un pied de ce pavot, obtenu de semis, a fleuri tellement abondamment dans une rocaille de Frontenex, qu'il n'a pas été possible d'en compter les fleurs. C'était un perpétuel bouquet d'albâtre et d'or pendant toute la belle saison. On fut très étonné, l'année suivante, de trouver de jeunes pavots alpins dans les différentes parties de la rocaille; le vent avait disséminé les graines qui avaient germé et donnèrent de nouvelles plantes. C'est encore dans ces pierriers si maudits du touriste, auquel ils ont plus d'une 
fois causé d'amères souffrances, qu'on rencontre le charmant Thlaspi rotundifolium Gaud,, le $R a$ minculus parnassifolius L., la Viola cenisia L., le Senicio Doronicum, la Linania alpina Mill, et tant d'autres plantes qui font les délices du voyageur. Ne médisons donc pas des pierriers, nous que leur flore passionne à juste titre.

Il est enfin un troisième cas dans lequel le rocher se présente à nous comme un réservoir d'humidité et de fraîcheur en faveur des plantes; je veux parler des lappiaz. Tout alpiniste com. prend ce mot de lappiaz, qui lui rappelle tant d'amers souvenirs et de déboires sans fin. Pour ceux qui ne le connaissent pas, je dirai que le lappiaz peut être comparé à un glacier de roches; c'est une vaste étendue de rochers plats, toujours calcaires, rongés, perforés en tous sens par le temps et les agents atmosphériques. Ne vous y aventurez jamais de nuit; malheur à vous si vous vous égarez dans un de ces épouvanta. bles champs de pierres, car rien n'est plus dangereux. Les trous, les fentes abondent de tous les côtés et vous ne pouvez faire deux pas sans rencontrer de ces creux cachés par des arbustes, des buissons dans lesquels vous risquez de vous tordre le pied. Dans ces cavités plus ou moins profondes, plus ou moins grandes et larges, 
nous trouvons une terre végétale de première qualité. Elle est poreuse, spongieuse et maintenue dans un état de constante humidité. Aussi ne s'étonne-t-on pas de rencontrer dans les lappiaz des Vergys, par exemple, ou dans d'autres une végétation paludéenne et des plantes qui exigent une grande fraîcheur. Dans les lappiaz du Marchairuz se trouvent les plus belles fougères et les plus riches espèces d'entre les plantes des régions humides et tourbeuses.

J'ai parlé de terreau et d'humus dans les cavités des lappiaz; comment, se demande-t-on quelquefois, comment cet humus, ce terrain riche et fécond, peut-il se former dans ces rochers arides et isolés? Comment, ont demandé bien des personnes, se forme le terreau qui se trouve dans les parties supérieures des montagnes, dans les fentes des rochers, sur les corniches avancées et sur les crêtes les plus élevées, là où toute vie organique fait défaut et où c'est à peine si quelques phanérogames peuvent fleurir pendant quelques semaines? Nous arrivons ici à la quatrième condition d'existence de la flore alpine, celle du sol, qui n'est pas la moins importante.

Pour se faire une idée exacte de la manière dont se forme, dans les hautes montagnes, le 
terreau dans lequel se développe toute cette végétation, il sera bon d'étudier la chose dans un. domaine plus rapproché de nous, qui nous soit plus familier et où nous puissions entreprendre une suite d'excursions et d'observations. Allons. par exemple sur le sommet du Salève et examinons-y attentivement les roches qui s'y trouvent. Ici ce sont de gros blocs de rochers fendus, crevassés, lézardés et travaillés par l'eau. et le temps. Jues crevasses se dirigent dans tous les sens et sont plus ou moins profondes; en plusieurs endroits elles sont devenues si grandes que la pierre est partagée en deux parties Dans chacune de ces fentes nous trouvons une végétation parfaitement établie et plus ou moins variée. Tandis que dans les plus jeunes et les moins développées nous ne trouvons que des lichens, des mousses et d'autres cryptogames, les plus profondes donnent asile aux espèces supérieures et même à des arbustes et à des arbres. Jans les petites fissures on ne voit pas encore de terreau; les lichens s'attachent au roc dont l'humidité et les quelques débris minéraux qui s'en détachent suffisent pour les faire vivre. Les mousses, plus développées en organisme et qui ont besoin de davantage de nourriture, viennent vivre dans les fentes plus profondes 


\section{$-93-$}

sur les détritus laissés par le lichen décomposé. Dans des trous plus grands, plus anciens, on voit les phanérogames enfoncer leurs racines dans un humus noirâtre et tourbeux et enfin dans les plus grandes cavités, on trouve un terreau riche en substances nourricières et qui entretient la vie d'un grand nombre de plantes, parfois très développées. Si nous visitons quelquefois les mêmes localités nous verrons bientôt augmenter la masse et la quantité de l'humus dans les fentes observées.

C'est là à peu près ce qui se passe dans les Alpes; si nous pouvions suivre attentivement le travail incessant qui se produit dans ces régions et qui y favorise le développement de la végétation, nous assisterions à quelque chose d'admirable. C'est d'abord un bloc de rocher qui se détache et va rejoindre dans la vallée les. nombreux débris qui s'y accumulent depuis des siècles. La paroi dont il s'est détaché est absolument nue et immaculée. Il semble impossible que jamais plante puisse venir s'y cramponner et y vivre. Et cependant au bout d'une cinquantaine d'années, si nous pouvions retourner visiter notre rocher, nous le verrions garni de taches de différentes couleurs et ses aspérités recouvertes d'un semblant de verdure. Ce ne sont. 


\section{$-94-$}

encore que des lichens dont le vent a transporté les spores en cet endroit et qui, sous l'influence de l'humidité, se sont développés. Mais plus tard ces lichens s'étendront davantage; ils deviendront plus fournis et formeront une couche de terreau qui deviendra de plus en plus épaisse et bientôt se formera un léger terreau. Dans ce sol viendra un jour ou l'autre germer la graine d'un végétal plus complet, amenée dans ces régions par l'une des causes de dispersement des graines énumérées dans un précédent chapitre. La plante grandira, ses feuilles se décomposeront petit à petit, ses graines tomberont autour d'elle et germeront à leur tour et bientôt une nouvelle station de plantes viendra animer ce bloc aride et autrefois sans vie. C'est ainsi que la végétation alpine s'étend et s'installe partout, grâce à la présence des lichens qui sont les précurseurs et les promoteurs de la vie végétale. Les lichens, si nombreux et si variés, dont les spores ténues remplissent l'atmosphère et l'air que nous respirons ont donc, comme tout autre détail de la création, leur rôle à remplir dans le grand organisme du monde.

Le terreau de la montagne est noir, spongieux, toujours frais et humide; il est mélangé 


\section{$-95-$}

d'une plus ou moins grande quantité de cailloux et de sable. C'est un humus des plus riches qui fournit à la végétation alpine tous les éléments dont elle a besoin. Au point de vue chimique ce sol offre diverses compositions. Il est toujours mélangé d'une certaine proportion de débris minéraux dont la présence exerce sur les plantes une influence plus ou moins sensible. Sa composition, à ce point de vue-là, correspond toujours à la nature de la roche qui prédomine dans la contrée. Les territoires calcaires fournissent un sol imprégné de chaux, tandis que dans les pays schisteux ou granitiques ce sont des débris de ces roches qui se trouvent dans le sol. La végétation est différente suivant la nature minérale des contrées; tandis que certaines espèces recherchent le calcaire et que plusieurs d'entre elles ne peuvent vivre ailleurs, d'autres, au contraire, le fuient et préfèrent les schistes ou les granits. Dans nos plaines les alluvions, les bouleversements successifs qui s'y sont succédé ont produit un tel mélange des terrains que des différences chimiques n'existent généralement pas entre eux.

On a donc divisé la flore alpine en flore calcaire et en flore granitique ou siliceuse. Il est probable que l'élément qui joue le plus grand 
rôle dans la distribution des plantes c'est la chaux. La présence ou le manque de calcaire dans un terrain paraît être la cause qui détermine l'existence ou l'absence de telle ou telle espèce dans une contrée. La plus grande partie des plantes alpines aiment ou supportent le calcaire, tandis que le nombre est relativement restreint des espèces qui fuient cette matière et sont franchement granitiques. Un grand nombre d'espèces paraissent avoir été modifiées par la nature chimique du sol et ont donné lieu soit à des variétés, soit à des espèces nouvelles. Les espèces granitiques paraissent, en général, plus difficiles à acclimater que les autres et fleurissent moins facilement dans nos jardins. Il est bon de savoir, lorsqu'on veut se livrer à la culture des plantes alpines, quelles sont les affinités chimiques des diverses espèces. Le $\mathrm{D}^{\mathrm{r}} \mathrm{Ker}-$ ner, qui a réussi d'une manière si merveilleuse à faire descendre la flore des Hautes-Alpes tyroliennes dans le Jardin botanique d'Innsbrück, a observé très soigneusement ces détails et paraît s'en être bien trouvé. Il donne dans sa " Cultur der Alpenpflanzen 》 des renseignements fort intéressants à ce sujet et entre autres une liste de noms d'espèces calcaires correspondant aux espèces granitiques et ayant toujours beaucoup. 
de rapports les unes avec les autres. Il est bien évident que chez la plupart de ces plantes c'est la composition chimique du sol qui a formé l'espèce. Voici du reste de la liste de Kerner quel. ques-unes de ces espèces parallèles :

Sol calcaire : Achillea atrata $\mathrm{L}$. Alyssum montanum L.

Androsace lactea L.

- Helvetica Gaud. Anemone alpina $\mathrm{L}$. Avenaria ciliata L. Dianthus alpinus L. Draba aizoides $\mathrm{L}$.

" 'tomentosa Wabl. Epilobium Dodonai Vill.
Sol granitique : Achillea moschata Wulf. Alyssum Wulfenianum Bernh. Androsace carnea L.

D glacialis Hoppe. Anemone sulfurea L. Arenaria multicaulis L. Dianthus glacialis Haenk. Draba Zahlbruckneri Hort.

Draba frigida Saut. Epilobium Fleischeri

Hochst.

Gentiana angustifolia Vill. Gentiana excisa Presl. Hutschinsia alpina R.Br. Hutschinsia brevicaulis Hoppe.

Phyteuma orbiculare L. Phyteuma hemisphaericum L.

Primula Auricula L. Primula villosa Jacq. Rhododendron hirsutum.L Rhododendron ferrugi-

Salix retusa L.

Silene alpestris Jacq.

Veronica saxatilis Jacq.
neum L.
Salix hastata L.
Silene rupestris L.
Veronica fruticulosa L. 


\section{$-98-$}

Quiconque connait un peu les espèces mentionnées ci-dessus n'aura pas de peine à reconnaître une grande analogie entre les espèces parallèles. Les caractères botaniques qui les dis. tinguent les unes des autres sont souvent bien peu importants, en tous cas peu apparents. Quelques-uns portent simplement sur la couleur de la corolle ou sur celle de la fleur. En général, les espèces appartenant aux sols cal. caires sont plus riches en coloris, leurs fleurs sont plus grandes que chez les espèces granitiques. Généralement aussi les feuilles sont velues ou laineuses, ce qui n'est que rarement le cas dans la flore siliceuse. Le $\mathrm{D}^{\mathrm{r}}$ Christ parlant de cette influence du sol sur la végétation dit :

1 C'est quan d des espèces semblables, liées l'une

a à l'autre par une étroite parenté, se compor-

" tent tout différemment dans le choix du ter-

- rain, que l'influence du sol sur la distribution

" des plantes devient la plus évidente. A cet

a égard, l'Anemone alpina est un exemple remar-

" quable. Chez nous, la forme à fleur blanche se

* trouve exclusivement sur le calcaire (il n'en est

" plus ainsi dans les Vosges), tandis que la forme

" à fleur jaune soufre (A.alpina $t$. sulfurea) ne se

- trouve que sur le terrain argileux et siliceux.

- La limite est si exactement tracée que, dans 
( les stations où les deux terrains se rencontrent a et empiètent l'un sur l'autre, les deux variétés a erı suivent fidèlement tous les contours, même a dans les endroits où la transition du calcaire " au sol dénué de carbonate de chaux n'a pas - lieu brusquement, mais par un mélange in" sensible, la fleur de l'anémone passe par une " série de nuances intermédiaires de la couleur ( blanche à la couleur jaune ( $\left.{ }^{1}\right)$. "

J'ai été souvent frappé de la manière dont les deux formes sont distribuées dans les Alpes suivant que le territoire est calcaire ou granitique. Ce phénomène se produit d'une manière toute particulière dans le charmant vallon de Fully, en Valais. Dans les pâturages qui se trouvent sur la rive droite du second lac (le premier en renant depuis Martigny) les fleurs de l'Anémone alpine sont d'un blanc très pur. Si l'on suit cette côte qui longe les lacs, passent au-dessous de la * Frête aux Gorgneules » et s'en va par le - Sex Trembloz " rejoindre le "Col de Fenêtraille, o la couleur de la corolle passe par tous les intermédiaires pour arriver au jaune soufre foncé. Or, on sait que la partie méridionale de ce massif de Fully renferme du calcaire tandis

(1) La flore de la Suisse et ses origines, p. $31 \%$. 


\section{$-100$}

que vers le nord, dans le fond du ravin, la roche est schisteuse. Je me souviens avoir trouvé sur le flanc méridional du Chasseron, en 1877, une petite station d'A. sulfurea au milieu d'un champ d'Anémones blanches. Très étonné de la chose, j'examinai le terrain et le trouvai dans cet endroitlà seulement argileux et glaiseux. Comme il se trouvait, plus bas, une petite fontaine, il est possible que ce soit le fait d avoir remué le sol pour y placer des tuyaux qui aura apporté cet argile à la surface et produit la chose. Je signale seulement ce fait sans y ajouter d'importance pour le moment. Je ne sache pas qu'on ait trouvé cette Anémone ailleurs dans le Jura.

Chez le Rhododendron, l'absence ou la présence de calcaire a déterminé la formation de deux espèces parfaitement distinctes dont l'une a les feuilles glabres et l'autre les a ciliées sur les bords. Les fleurs diffèrent en outre d'une manière notable et tandis que le feuillage de l'une est brun en dessous celui de $R$. hirsutum est absolument de même couleur des deux cotés. Le Rh. hirsutum se rencontre généralement dans les territoires calcaires tandis que le $R$. ferrugineum appartient à la flore granitique. On ne peut cependant pas assigner de limites précises à ces espèces car le Rhododendron 
possède une si vaste aréa et se trouve tellement répandu dans les Alpes qu'il lui est bien difficile de rester dans de certains limites. On trouve le $R$. Tirsutum dans des parties absolument granitiques de nos Alpes tandis que son congénère se rencontre sur certains points du Jura. C'est ainsi qu'on le trouve sur le Reculet où il paraît parfaitement établi, dans les endroits les plus calcaires et les plus rocailleux. Il faut cependant reconnaître que ces cas sont des exceptions et que la couche de terre végétale qui sépare dans ces endroits-là les racines des plantes, du rocher lui-même, est très épaisse et isole en quelque sorte ces racines.

On se demande souvent d'où peuvent provenir les cas d'albinisme qui se présentent parfois dans la flore alpine. Dans les Campanules, les Orchis, les Gentianes, le Rhododendron, les Primevères, les Soldanelles, le Cyclamen, etc., on rencontre fréquemment la fleur blanche alors qu'elle doit être d'une tout autre couleur. Evidemment cela tient à la composition chimique du sol qui est de différentes natures dans les Alpes au lieu que dans la plaine il est généralement partout très mélangé. C'est ce qui expliquerait pourquoi ces cas ne se présentent que rarement dans les plaines et plus rarement encore dans les pays 


\section{$-102-$}

plats, dénués de montagnes. Il y a sur le Jura des localités entièrement recouvertes de Gentiana verna à fleurs blanches. Mais ce qu'il y a de frappant c'est qu'entre les touffes de ces gentianes blanches croissent des plantes portant la corolle bleue dans son état naturel. J'ai fouillé partout pour voir s'il ne se trouvait pas de cas où les. deux couleurs se trouveraient sur le même pied mais je n'en ai jamais rencontré. Il y a là une question fort intéressante à étudier et tout un champ d'investigations pour les physiologistes. Les pieds de gentianes blanches, replantés dans la rocaille du Jardin botanique, ont refleuri blanc l'année suivante. Le Rhododendron blanc est connu de tous les alpinistes; il est fort beau et maintient très bien sa couleur dans les cultures. Il en est de même des autres plantes à fleurs blanches. Mais je n'ai pas ouï dire que cette couleur se maintînt constante par le semis; c'est une chose à essayer. Il est probable que les. cas d'albinisme sont le résultat d'une modification de l'espèce, modification dont la nature chimique du sol doit avoir été la cause.

Je n'en veux pour preuve que ce fait qui s'est passé sous mes yeux : J'ai reçu en automne 1878 des Pyrénées une collection de plantes contenant douze pieds d'Androsace ciliata. Je les. 
plantai dans de la terre de bruyère mélangée de terreau et de sable calcaire. Cette espèce produisit au printemps 1879 des fleurs blanches, comme c'est son état naturel. Mais quelle ne fut pas ma surprise, au printemps suivant, de voir ces plantes produire des corolles d'un pourpre vif et brillant, d'une couleur si intense que je ne puis la comparer à aucune autre plante alpine! Or, voici ce qui s était passé : les plantes avaient été déménagées du canton de Vaud à Genève; elles avaient souffert du froid et du sec pendant une partie de l'hiver, on les avait ensuite plantées dans un terreau de feuilles contenant fort peu de terre de bruyère et une certaine quantité de sable granitique. Cela suffit-il pour expliquer ce changement de couleur produit sur les huit pieds qui étaient restés? Je ne sais, mais il est un fait, c'est que cette teinte superbe ne peut avoir été produite que par suite du changement de régime et de terrain.

Il est très important, pour certaines planies, d'observer leurs affinités chimiques dans les cultures. On répond à ces exigences en mélangeant au terrain dont on se sert une proportion plus ou moins grande de sable calcaire ou de sable granitique. Le premier se rencontre sur le bord de nos lacs et des rivières qui descendent des massifs calcaires ; ainsi tous les sables qui nous 
viennent du Jura ou des montagnes de nos environs sont calcaires. Le sable granitique est celui que nous fournit l'Arve et qui descend du massif du Mont Blanc; on le trouve au bord des ruisseaux et des rivières des pays non calcaires. On peut aussi remplacer le sable granitique par de la terre argileuse et le sable calcaire par le « löss " lorsqu'on en a.

Les propriétés physiques du sol ont une influence moins grande sur les espèces, mais n'en sont pas moins très importantes au point de vue du développement des plantes. J'ai décrit, à la page 91 , la manière dont se forme le terreau de la montagne: il est donc inutile d'en reparler ici. Cependant il est bon d'observer que, dans ce domaine-là encore, il y a toute une série de variations, depuis le terrain tourbeux des prairies humides jusqu'au gravier glacé des plus hautes régions. L'humus, cette matière nutritive du sol qui provient de la décomposition des matières végétales, se trouve répandu en plus ou moins grande quantité dans ces différents terrains. Il est très abondant et presque uniquement représenté dans le terreau noir et spongieux qui rem. plit les interstices des rochers, tandis qu'il entre pour une faible part dans la composition des sols sablonneux et caillouteux qui bordent les glaciers 


\section{$-105-$}

ou les torrents alpins. Il est des corniches élevées sur lesquelles on trouve une végétation phanérogamique croissant dans un terrain qui semble n'être qu'un composé de cailloux et de sable. Une eau glacée entretient continuellement la vie et la fraicheur dans ces détritus de roches et si l'on examine attentivement le sol, on ne tarde pas à y découvrir quelques parcelles d'humus. Quelques espèces telles que l'Androsace glacialis Hoppe, l'Erytrichium ranum Schrad., la Saxifraga biflora All. semblent affectionner ce terrain là d'une manière particulière. On évitera donc, dans les cultures, de leur donner trop de terre et on mélangera son terreau avec une grande quantité de pierres et de sable. Certaines espèces, telles que Linnaea borealis L., Empetrum nigrum L., Pyrola uniflora L., Lycopodium Selago L. etc, ne croissent que dans un sol spongieux, moussu, extrêmement léger et rempli de détritus de bois et de feuilles. Quelques-unes semblent affectionner comme sol, la mousse pure et simple. Les espèces tourbeuses telles que Parnassia palustris L., Swertia perennis L., Gentiana bavarica L., exigent un sol humide, spongieux, fortement imprégné de Sphagnum ou d'une autre espèce de mousse très poreuse. Telle espèce qui réussira dans un sol léger, tourbeux, périclitera dans un 
sol lourd et moins poreux. Telle autre ne supportera pas un terrain léger et s'accommodera d'un sol consistant. Telle autre enfin ne se rencontrera que dans les débris de roches ou d'ardoises, dans les graviers ou les pierriers. J'ai vu en 1880, à la Combazellina, dans les Alpes Pennines, un vrai champ de jeunes Rhododendron qui offraient à peine quelques centimètres de haut et pouvaient n'avoir que deux ou trois années d'existence. C'était la première fois qu'il m'était donné de voir une telle pépinière car on sait que les jeunes Rhododendron sont fort rares. Le sol était, en cet endroit, formé d'une couche de sable d'alluvion absolument schisteux et granitique qui s'était répandu sur le terrain quelques années auparavant par suite de la rupture de la o bis" . En arrachant les jeunes plantes, je vis que leurs racines plongeaient uniquement dans ce sable et n'avaient pas encore atteint la couche inférieure formée de terre régétale. Or, ce sable ne m'a pas semblé contenir d'humus; en tous cas il était fort pauvre en matières organiques Mais attendons: petit à petit le feuillage se décompo. sera, les racines atteindront le sous-sol et nos plantes porteront fleurs et graines. Je ne pense pas que Kierner ait raison quand il suppose que le Rhododendron ferrugineum L. et l'Azalea procum- 


\section{$-107-$}

cumbens $\mathrm{L}$. puissent vivre dans un sol absolument dénué d'humus et être considérées comme premières colonisatrices. Les seules plantes qui, d'après mes expériences, puissent vivre dans un sol très pauvre en humus, sont les espèces des hautes régions que j'ai déjà nommées et les graminées. Ces dernières envahissent tous les endroits où se trouve quelque peu de sable et d'humidité; elles peuvent seules être considérées comme premières colonisatrices dans le sol préparé par les eaux et les lichens. Il y a dans le Torembec (vallée de Bagnes) une flore très riche qui vit dans un sable mélangé d'une faible proportion d'humus et il ya là des espèces qu'on ne rencontre généralement que dans le plus riche humus et qui cependant, s'accommodent fort bien de ce sable aride. Mais leurs racines sont ici démesurément développées et s'en vont au loin chercher la nourriture et la fraicheur. Elles ne sauraient être considérées comme premières colonisatrices par le fait qu'elles se rencontrent quelquefois dans des conditions pareilles. Le fait que leurs racines prennent un développement si considérable prouve à lui seul qu'elles ne sont pas dans leur élément. Cependant elles se contentent, au besoin, de ces conditions là et ne s'en portent pas plus mal, parce qu'elles re- 
trouvent une compensation dans le fait que le sable est continuellement humide et que l'eau transporte ici l'humus dont les plantes ont besoin. Il faut se garder de rendre à une plante qu'on rencontre dans de te!les conditions le même sol et la même proportion de sal)le et d'humus. Ce n'est que par une suite d'études et d'expériences quon parvient à trouver le terrain qui convient aux diverses plantes alpines.

En général, elles aiment un sol léger, riche en humus, mélangé de sable et de gravier, même de poussière de cokie et si possible d'un peu de Sphagnum. Le terreau de feuilles, lorsqu'il est pur, est à mes yeux préférable à tout autre terreau. La terre de bruyère ou celle de châtaigniers entreront dans une certaine proportion dans le mélange Dans la grande majorité des cas j'emploie un sol composé de ${ }^{2 / 3}$ de terreau de feuilles, $1 / 3$ de terre de bruyère ou de châtaigniers avec adjonction de sable, de colie, charbon ou sciure de bois, selon la plante. Pour les espèces délicates, je mets ${ }^{1} 3$ de terre de bruyère, $1 / 3$ terre de châtaigrier et $1 / 3$ terreau de feuilles avec adjonction de sable. Suivant les cas, je mélange des morceaux de pierres calcaires ou granitiques à cette composition. Il est cependant un certain nombre d'espèces alpines qui ne se contentent pas de ce 


\section{$-109-$}

terreau-là et qui ont d'autres exigences; nous nous en occuperons plus loin. Celles qui jouent dans la nature le rôle de premières colonisatrices sont naturellement les moins délicates dans les cultures. Elles offrent cependant un grand inconvénient, c'est d'envahir très facilement et de prendre trop de développement au préjudice des autres espèces leurs voisines. On remédie à cela en leur donnant un sol très pierreux et aride. Les graminées et certaines composées telles que les Hieracium sont dans ce cas.

\section{AGGLIMATATION ET GULTURE DES PLANTES ALPINES, LEUR MULTIPLIGATION ET LEUR REFRODUGTION PAR SEMIS.}

Intèrèt qu'offrent les cultures. - Causes de uon-réussite.

- Acclimatation.-Reproduction par semis.- Récolte des graines. - Bouturage et division des touffes. Culture en rocailles. - Terreau. - Culture en platesbandes - Culture en pots.

Bien des personnes pensent et disent qu'il n'est pas possible d'acclimater et de cultiver chez nous les plantes des Alpes. Notre climat plus chaud et plus sec est généralement considéré comme meurtrier pour elles. On a bien. 
essayé quelquefois, mais, n’ayant pas réussi, on a mis de côté la truelle et la boîte à botanique et pris la détermination de ne plus se laisser tenter par les fleurs des Alpes. Ce qui n'empêche pas que l'année suivante on recommencera de nouveau ses essais, ne pouvant se résoudre à ne jouir de cette adorable végétation alpine que pendant les quelques jours qu'il est permis de la contempler là haut. Quelquefois, à force de soins, on parvient à faire réussir quelques espèces; mais combien n'en sacrifie-t-on pas pour arriver à ce résultat! De tous temps les alpinistes ont cherché à acclimater les plantes de montagnes et nous savons maintenant que les premiers Genevois qui se sont illustrés dans la science alpine au siècle passé, Necker-de Saussure, Vaucher, ont déjà tenté des essais de ce genre ( $\left.{ }^{1}\right)$. Schleicher et Thomas cultivaient des plantes alpines à Bex en $1818\left(^{2}\right)$. Ce n'est point une affaire de mode, comme on l'entend dire parfois, un goût qui passera. Non, car aussi longtemps qu'on ira sur les Alpes on cherchera à emporter leurs admirables

(1) Bulletin de l'association protectrice des plantes, $n^{\circ} 2$, page 4 .

$\left({ }^{2}\right) 2^{2}$ Rapport de la Société Helvétique des Sciences naturelles 1818. 


\section{$-111-$}

plantes dans les jardins de la plaine. Quoi qu'on fasse et quoi qu'on dise, la culture des espèces alpines, est et deviendra toujours plus le passe-temps de tous les alpinistes qui possèdent un coin de jardin ou même un simple balcon avec une caisse de terreau. Mais comment se fait-il qu'on ait tant de peine à acclimater les plantes des Alpes et à les faire fleurir dans nos plaines? La raison en est bien simple. Irez-vous jamais, en plein été et alors qu'elle est en pleine floraison transplanter une plante quelconque de votre jardin avec l'espoir qu'elle vivra? C'est cependant ce qui se fait continuellement pour les plantes alpines. On arrache pendant la floraison parce qu'il est difficile pour beaucoup de gens de reconnaître les plantes après ou avant quelles soient en fleurs. Eh! bien, c'est pourtant par là qu'il faut commencer, car on ne réussira à acclimater convenablement une espèce alpine que lorsqu'on l'aura transplantée en temps convenable. Il faut apprendre à les reconnaître, alors même que leur seul feuillage les distingue des autres plantes. Cette connaissance s'acquiert rapidement.

Lorsqu'il s'agit de transporter d'un climat dans un autre une plante pour la cultiver, il faut qu'elle subisse pendant un certain temps un 
traitement spécial, afin de s'acclimater et de s'habituer petit à petit aux nouvelles conditions climatologiques auxquelles elle sera exposée. Ces essais, lorsqu'ils sont faits sans connaissance, arrivent souvent à des résultats purement négatifs et causent la perte d'un grand nombre de pieds arrachés bien inutilement de leur lieu d'origine. Mais lorsqu'ils sont faits d'une manière raisonnée et d'après certaines données, en tenant compte de leurs conditions antérieures d'existence et en les acheminant petit à petit vers de nouvelles conditions, il y a beaucoup plus de chances de réussir. Sur les huit à neuf cents plantes phanérogames qui habitent la chaîne des Alpes, il n'en est peut-être pas un demi-cent qui aient élé jusqu'à présent rebelles à toute culture. Il va sans dire que pour beaucoup. d'entre elles il faut adopter un systeme particulier et une culture spéciale, ce que chacun n'a pas la possibilité de faire. Mais dans la grande majorité des cas, les plantes alpines sont diune culture facile et simple et n'exigent que peu de soins. Leur acclimatation seule demande quelques ménagements; voici du reste quelques détails à ce sujet :

Nous avons déjà observé la manière dont se développe la flore alpine et la rapidité avec 
laquelle elle accomplit le cycle de son existence annuelle. C'est à la fin de cette existence, lorsque la plante a fleuri, qu'elle a mûri ses graines et que le mouvement de sève commence à se ralentir, qu'on peut essayer de la transplanter dans la plaine. Pas n'est besoin alors de l'arracher avec sa motte de terre; par contre il faut chercher à obtenir toutes ses racines, qu'on en. veloppe dans de la mousse humide. Il n'est pas nécessaire, dans ce cas, d'arracher une grande quantité de pieds pour être sûr d'obtenir un résultat. Tous pourront réussir si l'opération se fait avec soin. Je n'ai, je pense, pas besoin d'insister sur le fait que plus la plante sera jeune mieux elle réussira. J'ai en ce moment de superbes pieds de Rhododendron hirsutum L. qui ont été pris à l'état de jeunes plantons dans les montagnes bernoises et élevés en pots, lesquels ont fleuri abondamment et semblent tout à fait à leur aise sous notre climat. Les jeunes pieds de Dryades qui croissent dans les sables des torrents on entre les cailloux des pierriers sont les plus propres à être acclimatés. C'est, en général dans les sols maigres et sablonneux qu'on trouve les pieds les plus jeunes et les mieux formés; c'est aussi dans ces conditions qu'on peut obtenir toutes leurs racines avec le plus de facilité. 


\section{$-114-$}

C'est là qu'il faut butiner de préférence car, outre l'avantage qu'on en retirera pour soimême, il en résulte un moins grand dommage pour la flore alpine, la vie des plantes dans ces terrains-là étant très éphémère. Les lits de sables et de gravier sont, en effet, exposés à être constamment transformés et emportés par les eaux, leur végétation étant trop pauvre pour les protéger. Les plantes, une fois arrachées et embal. lées dans de la mousse ou de l'herbe, seront placées dans la boîte à botanique ou dans des caisses bien fermées afin que l'air ne les dessèche pas. Arrivées à destination on les déballe soigneusement et on les plante à mesure qu'on les sort à l'air. Si on ne peut s'occuper immédiatement de leur plantation il sera nécessaire de les enterrer provisoirement dans un endroit frais et abrité du soleil. On coupe légèrement et avec un canif bien tranchant le bout des racines. Il faut mettre ces plantes dans des pots aussi petits que possible afin qu'il se produise de nouvelles racines par le contact des anciennes avec le bord réchauffé du pot. Comme terreau on se servira, pour les espèces ordinaires, du composé dont j'ai parlé plus haut, c'est-à-dire de terreau de feuilles, mélangé à de la terre de châtaigniers ou de saules, à de la terre de bruyère et additionné d'une plus 


\section{$-115-$}

ou moins forte quantité de sable suivant la sécheresse de l'air ou de l'endroit. Plus il faudra arroser et plus la proportion de sable devra être grande afin que la terre laisse passer l'eau rapidement. Il faut alors placer tous ses pots dans une couche bien fermée ou dans un endroit quelconque où ils puissent être "étouffés » suivant l'expression des jardiniers. Il faut arroser abondamment, de façon que l'air soit humide, ce qui empêche les plantes de se flétrir et les maintient en bon état; il va sans dire qu'on ombrage. Petit à petit on habitue ces plantes à l'air, au scleil et à la chaleur et comme c'est généralement en septembre que cette opération a lieu, l'automne arrive bientôt avec ses jours frais et nébuleux offrant à ces plantes une température plus en rapport avec leurs besoins. A l'entrée de l'hiver on enterre les pots dans de la poussière de coke ou du sable dans un coffre (couche) et aussi près du verre que possible. On arrose peu et on découvre ces plantes toutes les fois que l'air est vif et sec; il faut donner autant d'air que cela se peut dans la froide saison. On doit également éviter l'humidité qui, pendant l'hiver, tue les plantes alpines. Aux premiers beaux jours de février on arrose, et s'il survient des pluies on découvre ses couches afin 
de permettre aux plantes alpines de se mouiller complètement et de se mettre en végétation. Plus tard, lorsque la plante a commencé à se développer, on la met en pleine terre dans la rocaille ou ailleurs. Quant aux espèces délicates, on leur donne le même traitement, mais on doit varier la composition du terreau d'après leurs diverses exigences. Nous retrouverons cela dans le chapitre des cultures.

Quelques personnes croient bien faire en recouvrant leurs plantes, dans la couche, de feuilles sèches afin d'empêcher les changements brusques de température. C'est une faute car ces fenilles provoquent la pourriture des plan. tes et favorisent le développement de champignons nuisibles. Si l'on pouvait se procurer assez de neige pour en recouvrir ces plantes pendant l'hiver, il va sans dire qu'elles ne s'en trouveraient que mieux.

A défaut de couches, qui ne sont pas en la possession de tout le monde, on acclimate les plantes alpines dans un endroit frais et étouffé, peu exposé aux courants d'air et aussi humide que possible. Petit à petit on les habitue à une position plus chaude et plus exposée à l'air ; enfin on peut en octobre-novembre les exposer au levant ou au couchant dans une plate-bande sèche en enterrant 
les rots dans de la poussière de coke ou de sable. Là, on les recouvre complétement, par un temps sec et beau, de branches de sapin ou de tel autre conifère qui les garantira contre les brusques changements de température, si fréquents chez nous en hiver. On ne les découvre qu'en février-mars, alors que les pluies et les rayons plus chauds du soleil provoquent le mouvement de la sève et le développement de cette végétation.

Voilà pour la transplantation des pieds arrachés dans les montagnes et leur acclimatation dans nos jardins. Tant qu'il y aura des Alpes et des grimpeurs qui les visiteront, il y aura aussi des amateurs qui essayeront d'emporter et de faire réussir chez eux les charmantes espèces qui croissent là-haut. Il était bon de traiter ce sujet. Ciependant, et j'ai hâte de le dire, il est un moyen bien plus simple d'arriver à obtenir chez nous la flore des Alpes, un moyen infaillible et qui m’a toujours donné les plus brillants résultats. C'est celui qu'emploie la nature pour reproduire et multiplier en aussi grandes quantités les espèces qui recouvrent notre globe. Ce moyen, c'est le semis. On pense généralement qu'il est lent, difficile à poursuivre. C'est une profonde erreur: la chose est simple et chacun peut l'entreprendre, à la condition d'y mettre 
quelques soins. J'ai élevé, soit au Jardin botani. que de Genève, soit au Jardin alpin, par semis, plus de la moitié des plantes alpines. Pour cela, j'ai suivi les conseils que donne le $D^{r}$ Kerner dans sa « Cultur der Alpenpflanzen » en modifiant et ajoutant d'après ce que m'avait appris ma propre expérience. D'après l'habile cultivateur d'Innsbrück, la presque totalité des plantes alpines peuvent être élevées par semis. Cette opération doit se faire en automne, aussi tardivement que possible, de manière à ce que les graines ne germent pas avant le printemps, mais se stratifient seulement. Les pots ou terrines qui doivent contenir les graines doivent être remplis jusqu'au bord d'un terreau léger, fin, riche en humus et en sable dans lequel ou mélange du sphagnum tamisé (mousse blanche) et une faible proportion de poussière de coke. On sème sa graine et l'on recouvre celle-ci d'une légère couche de terre; puis les pots sont placés dans une couche sèche ou toute autre place bien aérée où ils puissent être abrités contre la pluie et les rayons du soleil qui ne doivent pas les atteindre. On n'arrose absolument pas, mais si l'on peut avoir de la neige on l'entasse sur les pots, puis on la fait geler en versant, avant les nuits claires et froides, de l'eau sur ce tas de neige qui durcit 
et devient bientôt une couche de glace. Par ce moyen, on retarde la germination de ces graines, laquelle se fait alors plus tard au printemps, lorsque les jours sont plus longs.

Cette opération, facile à faire dans un pays où les hivers sont neigeux, l'est moins pour notre patrie. J'ai essayé un autre système qui m'a fort bien réussi: c'est de placer des pots dans une couche sèche recouverte de planches. Les graines, par le fait de l'humidité contenue en hiver dans la couche la plus sèche, se stratifient et se préparent à germer sous l'influence du premier rayon de lumière et de la première goutte d'eau qu'elles recevront. Cependant, les graines qui ont été semées au printemps dans le Jardin alpin ont toutes, ou à peu près toutes, parfaitement réussi. Il faut dire que j'avais un terrain spécialement propice. C'était un composé de terre de châtaignier, de terreau de feuilles, Sphagnum et sable. Le Sphagnum, que les cultivateurs anglais font entrer dans le sol de toutes leurs cultures délicates, est beaucoup trop négligé de la part de nos jardiniers. Grâce à ses propriétés spongieuses, il conserve la terre dans un état hygroscopique régulier, ce qui est très important pour les semis. Lorsqu'il est sec, on le passe au travers d'un tamis avec beaucoup de 
facilité. On se procure le Sphagnum en s'adiressant aux personnes qui exploitent la tourbe des marais de montagnes; quelques marchands de de terre de bruyère, à Cruseilles, peuvent en procurer. Il y en a au marais de Lossy et il est fort abondant dans certains marécages du Jura.

Lorsque les graines ont germé et que les plantes commencent à montrer un peu de consistance, on les repique, c'est-à-dire qu'on les isole en les plantant une à une dans de petits pots ou godets. On suivra alors les indications qui se trouvent plus loin au sujet des cultures en pots.

Certaines espèces alpines ont beaucoup de peine à germer et à croître par semis. Mœ, célèbre cultivateur de plantes alpines à Christiania, a fait, à ce sujet, des observations et des expériences fort intéressantes. Voici, à propos de quelques espèces délicates, le procédé qu'il dit a voir suivi avec succès :

Pour les Bruyères, les Lycopodes et les Fougères alpines, il prend des morceaux de tourbe coupés en carrés de deux ou trois pouces de haut sur autant de large. Il frotte les graines ou les spores des espèces précitées contre les parois et à la surface supérieure de ces morceaux de tourbe qu'il place ensuite dans l'eau jusqu'à un 


\section{$-121-$}

pouce de profondeur. Toute la partie supérieure se maintient alors dans une humidité constante et toujours égale, qui permet à cette germination difficile et lente de s'opérer d'une manière régulière. Pendant l'hiver, on place ceux de ces morceaux de tourbe qui sont semés de Vacciniées ou d'Ericacées dans une couche fraîche et abritée contre le soleil, tandis que ceux d'entre eux qui out reçu les spores de Fougères et de Lycopodiacées sont placés dans une couche ou une serre chaude où ils doivent cependant être abrités des rayons solaires par une toile. Mœ a même tenté avec succès d'élever de graines certaines plantes que nous regardons comme absolument rebelles à toute opération horticole, les Pyrolacées et les Orchidées alpines, par exemple. Voici ce qu'il dit à ce sujet:

" On remplit les pots qui doivent contenir les graines, diune composition contenant une part de terre de bruyère, une autre de terre de forêts, une troisième enfin de débris de bois de pin ou sapin pourris, auxquels on ajoute un peu de mousse hachée et d'aiguilles de sapin sèches. Cette composition est alors fortement pressée dans les pots; on plante ensuite là-dedans de petites mousses telles que les différentes sorles de Dycranum, Bryum argenteum, Mnium, etc. 
C'est dans cette mousse que l'on sème les graines en question, puis on place les pots dans une caisse contenant de l'eau de manière que la terre soit continuellement et régulièrement mouillée. La caisse contenant ces pots est alors placée, pendant quinze jours, dans une couche chauffée et ombragée d'une manière égale et qu'on tient hermétiquement fermée pendant tout le temps. De cette manière, dit-il, j'ai toujours obtenu de bons succès. »

Kerner pense qu'on pourrait, par ce moyen, élever les Rhynantacées alpines et tant d'autres espèces rebelles à la culture et au semis ordinaire.

La liste serait beaucoup trop longue à donner ici des espèces que j'ai obtenues par semis et qui ont fleuri avec abondance. Le fait est qu'elles sont bien rares celles qui n'ont absolument pas pu s'acclimater par ce moyen. Je crois que, avec le système du botaniste suédois que je viens d'indiquer, on parviendrait facilement à acclimater toutes ces espèces rebelles. Ce moyen si simple et si naturel d'élever les plantes alpines par semis est le plus recommandable de tous; il permet d'obtenir des pieds forts, vigoureux, florifères et tout acclimatés à nos contrées. Il offre, en outre, ce grand avantage que, 


\section{$-123-$}

pour les espèces rares, il contribue à leur pro tection et à leur conservation dans leurs lieux d'origine. A tous ces points de vue, l'élevage des plantes alpines par semis est le meilleur mode à employer; il serait bon qu'on l'utilisât davantage.

C'est dans le courant du mois de septembre qu'il est le plus facile de récolter les graines dans les Alpes. A ce moment-là, on peut encore reconnaître l'espèce à laquelle appartient la graine. Comme c'est également l'époque où s'arrachent les plantes qu'on veut transporter dans la plaine, une course dans les Alpes à ce mo. ment-là présente un double avantage.

C'est à cette époque-là qu'il convient de s'occuper de la multiplication des plantes alpines par le moyen de la division des touffes; les jeunes éclats replantés ont alors le temps de s'enraciner et de se développer avant l'hiver. Une bonne partie d'entre les plantes de montagnes se multiplient de cette façon, mais toutes ne supportent pas l'opération. Les espèces tapissantes, formant des touffes comme de la mousse, sont particulièrement propres à être divisées. Les Saxifrages, les divers Sedum, les Aubrietia, les Silènes, les Eillets, l'Edelweiss et les autres Composées, quelques Campanules, les Phlox nains et 
rampants, un certain nombre de Primevères, l'Aretia Vitaliana, quelques Labiées, semblent plutôt, dans les cultures, exiger la chose que la redouter. Ces plantes donnent des touffes d'autant plus belles et florifères qu'on les a plus divisées. Beaucoup d'autres espèces, surtout dans celles qui appartiennent aux pâturages et aux perites herbeuses; sont dans ce cas. Il n'en est point de même des Androsaces, de la Silene acaulis, des Gentianes, des Renonculacées en général, des Soldanelles, du Papaver alpinum, des Légumineuses et de la généralité des espèces saxatiles. Elles forment, il est vrai, des touffes composées d'un grand nombre de tiges, souvent couchées et rampantes, mais ces tiges ne sont point de nature à former des racines. Le meilleur moyen de les reproduire est le moyen naturel, c'est-à.dire le semis. Certaines espèces, telles que Salix retusa, S. reticulata et autres, Rosa alpina, Rhammus pumila, Atragene alpina, les divers Daphne, Androsace lanuginosa, Silene Pumilio. et Elisabetha, Dianthus alpinus et glacialis et les Campanulacées, se multiplient par boutures en août-septembre. Il va sans dire qu'on les traite à froid et dans un châssis fermé. La multiplication des espèces bulbeuses de nos Alpes est la même que celle des jacinthes ou des tulipes de 
nos jardins. Enfin, quelques espèces telles que les Daphne, les Betula, les Rhododendron, se greffent sur les espèces communes.

La culture des plantes alpines n'est pas difficile pour quiconque a déjà acquis quelques notions sur les Alpes et sur leur nature. Nous avons, dans les précédents chapitres, étudié la flore alpine et ses conditions d'existence. Il ne sera pas difficile à celui qui a compris ce développement de saisir la culture de ces frêles végétaux. Celles d'entre les plantes alpines qui appartiennent aux régions inférieures se cultiveront généralement comme les plantes vivaces de nos plates-bandes, avec cette différence toutefois qu il leur faut un terrain particulier et un bon drainage. Voilà pourquoi, au lieu de cultiver ces espèces en pleine terre, on les place généralement dans c'es rochers artificiels où elles reçoivent chacune selon ses exigences, un sol ou une position particulière. Les espèces appartenant aux zones supérieures et aux régions nivales des montagnes exigent une culture plus délicate et demandent davantage de soins. On trouvera plus loin, avec la liste des plantes alpines propres à la culture, quelques renseignements sommaires concernant les espèces faciles à élever. Celles qui demandent un traitement spécial sont trai- 
tées à part. Il me suffira, par conséquent, de rappeler ici les travaux qui incombent, dans le courant de l'année, aux personnes qui s'en occupent.

Si vous aver peu de temps à consacrer à ces cultures alpines ou que vous ne vous y intéressiez que médiocrement, alors placez dans votre rncaille un choix d'espèces robustes appartenant à la région des pâturages ou à la zone subalpine. Vous leur donnerez un sol riche en humus c'est-à-dire un composé de terreau de feuilles et de sable; vous drainerez le fond de vos niches et vous arroserez régulièrement. De temps en temps vous visiterez votre rocaille afin d'en enlever la mauvaise herbe et vous transplanterez les touffes trop envahissantes tous les trois ou quatre ans. A part cela, vous n'aurez aucuns soins particuliers à donner à vos cultures Mais si vous ètes amateur de plantes alpines, et que vous teniez à elles comme à des êtres vivants et chéris, alors étudiez leur nature et traitez-les en conséquence. Vous placerez telle ou telle espèce à l'ombre, telle ou telle autre dans la fente d'un rocher; d'autres iront au soleil, tandis que certaines espèces seront placées dans des niches au sec et d'autres dans les endroits humides. Aux unes vous donnerez un terrain spécial tandis que d'autres 
se contenteront du terreau de feuilles mélangé à du sable. Dans un chapitre subséquent, au sujet des jardins alpins, nous verrons comment il faut distribuer les plantes alpines dans les jardins.

La question du terreau à employer pour les cultures alpines est l'une des plus importantes si l'on veut bien réussir. En étudiant la nature du sol dans les Alpes, nous avons vu qu'elle est de différentes sortes soit au point de vue chimique, soit sous le rapport physique. Il s'agit donc d'amender le sol et de le modifier suivant l'espèce qu'on veut cultiver. Telle plante qui croit naturellement dans un sol tourbeux et spongieux ne parviendra pas à développer ses racines dans une terre lourde et consistante. Telle autre qui aime le roc ne fera rien dans un terrain tourbeux ou trop riche d'humus. On peut cependant admettre comme règle générale que les plantes des Alpes s'accommodent d'un terrain léger, spongieux en mème temps que nourrissant et que toutes exigent le drainage. Le sol de la montagne est différent suivant qu'on le trouve dans les bois, dans les pâturages, entre les fentes des rochers ou bien dans les régions tout à fait élevées. Nous avons vu que dans ces dernières conditions, on ne trouve plus qu'un 
sol formé de gravier et de sable, additionné d'une faible quantité d'humus tandis que le sol que nous trouvons entre les fentes des rochers est un terrain noir, spongieux, composé d'humus pur uniquement formé de débris végétaux décomposés. C'est lui qui nourrit et entretient la végétation des pâturages élevés et celle qui recouvre les fentes des lappiaz et des rochers. Dans les pâturages inférieurs, le sol est très mélangé par suite des différents phénomènes qui contribuent à amener du haut de la montagne du sable, de la terre, des pierres et des débris de toute sorte. Enfin, le sol qu'on rencontre dans les bois est un humus additionné de matières minérales qu’amènent les eaux dans une plus ou moins forte proportion, suivant que l'endroit est plus ou moins exposé à les recevoir. Sur les bords des glaciers et sur leurs moraines, nous trouvons des plantes qui croissent dans un sol sablonneux et dont les racines sont extrêmement développées. Mais les plantes se retrouvent à peu près toutes dans d'autres conditions et semblent n'appartenir qu'accidentellement à ces régions.

Lorsque les plantes de ces hauts parages sont transportées dans nos plaines pour y poursuivre leur existence, il va sans dire qu'il faut, autant que possible, chercher à leur rendre le sol qui 
leur convient. Ce sol pourra être, dans la grande majorité des cas, un composé de détritus végétaux (terreau de feuilles), de terre franche et de sable dans des proportions différant selon la nature des espèces. Ce qu'il faut chercher à obtenir, c'est un terreau léger, poreux, perméable à l'eau, permettant le développement rapide des racines et juste assez nourrissant pour que la plante garde son habitus nain et gracieux. Les plantes alpines qu'on cultive dans un sol trop fertile, développent leurs organes outre mesure et perdent leur aspect naturel. C'est une erreur de croire qu'il leur faut de l'engrais ; celui-ci ne les tue point, mais il cause dans leur état végétatif une vraie perturbation et développe quelques-uns de leurs organes d'une façon qui n'est point naturelle. La seule nourriture qui leur convienne, est celle que leur offre l'humus, c'est-àdire les organes végétaux qui sont dans le sol à l'état décomposé. Plus l'espèce est herbacée et développée, plus la proportion de cet humus sera grande dans le terreau qu'on devra lui donner. Une Primula Auricula aura besoin d'une proportion d'humus plus forte qu'une autre plante du même genre, appartenant à l'espèce minima; un Senecio Doronicum qu'un S. incanus et ainsi de suite. Il faudra d'autant plus d'humus que la 
plante croît et se développe avec plus de rapidité. $\mathrm{Au}$ contraire, une espèce à tiges ténues, peu garnie de feuilles et croissant peu rapidement, demandera plus de sable ou de terre de bruyère et moins d'humus. Les arbustes à croissance lente et à bois dur tels que les Rhododendron, les Bruyères, les Salix, les Daphne, se cultivent dans un sol plus léger et très peu fertile. C'est la terre de bruyère qui leur convient le mieux. Les espèces dont les tissus sont gonflés de sève, dont les cellules sont plus lâches, telles que les Gentianées, les Grassètes, les Primulacées, les Fougères, exigent un terrain spongieux et humide. Pour l'obtenir, on ajoute au sol du Sphagnum ou de la tourbe très spongieuse, telle qu'on la trouve dans les marais de montagnes. Si l'on ne peut se procurer ces matières, il faut alors doubler la proportion de terreau de feuilles que l'on mélange avec un tiers de sable sans ajouter d'autre terrain; mais alors il faut drainer très fortement le fond des niches ou des pots, parce que l'humus a la propriété de retenir l'humidité longtemps, ce qui peut parfois porter préjudice à la plante.

Un cultivateur de plantes alpines devra toujours avoir à sa disposition du sable et du terreau de feuilles. Ce terreau s'obtient facilement chez 
les personnes qui ont à leur disposition une campagne et des arbres feuillés. En automne, on amoncelle de la feuille dans un endroit exposé à la pluie et à l'air et on retourne son tas deux ou fois par an. Au bout de 18 mois, on possède un terreau propre à la culture; les feuilles de marronniers m'ont semblé préférables à toutes les autres pour les cultures alpines. Quant au sable, il sera bon d'en avoir du calcaire et du granitique. Le premier se rencontre au bord de toutes les rivières ou des ruisseaux descendant des autres montagnes calcaires, le second est abondant au bord de l'Arve et de tous les cours d'eaux qui descendent des montagnes cristallines. Il sera bon aussi d'avoir chez soi une provision de ce terreau noir dont j'ai déjà parlé et qui se trouve entre les fentes des rochers, dans les montagnes. C'est le sol le plus favorable aux cultures alpines; il demande à être mélangé à un tiers de sable et, suivant les espèces, additionné de terre de bruyère.

Le sol dans lequel on plante les espèces alpines doit être aussi frais que possible; unedes conditions importantes de la réussite de ces plantes est que ce sol ne se dessèche pas trop rapidement commec'est le cas pour les terrains légers et sablonneux. Il faut chercher à obtenir un équi- 


\section{$-132-$}

libre constant entre l'évaporation du sol et la transpiration de la plante d'un côté, et le degré d'hygrométrité du terrain de l'autre. Si la plante est de faibles dimensions ou que ses organes foliacés soient peu propres à une respiration active, comme c'est le cas chez les Saxifrages à feuilles épaisses, il faudra peu arroser et donner un sol léger. $\mathrm{Si}$, au contraire, on a une plante à tissus lâches et mous, une Soldanelle, une Pen. sée ou une fougère, elle exigera un arrosement plus copieux et un terrain plus consistant. S'il arrivait, en outre, qu'un jour le sol de ces cultures alpines soit absolument sec, puis qu'ensuite il reçût une forte dose d'humidité, après laquelle il serait de nouveau exposé à la sécheresse, la plante ne manquerait pas d'en souffrir. Nous avons vu que dans les Alpes, l'humidité du sol est constamment abondante pendant l'époque de leur floraison; puis vient un moment de sécheresse relative, pendant lequel la plante mûrit ses graines. Mais il ne se produit pas de changements bien sensibles dans l'état d'humidité du sol. Dans nos plaines, au contraire, la végétation est exposée à des changements hygrométriques très fréquents et subits. Il sera donc nécessaire d'obtenir comme sol, une composition poreuse qui agisse sur la plante, à la 
manière d'une éponge absorbant l'eau quand il y en a trop et la rendant à la plante au fur et à mesure qu'elle en a besoin. Le coke brisé et tamisé est une des meilleures matières à employer dans ce but. Les pierres, surtout celles de composition calcaire, sont propres à rendre les mêmes services et il sera nécessaire d'en placer une certaine quantité dans le sol même où l'on cultive les espèces délicates. Un sol fortement additionné de cailloux, calcaires ou granitiques selon l'espèce qu'on cultive, sera particulièrement propice aux espèces qui recherchent la fraîcheur. J'ai remarqué que les espèces les plus difficiles à conserver sont celles qui, dans les Alpes, croissent dans un sol pierreux et au milieu des cailloux. Les Hutschinsia alpina, Papaver alpinum, Thlaspi rotundifolium, Linaria alpina etc., sont des plantes qu'on réussit bien de semis mais qu'il est presque impossible de transplanter chez nous. Cela tient certainement au fait que ces espèces, dont le feuillage et les fleurs sont exposés au soleil le plus ardent, plongent leurs racines entre les pierres et sont maintenues par ce fait dans une absolue et constante fraîcheur. Il est bon de recouvrir le sol où l'on cultive les Soldanelles et d'autres plantes aimant l'humidité, de quelques cailloux qui maintiennent la frâ̂- 
cheur et empèchent que les rayons solaires ne brûlent les racines supérieures des plantes.

Comme je l'ai dit, il est nécessaire de drainer les niches ou les pots dans lesquels on cultive les plantes alpines. Ceci est un point très important, trop souvent omis dans les cultures. Il faut pouvoir arroser abondamment au moment de la floraison afin de rendre à la plante cette atmosphère d'humidité qu'elle trouve dans son état naturel et qui se produit par l'évaporation de l'eau contenue dans le sol. Or, si le sol n'est pas très perméable à l'eau, l'excès d'humidité devient préjudiciable à la plante et provoque en outre la formation d'algues et de mousses nuisibles. Il faut que l'eau qui ne s'évapore pas sous l'influence des rayons solaires ou qui n'est pas absorbée par les organes de la plante puisse s'écouler le plus rapidement et le plus facilement possible, car s'il est bon que les racines de la plante soient entretenues dans un état de fraîcheur continuelle, il est, par contre, dangereux qu'elles plongent dans l'humidité stagnante. C'est pour cela qu'il faut drainer le sol en plaçant au-dessous de lui une forte couche de cailloux ou de coke. Au moment où la plante commence à se développer, c'est-à-dire au mois de mars, on arrose fréquemment le sol. 


\section{$-135-$}

A mesure que la végétation saccroît, on arrose davantage, en cherchant toujours à maintenir l'équilibre entre l'évaporation et l'absorption. Après la période de floraison de la plante, on arrosera moins et quand viendra l'automne, l'atmosphère devenant plus humide, les jours plus courts, la chaleur moins forte, l'arrosement sera encore plus léger. Enfin, pendant l'hiver on n'arrosera plus, cela va sans dire.

En automne, après la récolte des graines, il sera bon de revoir chaque touffe afin de la nettoyer de ses tiges sèches et de la débarrasser des mauvaises herbes qui peuvent s'y être introduites. C'est à ce moment-là qu'on divise les touffes et qu'on les transplante si elles sont devenues grandes et gênantes. On nettoie alors soigneusement la rocaille ou la plate-bande contenant les plantes alpines et le moment viendra bientôt où le tout pourra revêtir son manteau hivernal. A cet effet, on choisit une journée sèche de novembre et on recouvre les plantes d'une couche de branches de sapin (si possible de sapin blanc) qu'on fixe le mieux possible sur le sol au moyen de pierres ou de crochets de bois afin que le vent ne les emporte pas. Le but de cette protection n'est point de tenir la plante au chaud comme on le croit parfois, mais de 
maintenir le sol dans une température plus égale et d'empêcher les alternatives de gel et de dégel qui causent un grand préjudice à la végétation alpine sous notre climat. On a vu, en effet, combien il faut peu de chose pour appeler à la vie ces végétaux frêles et délicats qui, pour vivre et se développer chez eux, se contentent d'un degré si faible de chaleur. Lorsque le terrain est dégelé et que le soleil darde sur la plante, le moindre degré de chaleur peut accélérer sa végétation, puis, sous l'influence des gels qui surviendront infailliblement, elle verra ses jeunes pousses endommagées et sa floraison compromise. C'est pourquoi il est nécessaire de remplacer la couche de neige de la montagne par une couverture qui tempère l'influence du froid comme celle du chaud. Nous avons déjà vu qu'il n'est pas bon de recouvrir ses plantes de feuilles sèches, comme le font quelques personnes parce qu'elles provoquent la pourriture chez la plante et communiquent des champignons à la végétation qu'elles recouvrent.

La couverture de branches de sapin s'enlève au commencement ou dans le ccurant du mois de mars, suivant l'état de la température. Il faut autant que possible les enlever par un temps pluvieux afin que, s'il s'est produit pen- 


\section{$-137-$}

dant l'hiver et malgré la couverture, quelque développement de végétation, les jeunes pousses ne soient pas détruites par le soleil et puissent se fortifier et s'habituer à la lumière avant de recevoir ses rayons. Plus on retardera le moment où l'on découvrira la rocaille, plus la floraison sera riche, car nous avons vu combien il est important que ce moment arrive lors des grands jours, le printemps alpin correspondant aux plus longs de l'année. A Innsbrück, le Dr Kerner avait imaginé de recouvrir ses rochers d'une épaisse couche de neige qu'il faisait changer en un bloc de glace en l'arrosant le soir avant les nuits froides. Il arrivait à avoir par ce moyen ses plantes recouvertes d'un vrai glacier qui disparaissait avec d'autant plus de lenteur que la couche était plus épaisse.Le moyen est excellent pour reculer l'époque de réveil chez ces plantes; il est malheureusement peu praticable chez nous où, depuis plusieurs années, nous n'avons pas de neige en hiver. Il est important, au sortir de l'hiver et lorsqu'on vient de découvrir la rocaille, de visiter chaque niche et chaque plante afin de raffermir celles que le gel ou toute autre cause aurait disloquées ou déracinées; on fait aussi la revue dés espèces qu'il faut remplacer et on s'occupe de vérifier toutes les étiquettes et 


\section{$-138-$}

de remplacer celles chez lesquelles l'humidité et le froid auraient détruit les caractères. Lorsque vient le moment de la floraison, on révise encore soigneusement l'étiquetage qui, dans la patrie des de Candolle et des Boissier, ne saurait être trop exact.

En pleine terre, les plantes alpines réussissent admirablement dans un sol composé d'un tiers de terre ordinaire, un tiers de terreau de feuilles et un autre tiers de sable. On peut, si l'on veut, s'organiser une plate-bande qu'on bordera solidement $\left({ }^{1}\right)$ et dans laquelle vous mélangez votre terre; puis vous établissez vos cultures en plantant les espèces naines au bord et les plus développées au centre. Il est bon d'introduire des pierres dans le sol et d'en placer également quelques-unes à la surface afin d'entretenir la fraîcheur autour des racines. En hiver, on recouvre également de branches de sapin blanc.

On le voit, la culture des plantes alpines dans les rocailles ou en plates-bandes n'exige pas de bien grands sacrifices. Elles demandent un peu

( ${ }^{1}$ ) La meilleure bordure à mon avis est le produit valaisan qui a été essayé au Jardin Botanique et qu'on se procure à Sembrancher chez M. Arlettaz. Ce sont des débris de dalles schisteuses parfaites comme solidité et très bon marché. 
plus de soins que les plantes vivaces de nos jardins et des frais d'installation plus considérables; mais combien est plus grande et plus complète la jouissance dont elles récompensent ceux qui s'y sont adonnés! Que de moyens n'offrent-elles pas d'étudier la nature et de contempler les œuvres de Dieu jusque dans leurs moindres détails.

La culture en pots, sans être plus difficile, exige cependant une surveillance plus active et des soins plus minutieux. Il faut veiller à ce que l'arrosement se fasse régulièrement et à ce que la plante soit constamment entretenue dans une atmosphère de fraîcheur el d'humidité. Il faut, autant que possible pour ces cultures, employer des pots profonds, au fond desquels on place une couche de drainage. Il faut les rempoter toutes les années, en automne, et leur donner un sol moins sablonneux que dans la pleine terre. Il est bon d'enterrer, pendant l'été, les pots dans du sable; en hiver, on tient les plantes au sec et on enterre les pots dans de la poussière de coke ou dans toute autre matière sèche. On les hiverne en couches, sous châssis froid, la plante aussi près du verre que possible. Si ces plantes se cultivent sur des fenêtres, il sera bon d'éviter les positions absolues du nord 
ou du midi; elles préfèrent le levant ou le couchant.

\section{PLANTES DES ALPES PROPRES A ÊTRE GULTIVÉES}

Ouvrages à consulter. - Liste des plantes alpines qui se cultivent. - Détails sur la manière de cultiver chacune de ces espèces.

Sur les 900 espèces de plantes qu'on rencontre d'un bout de la chaîne alpine à l'autre, il en est au moins 7 à $\$ 00$ qui méritent la culture. Quelques unes, telles que les Auricules, les Armeria, certaines Saxifrages sont entrées depuis longtemps dans les jardins, où elles figurent. comme plantes vivaces. Un certain nombre d'entre les plantes alpines sont d'une culture aisée et pourraient être cultivées dans la pleine terre comme les espèces vivaces de nos plaines, à la condition qu'on leur donne un sol convenable. C'est surtout le cas chez les plantes appartenant à la région des pâturages ou croissant sur les pentes herbeuses de la montagne. Cette catégorie de plantes que j'appellerai plantes des pâturages est la plus nombreuse. Les espèces saxatiles sont plus difficiles à acclimater et moins communes; il leur faut un traitement particulier. 
Enfin une troisième catégorie de plantes est celle qui comprend les espèces des hautes régions qui croissent dans un sol continuellement humide et glacé et exigent des soins spéciaux. On trouvera dans la liste que je donne plus loin, des espèces alpines propres à être cultivées, des renseignements sommaires sur la manière dont elles doivent être traitées. Les espèces absolument calcaires ou celles qui sont purement granitiques sont marquées par calc. et granit

Ne pouvant entrer dans des détails descriptifs, vu le cadre restreint de cet ouvrage, je renvoie les lecteurs qui ne connaîtraient pas encare les plantes citées, à l'importante publication du Club alpin autrichien, l' "Atlas der Alpenflora " qui contient la plupart des plantes alpines. Cet Atlas reproduit avec une grande fidélité les 500 espèces qu'il contient et celui qui le consulte peut être certain qu'il est là en face d'une œuvre sérieuse et bien réussie. Une autre publication de ce genre, également autrichienne, se trouve chez bon nombre de nos alpinistes ; c'est l'album de M J. Seboth édité par M. Tempsky à Prague et dont les planches sont également fort bien exécutées.

Ceux qui possèdent ces publications ou qui ont la facilité de les consulter, comprendront qu'il m'ait paru inopportun d'entrer dans des 
détails descriptifs, toujours si longs, si fatigants pour le lecteur et si peu propres à douner une véritable idée des formes et du coloris de ces plantes. Quant aux personnes qui ne les possèdent pas ou qui n'ont pas l'occasion de les consulter, je les engage à visiter souvent les Alpes ou à fréquenter notre Jardin alpin afin d'apprendre à les connaître au naturel.

Voici maintenant une liste, à peu près complète, des plantes alpines propres à subir l'acclimatation; nous suivrons l'ordre botanique:

\section{Renongulacées :}

Atragene alpina L. (calc.)

Cette superbe Clématite bleue des Alpes, réussit dans un sol caillouteux, mélangé de terreau de feuilles et de terre de bruyère. Elle aime un peu d'ombre.

Thalictrum alpinum L. (granit.)

aquilegitolium L
fretidum L.

Les Pigamons alpins recherchent la fraîcheur et un sol nourrissant.

Anemone narcissiflora $\mathrm{L}$.

" trifolia L. (Alpes orientales).

$\rightarrow \quad$ vernalis L. (granit.)

D. alpina L. (calc.) 
Anemone Burseriana Scop. (Tyrol).

" sul/urea L. (granit.)

" Halleri All. (Hautes-Alpes).

"baldensis L. (calc.)

Les Anémones ont, en général, une floraison très précoce. Elles réussissent fort bien dans les cultures. Les A. Halleri et baldensis sont plus difficiles et exigent un sol très poreux et tourbeux. Toutes, sauf l'A trifolia, aiment le soleil. Il leur faut un sol profond et riche en humus. Les A. montana $\mathrm{L}$. et $A$. pulsatilla $\mathrm{L}$. qui appartiennent toutes deux aux régions sèches des vallées et des plaines, peuvent être cultivées comme plantes alpines.

Les Anémones s'élèvent facilement de semis lorsqu'on a soin de semer les graines aussitôt après la récolte. Il y a, en ce moment, au Jardin alpin, toute une collection de ces Anémones provenant de semis. Au Jardin Botanique, l'A. sulfurea m'a fort bien réussi par ce moyen.

Ranunculus Thora L. (cale.)

"montanus Willd.

" lacerus Bell. (Alpes Dauphiné).

- hybridus Bir. (Tyrol).

") pygmaeus Wahlb. (granit).

- rutaefolius L. (Hautes-Alpes).

». anemonoides Zahlb. (Tyrol). 


\section{$-144-$}

Ramunculus pyrenaeus L.

$\bowtie \quad$ alpestris L.

" Traunfellneri Hopp. (Tyrol oriental).

") crenatus Waldst. et Kit. (Alp. Mérid.).

") bilobus Bert. (Alp. calc.: Tyr. Mérid.)

i) amplexicaulis L. (Alpes Méridionales).

- graminaeus L.

- aconititolius L.

- platanifolius L.

D. pamassifolius L. (granit.)

- Seguieri Vill. (Tyrol mérid.; calc.)

* glacialis L. (granit.)

Les Renoncules appartenant à cette série de plantes sont toutes de culture facile et demandent le soleil. On les élève par semis aussi facilement que les Anémones. Les $R$. aconitifolius et platanifolius appartiennent à la région montagneuse et réussissent dans la terre ordinaire de nos jardins. Elles aiment cependant la fraìcheur et un sol rocailleux. Les trois dernières espèces, qui appartiennent aux détritus rocheux des régions élevées, demandent un sol fortement drainé, mélangé de sable et de petits cailloux calcaires ou granitiques suivant l'espèce et un arrosement abondant avant la floraison.

Trollius europaeus L.

Il aime un sol nourrissant et frais. On le ren- 


\section{$-145-$}

contre quelquefois dans nos plaines; c'est ainsi qu'il croît avec abondance dans les prés qui bordent la route de Gimel, à trois quarts d'heure au-dessus de la ville de Rolle.

Helleborus niger L. (Alpes méridion.)

La Rose de Noël se plaît dans les rocailles exposées au soleil; elle aime un sol profond et nourrissant.

Aquilegia atrata Koch.

" thalictrifolia Schott et Kotschy.

„Einseleana F. Sch.

Sol frais, nourrissant.

Aquilegia alpina L.

Elle exige un terrain frais, léger et tourbeux et demande l'ombre et l'humidité. Cette plante si gracieuse est sujette à dégénérer facilement dans nos cultures; c'est pourquoi il faut, autant que possible, lui rendre ses conditions d'existence. Je ne l'ai jamais obtenue par la culture aussi belle qu'elle l'est dans la nature.

Delphinium elatum L.

ఎ Tiroliense Kern.

Aconitum Napellus L.

» anthora $\mathrm{L}$.

- Lycoctonum L.

" paniculatum Lam.

Plantes élevées et rameuses appartenant à la 
région des bois; elles peuvent être cultivées dans la pleine terre ordinaire, ou bien être utilisées pour garnir les grandes rocailles et les coins sauvages. En général elles aiment un sol riche et frais.

\section{Papavéracées :}

\section{Papaver alpinum L.}

DPyrenaicum L.

Le Pavot des Alpes et celui des Pyrénées, qui croissent tous deux dans les endroits pierreux de nos Alpes, réussissent fort bien dans nos cultures. Il faut avoir soin de leur donner un sol pierreux et les arroser souvent. La fraîcheur de l'air leur est particulièrement favorable. Ils se ressèment d'eux-mèmes sur les rocailles.

\section{CructFères :}

Arabis alpina L.

- alpestris Schl.

- saxatilis All. (Tyrol).

- ciliata R Br.

"Vochinensis Spreng. (Tyrol).

- serpyllifolia Will.

- bellidifolia L.

"Halleri L.

- arenosa Scop. (calc.) 


\section{$-147-$}

Arabis ovirensis Wulf. (Carinthie).

- cærulea All.

- pumila Jacq.

Les Arabettes alpines sont de gracieuses petites fleurs tantôt blanches, tantôt bleues, qui font le plus gracieux effet dans les rochers. Elles aiment la fraîcheur et un sol pierreux. Toutes se reproduisent facilement par le semis. L'espèce jurassique. A. arenosa, célèbre par sa rareté et par la chasse que lui font les membres des a Tauschvereine ", possède une jolie fleur rose et demande le calcaire.

Cardamine alpina L. (granit.)

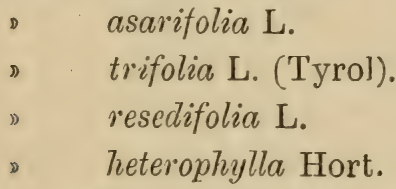

Ces plantes aiment l'ombre et l'humidité; elles réussissent également bien par le moyen du semis.

Dentaria diyitata Lam.

- pinnata Lam.

" bulbifera L. (Alpes orient.)

- polyphylla Waldst. et Kit.

D intermedia Sond. (Tyrol mérid.)

enneaphyllos L.

Les Dentaires aiment l'ombre et un sol riche 
quoique rocailleux. Elles recherchent de préférence les taillis qui sont à la base des montagnes calcaires et deviennent fort belles dans les cultures.

Hugueninia tanacetifolia Reich.

Plante rare de la vallée de Bagnes; même culture que les précédentes.

Braya alpina Sternb.

- dentata All.

Culture des Arabettes.

Erysimum pumilum Gaud.

๖. ocholeucum D G.

Alyssim alpestre $\mathrm{L}$.

"Wulfenianum Bernh.

Sol léger; exposition sèche - soleil.

Petrocallis pyrenaica $\mathrm{R}$. Br.

Draba aizoides $\mathrm{L}$.

n Sauteri Hoppe.

- tomentosa Wańl.

- stellata Jacq.

" nivea Saut.

- Lapponica D C.

" ciliata Scop.

- Fladnitzensis Wulf.

D laevigata Hoppe.

"Thomasii Koch.

») incana L.

.) Davosiana Brüg. 
Ces différentes espèces aiment toutes un sol rocailleux, une exposition au levant ou au couchant et une position fraiche. Elles se multiplient facilement par le moyen du semis.

Cochlearia saxatilis $\mathrm{L}$.

" alpina Tausch.

Thlaspi alpestre L. (granit.)

- Mureti Gremlj.

" alpinum Grntz.

"Silvium Gaud.

n rotundifolium Gaud.

Biscutella laevigata L.

Sol frais, riche en humas; soleil. Le T. rotundifolium croit naturellement dans les décombres ardoisifères et schisteux des Alpes. Il faut donc lui donner un sol pierreux, si possible ardoisifère ou granitique et une exposition fraîche.

Aethionema saxatile $\mathrm{R}$. Br.

Petite plante des rocailles sèches et calcaires.

\section{Cistinées :}

Hutschinsia alpina $\mathrm{R}$. Br. (calc.)

"brevicaulis $\mathrm{R} . \mathrm{Br}$. (granit.)

Aiment la fraîcheur et un sol pierreux.

Helianthemum Oelandicum DG.

)

)) serpyllifotium Mill. (Alp autr.) grandiflorum DG. 


\section{$-150-$ \\ Helianthemum Canum Dun.}

Les Hélianthèmes aiment le calcaire et l'exposition au midi.

\section{VIOLARIÉES :}

Viola pinnata L.

D palustris L.

, elatior Fries.

- sciaphila Koch.

"Thomasiana Perr. et Song.

- biflora L.

) alpina L. (Nlp. orient.)

- calcarata L.

lutea Huds.

Dheterophylla Bert. (Alp. calc.; Tyrol).

Le genre Viola se divise au point de vue du public amateur en pensées et en violettes. Tandis que les six premières espèces sont considérées comme des violettes, les quatre dernières, sans doute à cause de la grandeur relative de leurs corolles, sont généralement appelées pensées. Toutes sont gracieuses et intéressantes; elles aiment un sol frais, riche en humus et une position légèrement ombragée.

Viola cenisia L.

Cette espèce, particulièrement belle, est très stolonifère et ne peut vivre que dans un sol formé 
de détritus pierreux et granitiques. Elle veut le soleil. Je n'ai pas encore réussi à la faire fleurir.

\section{Polygalées :}

\section{Polygala chamaebuxus L.}

Cette plante est assez capricieuse. Elle réussit parfois fort bien dans un sol ordinaire, pourvu qu'elle soit à l'ombre, tandis que d'autres fois on ne peut la faire croître malgré toutes les précautions. Fin général, elle veut un sol tourbeux, humide et le soleil. Je l'ai réussie par semis et la cultive dans un sol léger mélangé de Sphagnum.

\section{Garyophyllées :}

\section{Gypsophila repens L.}

Cette plante appartient aux massifs calcaires, mais elle se propage si facilement qu'on la rencontre partout, même dans les contrées granitiques. C'est l'une des meilleures plantes à cultiver dans les rochers; elle fleurit de mai à novembre et s'accommode de tous les sols et de toutes les expositions. On s'en sert aussi comme de plante tombante à cause de ses longues tiges qui retombent chargées de fleurs et qui produisent un grand effet.

\section{Tunica Saxifraga L.}

Culture de l'espèce précédente; propre à faire des bordures. 


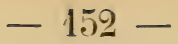

Dianthus atrorubens All.

" neglectus Lois (Mt. Cenis).

- alpinus L. (Alp. or. et calcaires.)

" glacialis Haenke (Alp. or.; granit.)

"sulacaulis Lois (Alp. Dauphiné)

" caesius $\mathrm{L}$.

demandent un terrain léger, rocailleux, composé d'un tiers de terre de bruyère, un tiers d'humus (terreau de feuilles) et un tiers de sable ou de débris pierreux. Il est nécessaire de drainer fortement et de les placer en plein soleil.

Dianthus sylvestris Jacq.

" Balbisii Ser. (Alp. marit.)

" monspessulanus L.

"superbus L.

" carthusianorum L.

"deltoides $\mathrm{L}$.

réussissent dans tous les terrains légers, au soleil.

Saponaria ocymoides L.

") lutea L. (Mt. Rose).

Position sèche et exposée au soleil.

Silene alpestris Jacq. (Tyrol ; calc.)

" quadrifida L.

" rupestris L.

- saxifraga L.

Ces Silènes alpines aiment l'exposition au so- 
leil et un sol riche en humus. La S. quadrifidx préfère cependant la fraîcheur.

\section{Silene Pumilio Wulf. (Tyrol)}

" Elisabethæe Jan. (Tyrol mérid.; calc.)

ఎ) acaulis $\mathrm{L}$.

1) exsapa All.

Ces quatre espèces de Silènes aiment un sol rocailleux. Elles appartiennent à la catégorie des espèces saxatiles; les $S$. Pumilio et $S$. Elisabethce croissent dans les fentes des rochers d'où l'on a beaucoup de peine à les extraire. Pour les bien réussir, il faut avoir soin de les planter en biais et même dans une position parfaitement perpendiculaire afin que l'eau ne puisse s'introduire dans les touffes et les pourrir.

Lychnis alpina L. (granit.)

•Flos Jovis L.

Tandis que la première de ces plantes demande un sol léger, peu profond et fortement drainé, la seconde, qui est très vorace, veut un sol profond et nourrissant.

\section{AlsinéES :}

Sagina bryoides Reichb.

- glabra Koch.

D macrocarpa Naly.

Alsine rupestris Scop. 


\section{$-154-$}

Alsine Gerardi Wahlb. (calc.)

" decandra Reichb.

" mucronata L.

" biflora Wahlb.

" laricifolia L.

- liniflora L.

" Austriaca Jacq.

"Villarsii Balb.

Cherlsria sedoides L.

Les différentes espèces de ces trois genres se cultivent toutes comme les Silènes. Elles aiment cependant un sol plus rocailleux et se contentent d'un terrain moins riche en humus et plus sablonneux. Quelques unes prennent beaucoup d'extension dans les rocailles.

Moehringia muscosa $\mathrm{L}$.

" glaucovirens Bertol. (Tyrol)

aiment la fraîcheur et les sols pierreux.

Arenaria alpina Gaud.

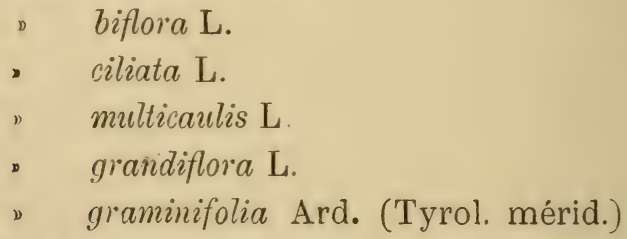

Exposition sèche, au soleil ; sol léger, peu profond, bien drainé. 


\section{$-155-$}

Cerastium lanatum Lam.

- grandiflorum Waldst. et Kit.

D) latifolium L.

" uniflorum Murr.

- alpinum L.

) carinthiacum Vest.

Mêmes conditions

\section{LiNÉES :}

Linum alpinum Jacq.

Soleil; pas difficile quant au terrain.

\section{Hypericinées :}

Hypericum Richeri Vill.

»Coris $\mathrm{L}$.

¿ nummularium L. (Alp. marit.)

dem.

Geranium argenteum L. (Sud. Tyr.; calc.)

Demande le calcaire, le soleil et un sol pierreux.

Geranium macrorrhizum L. (Tyrol)

„ $\quad$ ilvaticum $\mathrm{L}$.
„.
aconitifolium L'Hér.
sanguineum L.

Ces quatre espèces se contentent de tous les terrains un peu légers et aiment à avoir un peu d'ombre. 
Rhamnus pumila L. (calc.)

» alpina $\mathrm{L}$.

^ Carniolica Kern. (Alp. orient.)

Ces arbustes alpins prennent en général trop d'extension pour pouvoir être placés dans les petites rocailles. On les réserve pour les grandes. où ils font un très bon effet.

\section{Papilionacées :}

Genista pilosa L.

\Tumifusa L. (Alpes du Dauphiné.)

Cytisus radiatus L. (Tyrol méridional.)

, alpinus $\mathrm{L}$.

Ononis fruticosa L. (Dauphiné.)

D Natrix L.

"rotundifolia $\mathrm{L}$.

Ces arbustes des régions alpines inférieures conviennent pour les grands rochers et pour la pleine terre. Sol profond et fertile.

Anthyllis montana L.

Cette charmante plante de notre Salève demande un sol pierreux, léger et une exposition au soleil.

Trifolium badium Schrb.

- saxatile All.

) spadiceum $\mathrm{L}$.

Exposition sèche et terrain fertile. 


\section{$-157-$}

Phaca alpina $\mathrm{L}$.

"frigida L.

"australis $\mathrm{L}$.

Demandent un sol frais et une position un peu ombragée.

Oxytropis Halleri Bunge.
" velutinus Sieb.
" $\quad$ fatida DG.
campestris DG.
" Lapponica Gaud.
" Jacquini Bunge.
" montana Bunge.
neglecta Gay.

Astragalus aristatus L'Her.

- $\quad$ alpinus L.
$\Rightarrow \quad$ depressus L.
" Leontinus Wulf.
" $\quad$ morpureus Lam.
monssulanus L.

Hypociepis comosa DG. (calc.)

ROSACÉES :

Dryas octopetala DG.

Cette plante, qui pourrait passer pour une espèce saxatile, réussit très bien comme plante terrestre dans nos rochers et y fleurit abondam- 
ment. Il lui faut une terre tourbeuse, riche en humus et l'exposition au soleil. Si l'on ne possède pas de terrain noir et tourbeux, on lui donnera un terreau de feuilles pur mélangé de sable calcaire. Comme elle prend beaucoup d'extension, il faut lui donner une large place, de manière qu'elle puisse se développer. Je n’ai jamais pu récolter de graines fertiles sur les pieds cultivés dans la plaine.

\section{Geum reptans L.}

Plante des rochers granitiques Elle réussit dans une niche pierreuse, bien drainée et, au soleil.

\section{Geum montanum L.}

» inclinatum Schleich.

Soleil; terre riche et nourrissante, quoique légère.

\section{Rubus saxatilis $\mathrm{L}$.}

Cette ronce alpine doit être placée à l'ombre, dans une terre pierreuse et dans un endroit où elle puisse s'étendre et se lévelopper.

Comarum palustre L.

Quoique appartenant aux marécages, cette plante réussit dans les rocailles et y fleurit abondamment si l'on a soin d'ajouter au sol une proportion plus ou moins forte de Sphagrum. 
Potentilla nitida L. (calc.)

" nivea L. (granit.)

- trigida Vil. (granit.)

Ces trois espèces de potentilles appartiennent aux régions supérieures et glacées. Elles se laissent cependant aisément cultiver. Il leur faut un sol léger, peu profond, abondamment drainé et sablonneux.

Potentilla Clusiana Jacq. (Alpes autrich.)

$\rightarrow \quad$ caulescens L. (calc.)

" cinerea Chaix (Alp. du Dauph.)

" petiolulata Gaud.

, alba L.

- multifida L.

- erecta L.

- Teptaphylla Mill.

"aurea L. (calc.)

" alpestris Hall. fil.

- Sabauda DG.

" grandiflora. L.

" minima Hall. fil. (calc.)

- Engadinensis Brügg.

* splendens Ram.

Sibbaldia procumbens L.

Aremonia agrimonoides 1.

Les diverses potentilles qui garnissent les pentes herbeuses et les pâturages des montagnes 
sont toutes d'une culture facile. Elles aiment le soleil, un sol fertile, léger et profond. Un bon drainage est nécessaire. Toutes les potentilles se reproduisent par le moyen du semis.

\section{Rosa alpina $\mathrm{L}$.}

L'églantine des Alpes demande l'ombre et la fraîcheur. Elle réussit fort bien dans les cultures. et je n'ai pas observé qu'elle prît des épines.

\section{Alchemilla montana Willd.}

" procumbens M. Bieb. (granit.)
" $\quad$ sissa Schum (granit.)
sutsericea Reut. (granit.)
"alpina L. (calc.)
Hoppeana Rchb. (calc.)
pentaphylla L.

Sol fertile; soleil.

Cotoneaster vulgaris Lindl.

๖ tomentosa Lindl.

Ces deux arbustes appartiennent à la partie montagneuse et rocailleuse des montagnes calcaires. Ils prennent un grand développement dans les cultures et ne devront être placés que dans les grandes rocailles.

\section{ONAGRARIÉES :}

Epilobium spicatum Lam.

- rosmarinifolium Hänke. 


\section{$-161-$}

Epitobium Fleischeri Hochst.

^alpestre Jacq.

" alsinaefolium Vill. (Tyrol)

) alpinum Koch.

Circaea alpina L.

Toutes les plantes de cette famille, sauf les deux premières espèces indiquées qui aiment un sol pierreux et une exposition au soleil, demandent la fraîcheur, l'ombre et l'humidité. Elles sont toutes plus ou moins envahissantes.

\section{Crassulacées :}

Rhodiola rosea L. (granil.)

Sedum Anacampseros L.

„villosum L.

, atratum $\mathrm{L}$.

" annuum $\mathrm{L}$

" dasyphyllum L.

" hirsutum All.

- ochroleucim Chaix.

Sempervivum Wulfeni Hoppe (granit).

$\begin{array}{ll}\text { " } & \text { actorum L. } \\ \text { „Mettenianum } & \text { Schn.\&Lehm. „ } \\ \text { dolomiticum Facch. (Tyrol) } \\ \text { fimbriatum Schn.\&Lehm. " } \\ \text { angustifolium Kern (Tyrol) }\end{array}$


Sempervivum heterotrichum Schott (Tyrol)

arachnoideum $\mathrm{L}$.

Dællianum Lehm.

Funkii Braun.

montanum L.

debile Schott (granit; Tyrol)

rupicolum Kern. (Tyrol)

Gaudini Christ.

Pittonii Schott \& Kots. (Tyrol)

Braunii Funk (Tyrol; granit.)

WidderiSchn. \& Lehm. (Tyrol)

hirtum L. (Tyrol)

arenarium Schott \& Kotschy

(Tyrol; granit.)

Neilieichii Schott \& Kotscny

(Autriche; ardoisif.)

Hildebrandti Schott (Tyrol; granit.)

brevistylum Lam (Basses-Alp.) speciosum Lam. (Mt. Viso)

brachiatum Lam. (Dauphiné) affine Lam. (Mt. Vizo) ambiguum Lam. (Basses-Alp.) Maitrei Lam. (Alpes Grecq.) Verlotii Lam. (Isère) Guillemotii Lam. (Basses-Alp.) Lamottei Boreau (Basses-Alp.) 
$-163-$

Sempervivum arvernense Lec. \& Lam. (Mont. françaises)

D

))

)

$D$

)

D

D

b Boutignianum Bill. \& Gren.

(Alpes du Dauphiné) calcareum Jord. (Dauphiné) compactum Lam. (Alp. Grecq.) piliferum Jord. (Basses-Alpes) alpestre Lam. (Mt. Viso) frigidum Lam. (Alp.du Dauph.) Fauconneti Reut. (Reculet.) Juratense (Jura). ( ${ }^{1}$ )

Toutes les espèces appartenant à la famille des Crassulacées sont saxatiles; elles demandent un sol rocailleux quoique léger et une exposition sèche. On cultive quelquefois les Sempervivum sur les toits ou le sommet des murs.

\section{GrossulariÉEs :}

Ribes alpinum L. (granit.)

- petraeum Wulf. (calc.)

Deux arbrisseaux de la région montagneuse prenant beaucoup da développement par la culture.

(1) Tous ceux qui connaissent un peu de botanique savent combion ce genre si varié est embrouillé et peu connu. Je me suis borné ici à mentionner, soit d’après l'Atlas der Alpenflora, soit d'après les travaux du botaniste Lamotte, les espèces qui me paraissent ètre distinctes et recommandables. 


\section{Saxifragées :}

Saxifraga umbrosa L.

) rotundifolia $\mathrm{L}$.

ఎ cuneifolia L.

"Apennina Bertol. (Tyrol mérid.)

Ces espèces aiment l'ombre ; les deux dernières veulent un sol léger et craignent une trop grande humidité ; du reste fort rustiques.

Saxitraga Hostii Tausch. (Tyrol) elatior M. \& K. (Suisse orient. et

(Tyrol)

D crusiata Vest. (Tyrol; calc.)

" purpurata Gaud.

»Cotyledon L.

„ Portae Kern. (Tyrol)

" brevifolia Sternb.

" Carinthiaca Schott et Kotschy.

" elongata Engl. (Suisse orient.)

- lantoscana B. \& R. (Alpes orient.)

" lingulata Bell. (Alpes Dauphiné.)

Toutes ces espèces, appartenant au groupe Aizoon, sont extrêmement faciles à cultiver. Une exposition au soleil, un sol peu profond, rocailleux, peu d'humidité et elles réussissent toujours. Elles se ressèment abondamment sur les rocailles où elles forment parfois des hybrides. Le cas 
s'est présenté au jardin botanique où j'ai observé une forme intermédiaire entre $S$. Cotyledon et $S$. Aizoon. Le Jardin Alpin d'acclimata.tion a reçu de $M$. le $D^{r}$ Regel des graines de plusieurs variétés et formes de la Saxifraga Aizoon. Toutes ont levé et sont en voie de prospérité.

Saxifraga florulenta Moret.

Cette espèce, fort belle et très rare, se rerıcontre dans les Alpes Maritimes aux environs de Nice. Sa culture est difficile. Il faudrait essayer de l'élever toute jeune encore dans des murs, et dans la position perpendiculaire qu'elle adopte naturellement à l'état sauvage. Je ne l'ai jamais réussie.

Saxifraga diapensioides Bell.(Valais et Tyrol.)

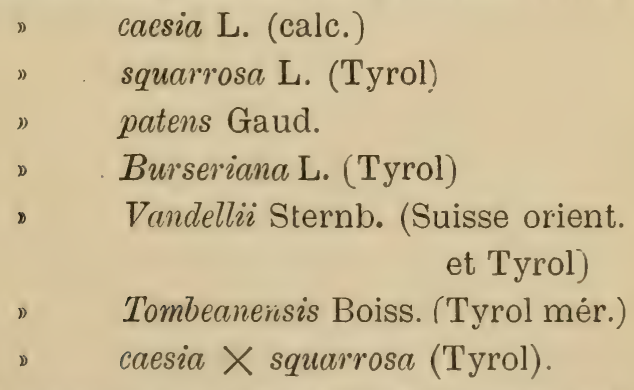

Toutes ces espèces sont saxatiles et demandent le sec. Il est bon de les planter en biais, entre deux pierres ou dans les fentes des murs. 
Saxifraga arachnoidea Sternb. (Tyrol mér.) ๖ cermua L.

1) hieraciifolia W. et K. (Tyrol.)

Trois plantes assez difficiles à faire fleurir dans les cultures. Je les ai réussies dans un mélange de tourbe, de Sphagnum et de gravier. (Voir Cultures spéciales.)

Saxifraga controversa Stbg.

„ petraea L. (Tyrol mér.)

Demandent une exposition au soleil et un sol riche d'humus; la première ne supporte pas le calcaire tandis que la seconde l'exig'.

Saxifraga stellaris L.

))

1)

i) hispidula Roch. glabrata Sternb. Engleiri D. C. (Tyrol) aphylla Sternb. Pedemontana All. (Mont-Rose) acaulis Gaud. (Hautes-Alpes) muscoides Wulf. laxa Sternb. atropurpurea Sternb. crocea Gaud. maculata Reich. pygmaea Haw. (Tyrol) Facchinii Koch (Tyrol) androsacea $\mathrm{L}$. 


\section{Saxifraga sedoides L. (Tyrol; calc.) \\ ) aizoides $\mathrm{L}$. \\ D atrorubens Bertol. (Tyrol) \\ ) tenella Wulf. (Alpes orient.) \\ 1) aspera L. \\ D bryoides L. \\ D intermedia Heg. \\ ») mutata L. \\ „Seguieri Sprgl.}

Ces différentes espèces aiment un sol tourbeux, humide, spongieux et une exposition au soleil. On remplace la tourbe, lorsqu'on n'en a a pas, par une proportion d'un tiers de Sphagnum. Il faut cependant drainer fortement les niches, afin que l'humidité ne produise pas des algues et des mousses. La $S$. mutata demande à être plantée en biais et dans un terrain argileux.

Saxifraga Allionii Gaud.

D exarata Will. (Tyrol et Suisse or.)

Ces deux plantes sont des Saxifrayes mousses qui tapissent rapidement les rochers et qui les garnissent très joliment.

Saxifraga hypnoides (Alpes occ. et Ciévenn.)

Rien de spécial comme culture.

Saxifraga retusa Gouan.

, Rudolphiana Horns. (Tyrol).
oppositifolia L.


Saxifraga Hegetschweilerii Brügg. (Tyrol.) - biflora All.

Ces cinq différentes saxifrages appartiennent à la zone supérieure et glaciale. Elles fleurissent très bien dans les cultures mais exigent un sol peu profond bien drainé, sec et une exposition alu nord ou au levant.

Zahlbrucknera paradoxa Reich.

Chrysosplenium alternifolium $\mathrm{L}$.

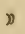
oppositifolium L.

Trois plantes de la région montagneuse et inférieure; aiment l'humidité et l'ombre.

\section{OMBELLIFÈRES :}

Hacquetia Epipactis D. G. (Carinthie). Soleil, sol fertile.

Astrantia bavarica F. Sch. (Alpes bav.; calc.)

" Carniolica Wulf. (Alpes carnioles) major L.

" Carinthiaca Hoppe (Carinthie).

Sol riche, profond et exposition au soleil.

Astrantia minor L. (granit.)

Sol spongieux, tourbeux et exposition ombragée. Eryngium alpinum L.

Réussit admirablement dans un sol de jardin ordinaire; il lui faut un terrain riche et profond et une exposition légèrement ombragée. 


\section{- $169-$}

Bupleurum stellatum L.

» petraeum L. (T'yrol mérid.)

"ranunculoides L.

Libanotis athamantoides D. C.

- montana Crntz.

D gracilis Reichb. (Tyrol mérid.)

Athamantha Cretensis L. (calc.)

D Matthioli Wulf. (Alpes mér.)

Meum athamanticum Jacq. (calc.)

¿ mutellina $\mathrm{L}$.

Heracleum alpinum $\mathrm{L}$,

- montanum Schleìch.

" Pyrenaicum Lam. (Alpes mérid.)

1) Austriacum L. (Alpes orient.)

Soleil; sol profond et nourrissant. Ces plantes prenant un assez fort développement elles ne doivent figurer que dans les grandes rocailles ou les coins pittoresques des campagnes.

\section{GAPRIFOLIIAGÉES :}

Sambucus racemosa L.

Lonicera nigra $\mathrm{L}$.

๖ crerulea L.

»alpigena L.

Arbustes propres à garnir les grandes rocailles et les massifs rocailleux des campagnes.

\section{Linnaea borealis L.}

(Voir aux Cultures spéciales.) 


\section{$-170-$}

\section{RubiacÉEs :}

Galium rupicolum Bertol.

" Baldense Sprgl..(Alpes mérid.; calc.)

- Austriacum Jacq. (Tyrol mér.)

* rotundifolium L.

๖ pumilum Lmk.

Soleil; sol léger et sec. Ces plantes sont en général envahissantes.

\section{VALERIANÉES :}

Valeriana supina L. (calc.)

$" \quad$ saliunca All. (granit.)
$" \quad$ Celtica L. (granit.)
$\Rightarrow \quad$ saxatilis L. (calc.)
"elongata L. (Tyrol; calc.)
"tripteris L.
montana L.

DiPSACÉES :

Cephataria alpina L.

Plante très élevée et propre à garnir les grandes rocailles et à être cultivée comme plante vivace.

Knautia transalpina Cihrist.

- longifolia W. et K. (Tyrol).

Idem. 


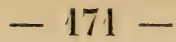

Scabiosa lucida Will. (Tyrol calc.)

Soleil; sol léger, riche en humus.

\section{Composées :}

Adenostyles alpina (Bl. et Fing.)

》) Tyybrida Koch.

- albifions Rehb.

¿ leucophylla Rchb.

Sol profond, riche en humus.

Homogyne discolor Cass. (Tyrol et Alpes orientales; calc.)

- silvestris ('ass. (Carinth. et Carn.)

- alpina Cass.

Sol spongieux, riche en humus.

Petasites albus Gärtn.

- niveus Baumg.

Plantes prenant un gros développement et propres à garnir les endroits frais et rocailleux des campagnes.

Aster alpinus L.

). Wolfii Favr.

- Garibaldii Brügg.

Soleil; terrain léger, calcaire.

Bellidiastrum Michelii Cass.

Sol humide, profond et nourrissant.

Erigeron Villarsii Bell.

» Schleicherii Gremli (Valais). 


\section{$-172$}

Erigeron intermedius Schleich. (Valais)

"alpinus L.

- Prantlii D. T. (Alpes bavar.; calc.)

a uniflorus L. (granit.)

D neglectus Kern. (Tyrol; calc.)

Les Erigerons croissent généralement dans les endroits secs et rocailleux des Alpes; il faut leur rendre ces conditions dans les rocailles.

Solidago alpestris W. et K.

Buphthalmum salicifolium L.

Gnaphalium Leontopodium Scop.

Sol profond, nourrissant; exposition au soleil.

L'Edelweiss est l'une des plantes favorites des alpinistes. C'est aussi l'une de celles qui réussissent le mieux dans les cultures. On l'élève par semis; puis on la met en pots dans un sol calcaire avec le fond du vase garri de pierres calcaires concassées. Il lui faut le plein soleil. Elle se ressème souvent seule dans les rocailles. Le Jardin Alpin en a eu cet été un pied comptant ving-cinq fleurs à la fois; ces fleurs étaient superbes, d'une grandeur extraordinaire. Sans calcaire dans le sol, les bractées qui font tout le charme de la fleur, par elle-même très peu séduisante, deviennent verdâtres et s'allongent démesurément. La culture rend parfois les Edelweiss méconnaissables et mons- 
trueuses dans leurs formes. On évite tout cela en rendant au sol le calcaire qu'elles trouvent dans les rochers sur lesquels elles croissent. Dans le Tyrol, il y a cependant une station d'Edelweiss qui se trouve sur un sol absolument granitique et schisteux. 11 est probable que le terrain contient cependant du calcaire, ne fût-ce qu'à l'état de molécules.

Gnaphalium dioicum $\mathrm{L}$.

- Carpathicum Wahl.

Sol léger, rocailleux; exposition au soleil.

Artemisia valesiaca All. (Valais).

- austriaca Jacq. (Autriche)

"tanacetifolia All. (Alpes orient.)

" Campestris L.

- lanata Will. (Tyrol mérid.; calc.)

D nana Gaud. (Valais, Alp. Dauph.)

D glacialis L.

Ces quatre espèces d'Armoises, qui appartiennent plutôt aux régions inférieures des Alpes, demandent une exposition sèche, méridionale, un sol sablonneux et léger.

Artemisia Mutellina Vil.

D spicata Wulf.

Sont des espèces appartenant à la région alpine et glacée. Elles demandent un sol rocailleux, peu profond, un fort drainage et une exposition au levant ou au couchant. 
Achillea Clavenae L. (granit.)

. moschata L. (granit.)

- atrata L. (calc.)

- Clusiana Tausch.'(Alp. orient.; calc.)

"nana Gaud. (granit.)

- herba-rota All. (Alp. Dauph.)

Ce sont les plantes dont on fait l'Iva de l'Engadine et le Genépi dans les vallées de nos Alpes occidentales. Elles ne réussissent à vivre et à fleurir dans les rocailles que lorsqu'on a soin de leur donner une position intermédiaire entre le sud et le nord et un sol peu profond, riche en humus et fortement drainé avec du coke ou des pierres calcaires ou granitiques suivant les espèces.

Achillea alpina L. (St-Gothard).
" tanacetifolia All. (Alpes orient.)
„ macrophylla L.
„ magna Hänke.
" distans W. et K. (Alpes orient.)
tomentosa L.

Espèces voraces, faciles à cultiver, demandant un sol fertile et une exposition au soleil.

Anthemis montana Koch.

$\quad$ alpina L.

Chrysanthemum alpinum $\mathrm{L}$.

Plantes des Alpes orientales, demandant un 
sol rocailleux, profond et une exposition au soleil.

Doronicum Austriacum Jacq. (Alp.autr.,calc.)

- Pardalianches L.

D scorpioides $\mathrm{L}$.

- cordatum Keri. (Alp. autr.; calc.)

Aronicum glaciale Reich. (granit.)

》Doronicum Jacq. (granit.)

„ Jacquini Tausch. (Alp. orient.)

Terrain rocailleux; soleil.

Arnica montana L.

Cette plante, si populaire et si estimée, est d'une culture difficile. Je n'ai jamais réussi à la faire fleurir bien richement. Elle a fleuri dans une rocaille fort bien soignée, il est vrai, à Malagnou. Il lui faut le nord, un sol tourbeux et cependant bien drainé. J'en ai eu d'assez beaux pieds par semis, lesquels n'ont pas encore fleuri.

Senecio uniflorus All.

" carniolicus Willd.

¿ incanus l.

Plantes délicates, craignant l'humidité; il leur faut une exposition au levant ou au couchant, un sol bien drainé ou rocailleux.

\section{Senecio Doronicum L.}

" subalpinus Koch (Tyrol).

„ cordifolius Gouan (Alpes orient.) 
Senecio Cacaliaster Lam. (Alpes orientales et méridionales).

- Jacquinianus Reich.

"spathulafolius D. C.

* longifolius Jacq. (Alpes orient.)

- aurantiacus D. C.

1) abrotanifolius L. (Alp. orient.; calc.)

Espèces passablement développées, demandant un sol fertile et profond et une exposition au soleil.

Cirsium acaule Scop. (calc.)

- spinosissimum Scop.

- Carniolicum Scop. (Carniolie).

Carduns defloratus L.

") glaucus Baumg.

"Personata Jacq.

Carlina acaulis $\mathrm{L}$.

Chardons de formes, port et couleurs diverses, pouvant garnir avantageusement les grandes roches et les coins sauvages, et ne demandant qu'un sol profond et une exposition découverte.

Saussurea pygmaea Sprgl. (Tyrol; călc.)

$\Rightarrow \quad$ discolor D. C. (calc.)
$\Rightarrow \quad$ depressa Gren.
$\Rightarrow \quad$ alpina D. C. (granit).
$\Rightarrow \quad$ macrophylla Saut.


Les Saussurées recherchent dans la nature un sol caillouteux et profond.

Serratula nudicaulis D. C. (Salève).

Terrain fertile et soleil.

Centaurea montana L.

, axillaris Willd. (Alpes mérid.)

D transalpina Schleich. (Alp. mér.)

"nigrescens Willd. (Alpes orient.)

") Phrygia L.

) plumosa Lem.

Les Centaurées sont généralement des plantes voraces et envahissantes. Elles aiment un terrain profond el une exposition au soleil.

Leontodon saxatilis All.

" pyrenaicus Gouan.

Scorzonera rosea W. et K.

" montana Mut. (Alp. du Dauph.)

Hypochoeris maculata $\mathrm{L}$.

» uniflora Vill.

Taraxacum nigricans Kit.

Pacheri Sch.

Soleil; terre fertile et profonde.

Prenanthes purpurea L.

1) tenuifolic L. (Dauphiné).

IIulgedium alpinum Less.

D Plumieri D. C.

Plantes élevées, demandant un sol fort, 
profond, riche et une position un peu ombragée.

Crepis montana Scop.

- aurea Cass.

1) pygmaea $\mathrm{L}$.

1) jubata Koch.

- pontana L.

- alpestris Tausch.

Sol léger et rocailleux; position au soleil. Le Crepis aurea demande un sol riche en humus et profondément drainé par des pierres calcaires.

Hieracium staticefolium Vill.

- Pilosella L.

^alpicolum Schl.

Daurantiacum $\mathrm{L}$.

- flavum Gaud.

»alpinum L.

" glabratum Hoppe.

" porrifolium $\mathrm{L}$.

Dglaucescens Gremli.

ఎ amplexicaule L.

- ligusticum Fries.

" humile Jacq.

, caesium Fries.

„rupicolum Fries.

) australe Fries. 


\section{- $179-$}

Plantes envahissantes et qu'il ne faut planter que dans les grands rochers, dans les vieux murs ou dans les ruines que l'on désire garnir de végétation. Le Hieracium aurantiacum fait cependant exception et doit figurer dans chaque rocaille alpine, parce que la couleur rouge vif de ses fleurs y produit le plus grand effet. Elle a, en outre, cet avantage de fleurir alors que les autres plantes sont défleuries.

Hieracium lanatum Vill.

$$
\text { „villosum Jacq. }
$$

Deux espèces bien développées et qui produisent un bel effet. Elles aiment le soleil et les fentes de rochers ou de murailles.

\section{Gampanulacées :}

Phyteuma comosum L. (Tyrol mérid.)

D) Scheuchzeri All. (Tyrol).

¿ pauciflorum L.

1) Tumile Schlch. (granit).

„ Sieberi Sprg!. ('Tyrol.; calc.)

Plantes saxatiles, dont les racines sont très développées et s'enfoncent profondément dans les fentes des rochers exposés au soleil. Il est bon de leur rendre ces conditions et de les placer soit dans les fentes d'un mur, soit dans celle d'une rocaille perpendiculaire. 
Phyteuma orbiculare L.

- $\quad$ scorzonercefolium Vill.
" $\quad$ spicatum L.
" nigrum Schmidt.

Ces espèces appartiennent aux pâturages et à la lisière des bois de la partie montagneuse; elles ne demandent autre chose qu'un sol fertile et profond.

Campanula Zoysii Wulf. (Alpes de la Carinthie; calc.)

» pulla L. (Tyrol).

- Raineri Perp. (Tyrol mérid.)

" Morettiana Richb. (Tyrol mérid)

" petrcea L. (Tyrol).

Dexcisa Schl.

" carnica Schied. (Carinthie).

- ccespitosa Scop. (Tyrol).

Espèces saxatiles, à racines ténues et nombreuses.

$$
\begin{gathered}
\text { Campanula thyrsoidcea L (calc). } \\
\text { " alpina L. (Tyrol). } \\
" \quad \text { barbata L. } \\
\text { " Allionii Vill. (Alp. Dauphiné). } \\
\text { " rhomboidalis L. } \\
\text { "Scheuchzeri Vill. } \\
\text { "rotundifolia L. }
\end{gathered}
$$




\section{$-181-$}

Sol riche en humus; position légèrement ombragée.

Campanula Cenisia L.

Cette plante, qu'on rencontre généralement dans les éboulis schisteux et ardoisifères des Hautes-Alpes, réussit à fleurir dans les cultures si l'on a soin de la cultiver dans un sol tourbeux, léger et très poreux.

Edrayanthus Cioatious Kern. (Carinthie).

Sol pierreux; exposition au soleil.

\section{VACGINIÉES :}

Vaccinium Oxycoccos L.

„Vitis 1dea L.

"Myrtillus L.

- uliginosum L.

Voir aux cultures spéciales.

ERIGaGÉES :

Arctostaphylos alpina Sprgl.

DUva ursi Sprgl.

Azalea procumbens $\mathrm{L}$.

Rhododendron Chamacistus L.

n

ferrugineum L.

») hirsutum L.

- intermedium Tausch.

(Voir aux cultures spéciales.) 
Erica carnea L.

Soleil ; terre légère.

\section{Pyrolacées :}

Pyrola uniflora L.

- meedia Sw.

" secunda $\mathrm{L}$.

- rotundifolia L.

- minor L.

1) umbellata $\mathrm{L}$.

- chlorantha Sw.

Voir aux cultures spéciales.

\section{Gentianées :}

Swertia perennis $\mathrm{L}$.

Sol tourbeux, spongieux et humide; soleil. Lomatogonium carinthiacum A. Br. Sol riche en humus; soleil.

Gentiana lutea L.

" Thomasii Hall. (Alpes autrich.)

v Charpentieri Thom. (Alp. autrich.)

" Gaudiniana Thom.

- purpurea $\mathrm{L}$.

"Pamonica Scop. (Alp. autr.; calc.)

"punctata $\mathrm{L}$.

- cruciata L.

- Frölichii Jan. (Tyrol). 


\section{$-183-$}

Espèces aux racines très développées; il leur faut un sol profond, riche et nourrissant et une exposition au soleil.

Gentiana asclepiadaca L.

"Pneumonanthe L.

Plantes marécagreuses, aimant un sol tourbeux et humide.

Gentiana ciliata L.

Difficile à cultiver; elle aime un sol lourd et une exposition au soleil. Je l'ai cependant réussie dans la tourbe.

Gentiana acaulis L. (granit.)

\begin{tabular}{|c|c|}
\hline ) & ఎ var angustifolia Vill. \\
\hline 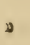 & var Kochiana Perr. etSong \\
\hline D & Clusii Perr. et Song. \\
\hline " & frigida Hänke (Tyrol). \\
\hline$?$ & Bavarica L. (calc.) \\
\hline & imbricata Fröl. (granit.) \\
\hline & pumila Jacq. (Tyrol). \\
\hline 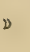 & brachyphylla Vill. \\
\hline " & verna $\mathrm{L}$. \\
\hline
\end{tabular}

Voir aux cultures spéciales.

\section{Polénoniacées :}

Polemonium coruleum L. 
BorRaginḱEs :

Cerinthe alpona Kit.

$$
\text { - major L. }
$$

Myosotis alpestris Schmidt.

Sol léger, plutôt frais; exposition au soleil.

Evytrichium nanum Schrad.

Voir aux cultures spéciales.

\section{AntrRrhinées :}

Digitalis purpurea L.

Digitalis grandiflora Lam.

$$
\text { „lutea } \mathrm{L} \text {. }
$$

Sol ordinaire de jardin.

Linaria alpina $\mathrm{L}$.

" origanifolia DG. (Dauphiné).

" linifolia Koch. (Dauphiné).

Terrain léger et sablonneux, fortement drainé ; exposition au soleil.

Erinus alpinus L.

Veronica latifolia L.

Aime à vivre entre les fissures des pierres calcaires.

Veronica latifolia $\mathrm{L}$.

» fruticulosa $\mathrm{L}$.

- saxatilis Scop.

* spicata L. 
Veronica alpina L.

„ aphylla $\mathrm{L}$.
„ bellidioides L.

Tandis que les quatre premières espèces aiment un sol sec, léger et sablonneux, les trois dernières, au contraire, exigent un terrain tourbeux, frais, riche en humus; il faut bien drainer.

\section{RHINANTHACÉES :}

\section{Bartsia alpina L.}

Sol tourbeux et spongieux; mi-soleil.

Le genre Pedicularis nous offre un certain nombre d'espèces fort jolies et intéressantes; elles sont malheureusement difficiles à acclimater et à cultiver. Je nai jamais pu en obtenir des fleurs. Un cultivateur distingué, M. Prévost, de Chambésy, en a fait des semis qui semblent devoir réussir. Ces semis, qui ont déjà cinq ans, forment de fortes plantes en ce moment, mais n'ont pas encore fleuri. S'ils parvenaient à le faire, on aurait là une preuve du non parasitisme de ces plantes et la possibilité de leur acclimatation serait alors démontrée.

\section{LABIÉES :}

Calamintha alpina Lam. (calc.)

Soleil; terrain léger et caillouteux. 


\section{$-186$}

\section{Horminum pyrenaicum L. (calc.) \\ Melittis melissophylla I. \\ Dicacosephatum Ruyschianum L \\ - Austriacum L. \\ Stachys alpina L. \\ Betonica Tirsuta L \\ Alopecuros L.}

Sol frais et riche en humus; mi-soleil.

Sideritis hyssopifolia L.

Scutellaria alpina L.

Teucrium montanum Schreb.

$$
\text { „Polium L. }
$$

Sol rocailleux, terrain sec. exposition au soleil.

Ajuga alpina Vill.

- pyramidalis L.

Sol frais, spongieux; mi-soleil.

\section{LeNtibulariées :}

Pinguicula alpina $\mathrm{L}$.

- flavescens Flœrk.

"vulgaris L.

- leptoceras Rchb.

" grandiflora Lam.

- longifolia Ram. (Alpes Dauph.) 


\section{Primulacées :}

Trientalis europaea $\mathrm{L}$ Anagallis tenella L. Androsace Helvetica Gaud. (calc.)

" Heerii Koch (Martinsloch).

- imbricata Lam. (Tyrol.)

"Wulfeniana Sieb. (Tyrol: ardois.)

" Hausmanni Leyb. (Tyrol).

" pubescens D G.

- glacialis Hop. (granit.)

- Charpentieri Heer (Valais).

Voir aux cultures spéciales.

Androsace lactea L. (calc.)

: carnea L. (granit.)

" obtusifolia All.

n villosa L. (calc.)

" chamaejasme Host.

Aretia Vitaliana L. (calc.)

Sol léger, peu profond; bon drainage et exposition au levant ou au couchant.

Primula Auricula L.

" Balbisii Lehm. (Tyrol mérid.)

- venusta Host. (Tyrol).

- Camiolica Jacq. (Carniolie). 


\section{$-188-$}

Primula alpina Schl. (Grisons).

- pubescens Jacq. (Tyrol).

1) discolor Leyb. (Tyrol).

- Muretiana Mor.

1) Clusiana Tausch. (Alp. orient.; calc.)

n spectabilis Tratt (Tyrol mérid.; calc.)

- Tiroliensis Schott. (Tyrol mérid.)

D viscosa All. (granit).

" villosa Wulf. (Carinthie; granit.)

- commutata Schott. (Tyrol; serpentine)

" ciliata Schrk. (Tyrol).

) Tirrsuta All.

") Oenensis Thom.

"Flörlieana Schrad. (Tyrol mérid.)

"Portce Hut. (Tyrol).

" marginata Curt. (Alp. du Dauph.)

- pedemontana Thom. (Piémont).

Ces différentes Primevères sont généralement faciles à cultiver; quelques espèces hybrides, telles que Muetiana, alpina, discolor, venusta, demandent cependant quelques soins particuliers pour arriver à fleurir. Il y a quelques années, j'avais reçu d'Innsbrück toutes les espèces tyroliennes mentionnées ici et les ai plantées soit dans un terrain rocailleux, soit entre les pierres de la rocaille, placées perpendiculairement. Elles ont fort bien réussi. Toutes ces espèces aiment 
cette position; elles craignent une trop grande humidité mais veulent la fraicheur autour de leurs racines. Elles demandent une position un peu ombragée; le levant ou le couchant leur conviennent particulièrement.

Primula integrifolia L.

๖ glutinosa L. (granit.)

" minima L. (calc.)

"Wulfeniana Schott ('Tyrol; granit.)

- longiflora L. (granit.)

) farinosa $\mathrm{L}$.

Cortusa Matthioli L.

Soldanella montana Willd. (Tyrol)

" alpina L.

- pusilla Baumg.

" minima Hop.

Sol bien drainé, peu profond, tourbeux èt riche en humus, mélangé d'un tiers de sable granitique ou calcaire, selon l'espèce. Contrairement aux espèces précédentes, celles-ci doivent avoir une position horizontale. Il en est pour ces plantes comme pour la plupart des espèces vernales des Alpes; il leur faut l'humidité de l'air pour vivre et se développer. J'ai longtemps cultivé des Soldanelles sans réussir à les faire fleurir. J'avais cependant aperçu s'élever du sein de leurs feuilles de petites tiges florales qui don- 
naient le plus grand espoir. Ces tiges se desséchaient et disparaissaient sous l'influence du vent du nord ou des rayons solaires qui les brûlaient. Ce qui manquait à ces plantes, c'était évidemment l'humiditè de l'air, qui seule pouvait atténuer ces effets pernicieur. Il fallait donc arroser davantage et chercher à produire une forte dose de vapeur sans cependant provoquer la pourriture de la plante. Dans ce but, je construisis une niche grande et profonde, dont je garnis le fond, jusqu'd mi-hauteur, de scories de coke et de gravier. Le reste de la poche fut rempli d'un terreau composé d'un tiers de terre de feuilles, un tiers de terre de bruyère et un tiers de sable. C'est là que je plantai, en septembre, une vraie corbeille de Soldanelles dont on ne s'occupa pas jusqu'à la fin du mois de février et qui furent, pendant l'hiver, recouvertes de branches de sapin. Aux premiers jours de mars, les petites tiges florales se montrèrent comme toujours au sein des touffes; cette fois, je ne les laissai pas se flécrir et j'eus soin d'arroser plusieurs fois dans la journée au moyen d'une grille d'arrosoir que je tenais à une grande distance du sol, afin que l'air s'im. prégnât d'humidité. L'opération fut faite par le plus fort soleil; on comprend facilement com- 


\section{$-191-$}

bien rapide fut l'évaporation. Ce sol, bien drainé et contenant une forte proportion de sable, laissait filtrer l'eau dont il ne retenait que ce dont les racines avaient besoin. Et c'est ainsi que bientôt on put admirer, dans cette corbeille, une niche de Soldanelles absolument recouverte de fleurs et formant un véritable tapis. On y a compté jusqu'à dix-sept hampes florales par pied. Ce moyen ma réussi pour toutes les plantes alpines à floraison vernale et tont les fleurs doivent se développer rapidement.

Cyclamen Europaeum L.

Aime l'ombre et les sols rocailleux.

Globulariacées :

Globularia cordifolia L.

vidicautis L.

- vulgaris L.

Sol rocailleux, léger; exposition au soleil.

\section{Plombaginées :}

Armeria alpina Willd.

Sol rocailleux, léger; exposition au soleil.

\section{THYMÉLÉES :}

Daphne Cneorum L.

" petraea Leyb. (Tyrol mérid.) 


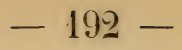

\section{Daphne striata Tratt. (Tyrol). „alpina L.}

\section{EMpétrées :}

\section{Empetrum nignum L.}

Voir aux cultures spéciales.

\section{SAlicinéEs :}

Salix repens L.

» myrtilloides L.

" serpyllifotia Scop.

) Lapponum L.

» caesia Vill.

„glauca L.

Ces six espèces de saules appartiennent à la végétation sous-arborescente de la région alpine: elles peuvent être placées dans les grandes rocailles.

\section{Salix herbacea L.}

- retusa L.

» reticulata L.

Saules nains et rampants appartenant à la région glacée des Hautes-Alpes. Ils prennent peu de développement dans les cultures et demandent un sol léger, spongieux, si possible tourbeux. 


\section{Bétulinées :}

\section{Betula nana L.}

Le petit bouleau des Alpes qui est aussi celui du nord de l'Europe, produit un très joli effet dans les rocailles. Il aime un sol profond, fertile et une exposition légèrement ombragée.

\section{GonifÈres :}

Jumiperus nana Willd.

D Sabina L.

Pinus uncinata Ram. $\beta$ pumilio Hänke. D montana Mill.

Sol rocailleux, profond, mélangé à une forte proportion de terreau de feuilles. Ces arbustes font un bel effet dans les grandes rocailles où l'on doit éviter de placer le sapin ordinaire, trop vorace et dont la présence donne à l'ensemble quelque chose de trop ordinaire.

\section{Orchidées :}

Orchis ustulata L.

„ coriophora L.
„ mallens L.
" specila L.
¿axiflora Host.




\section{$-194-$}

Orchis palustris Jacq.

" sambucina L.

) maculata L.

) globosa L.

¡) incamata L.

) latifolia L.

D fusca Jacq.

" simia Lam.

- militaris L.

„) morio L.

) Spitzelii Saut.

Anacomptis pyromidalis Rich. Gymnadenia conopsea Rich.

- odoratissima Rich.

ఎ albida Rich.

Caeloglossum viride Hart.

Himantoglossum hircinum Rich.

Platanthera bifolia Rich.

Nigritella angustifolia Rich.

- suaveolens Koch.

Ophrys myodes Jacq.

„ apifera Huds.

» arachnites Hoffm.

- aranifera Smith.

Chamaeorchis alpina Rich. Aceras anthropophora R. Br. Herminium monorchis $\mathrm{R}$. Br. 


\section{$-195-$}

Listera ovata $\mathrm{R}$. Br.

1) cordata $\mathrm{R}$. Br.

Cypripedium Galceolus L.

Les Orchidées que l'on rencontre dans les différentes parties des Alpes et de la région mon. tagneuse sont, pour la plupart, faciles à cultiver. J'indique ici celles que j'ai réussi à acclimater ou dont j'ai constaté la réussite chez d'autres personnes. La manière de les traiter est différente suivant les espèces. Tandis que les unes telles que : Orchis ustulata, coriophora, pallens, mascula, speciosa, sambucina, maculata, globosa, latifolia, simia, militaris, morio, Spitzelii, Anacamptis pyramidalis, Gymnadenia conopsea, odoratissima, albida, Caeloglossum viride, Platanthera bifolia, Ophrrys myodes, apifera, arachnites, aranifera, Aceras anthropophora, Listera ovata et cordata s'acclimatent sans difficulté et réussissent dans tous les terrains riches en humus exposés au mi-soleil et de nature un peu fraîche, d'autres exigent pour fleurir et développer leurs organes des conditions spéciales. Tels sont: Orchis laxiflora, palustris, incamata, qui exigent un sol poreux et tourbeux; O. fusca et $H$. hircinum qui préfèrent les terres fortes, mélangées de rocailles et l'exposition au levant et au couchant; Chamaeorchis alpina, Herminium monorchis et les Nigritelles qui demandent une niche 
fortement drainée, un sol peu profond et mélangé de sable; enfin le Sabot de Vénus ou Cypripède qui veut un sol spongieux, tourbeux quoique fertile et une exposition légèrement ombragée. Les pelouses et les places gazonnées des jardins d'agrément peuvent avantageusement être consacrées aux cultures d'Orchidées. On dissémine les plantes à droite et à gauche et on cherche à planter les espèces d'après leurs conditions d'existence. On peut ainsi réunir dans un enclos d'étendue restreinte des Orchidées se rencontrant dans des territoires très divers et étendus, ce qui ne manque pas de donner à l'ensemble du jardin un caractère pittoresque et naturel. Il faut avoir soin de planter profond.

La plupart des Orchidées à racines bulbeuses que l'on transplante pendant l'époque de leur floraison périssent ou périclitent petit à petit. Cela provient du fait qu'on a endommagé ou négligé de prendre la partie principale de la plante, le bulbe de l'année, lequel contient le germe et la vie du végétal. Au moment où elles fleurissent, le genre d'Orchidées en question possède deux bulbes opposés l'un à l'autre et placés en dessous des racines fibreuses. L'un de ces bulbes est de couleur noirâtre et commence 


\section{$-197-$}

à se rider; c'est celui de l'année précédente, le réservoir qui a fourni à la plante la nourriture pour le moment de sa floraison. L'autre est blanchâtre, absolument lisse et gonflé de sucs: c'est lui qui contient la vie de la plante et la conserve pour l'année suivante. C'est ce dernier bulbe qu'il faut obtenir, car sans lui la plante est absolument détruite. Mais il est bon de faire remarquer ici que le moment de la transplantation doit être retardé jusqu'à ce que ce bulbe soit suffisamment mûr et qu'il se délache facilement du reste de la plante. C'est pourquoi on ne doit arracher les Orchidées bulbeuses qu'après leur floraison. Quant aux espèces dont les racines sont fibreuses telles que les Epipactis, les Céphalanthères ou qui sont stolonifères comme la Goodyera repens $\mathrm{l}$. Br. elles sont difficiles à acclimater. Les seules avec lesquelles on ait jus. qu'à présent bien réussi sont les Listera, les Spiranthes et les Cypripèdes. On parviendra certainement à les cultiver dans du Sphagnum et avec des soins particuliers; c'est une affaire à entreprendre et à étudier.

\section{IRIDÉES :}

Crocus albiflorus Kit.

, vernus Wulf. 


\section{$-198-$}

\section{AMaryllidéEs :}

Narcissus Pseudo-narcissus L.

" juncifolius Req. (Alpes marit.)

- poeticus L.

" radiiflorus Salisb.

Galanthus nivalis L.

Lencojum vernum $\mathrm{L}$.

\section{LILIACÉES :}

Lilium bulbiferum L.

» croceum Chaix.

- Martagon L.

- Caniolicum L. (Alpes orient.)

Erythronium Dens Canis L.

Paradisia Litiastrum L.

Anthericum Liliago L.

, ramosum L.

Gagea Liottardi Schult.

» minima Schult.

Allium Victoriale L.

) montanum Schmidt.

, ochroleucum W. et K.

\ schcenoprasum L.

Fritillaria Maleagris L.

Lloydia serotina Rchb.

Toutes ces plantes bulbeuses se cultivent de 
même; elles reulent un sol profond, riche, fertile et une exposition au soleil. Les deux dernières sont seules exceptées; ce sont des espèces plus délicates, aimant un sol spongieux, tourbeux, mais peu profond et bien drainé.

\section{Colchicacées :}

Bulbocodium vermum L. (Alp. du Dauph.)

Colchicum alpinum D C.

Sol profond; exposition au soleil.

Veratrum nigrum L.

"album L.

Sol profond, fertile, riche en humus; soleil.

Tofieldia calyculata L.

ఎ palustris Huds.

$s$

Sol spongieux, tourbeux; soleil.

\section{JONCACÉES :}

Luzula flavescens Gaud.

nivea D C.
$\Rightarrow \quad$ nutea $\mathrm{D} \mathrm{G}$.
$\Rightarrow \quad$ nigricans Desv.
spicata D G.

Cypéracées :

Carex leporina L.

- atrata L. 
Carex frigida All.

") capillaris $\mathrm{L}$.

„ sempervirens Vill.

Graminées :

Phleum Michelii All.

- alpinum L.

Agrostis alpina Scop.

Aira ccespitosa L.

" flexuosa L.

Poa alpina L.

) pumila Host.

Festuca nigrescens Lam.

- alpina Sut.

, flavescens Bell.

" glauca Lam.

Nardus stricta L.

Les Joncacées et les Graminées alpines sont peu difficiles et se contentent de tous les terrains secs et légers, quelque maigres qu'ils soient. Les Garex aiment l'humidité.

\section{Fougères :}

Botrychium Lnnaria L. (calc.) Athyrium Rhaticum L.

Sol profond, riche en humus; soleil.

Woodsia hyperborea $\mathrm{R}$. Br. (granit.) 


\section{$-201-$}

Sol rocailleux, mélangé de débris granitiques.

Aspidium Lonchitis Sw. (calc.)

Polystichum rigidum D C. (calc.)

Sol léger, tourbeux; mi-ombre.

Cystopteris montana Lk.

- fragilis Bernh.

¿ alpina Lk.

Sol rocailleux; position ombragée.

Asplenium septentrionale Stv. (granit.)

Entre les fentes des rocailles granitiques; doit être plantée dans le sens vertical.

Asplenium Trichomanes L.

\ viride L.

„fontanum Bernh.

" Germanicum Weiss.

Scolopendrium vulgare Sm.

Sol rocailleux ; position ombragée.

Blechnum Spicant Roth.

Sol spongieux, léger; position ombragée.

Allosorus crispus Bernh.

Entre les pierres et les fentes des rocailles.

On remarquera que parmi les plantes mentionnées dans cette liste ne figurent pas les espèces annuelles. Celles-ci sont du reste fort rares parmi la flore alpine et n'offrent pas grand intérêt pour un amateur. Dans le chapitre con- 


\section{$-202-$}

cernant les Jardins alpins on trourera des renseignements plus précis au sujet de quelques espèces alpines qui exigent une culture spéciale.

\section{PLANTES DES DIFFÉRENTES RÉGIONS NIVALES DU GLOBE}

Dans un précédent chapitre, nous avons étudié les rapports qui existent entre la flore alpine et celle des autres montagnes. Il existe sous pres que toutes les latitudes des montagnes, des sommités élevées qui possèdent une flore analogue dans ses formes à celle de nos Alpes. Les phénomènes glaciaires se rencontrent sur des montagnes de l'Asie, de l'Amérique, de l'Océanie, aussi bien qu'en Europe. On retrouve là, dans les régions élevées et glacées, une régétation naine et rabougrie, s'étalant sur le sol et garnissant les fentes des rochers comme le fait la mousse en certains endroits rocailleux. Les conditions d'existence étant, dans ces régions, partout les mêmes, c'est-à-dire celles de nos contrées alpines, il serait inutile d'y revenir. Nous 
passerons seulement en revue les plantes que nnus offrent ces différentes régions et qui ont de l'intérêt comme plantes alpines. Ces espèces se trouvant, dans les catalogues des cultivateurs, toujours mélangées à la flore des Alpes proprement dite, il était bon de les séparer ici et d'établir leur origine. J'ai actuellement une collection de cent soixante Saxifrages, dont près de la moitié sont de provenance septentrionale ou américaine. C'est à peine si, sur cette grande collection de Saxifrages, quarante espèces appartiennent à la chaîne des Alpes. Toutes, sauf les espèces asiatiques, ont du rapport avec les nôtres et pourraient être considérées comme telles par les amateurs peu au courant de cette flore. Il est donc nécessaire de les distinguer ici; nous commencerons par les montagnes les plus rapprochées pour terminer par les contrées les plus éloignées de nous et ne nous occuperons que des espèces locales, non représentées sur les Alpes.

\section{PyréNÉEs :}

Aconitum pyrenaicum Lam.

Thalictrum glaucum Desf. Adonis pyrenaica $\mathrm{D}$ C. 


\section{$-204-$}

Aquilegia pyrenaica $\mathrm{D} \mathrm{C}$.

„ venosa Gouan.

Helleborus occidentalis Reut.

Sol profond, riche en humus; l'Adonide et l'Ancolie des Pyrénées préfèrent cependant les terrains rocailleux et bien drainés; exposition au soleil.

Meconopsis cambrica Vig.

Sol profond, riche en humus; ombre et fraîcheur.

Alyssum pyrenaicum Lap.

Draba levipes D G.

- contorta Ehr.

, nemoralis Ehr.

- pyrenaica L.

Aethionema pyrenaica Gay.

Sol rocailleux, peu profond et bien drainé : mi-soleil.

Iberis pyrenaica Lap.

" carnosa Lap.

, Garrexiana All.

Sol profond, fertile; soleil.

Helianthemum roseum D C.

Viola pyrenaica Ram.

Sol léger, peu profond, rocailleux; soleil.

Reseda glauca L.

Sol riche en humus, légèrement rocailleux; mi-soleil. 
Dianthus pyrenaeus Bernh.

Saponaria caespitosa D C.

1) bellidifolia Smith.

Silene ciliata Pourr.

Lychnis pyrenaica Berg.

Sagina filiformis Pourr.

Arenaria purpurascens Ram.

Sol léger, reu profond, rocailleux; soleil.

Moehringia pentandra Gay.

Sol léger, rocailleux; fraîcheur et mi-soleil.

Cerastium lanatum Lam.

Plante vorace, envahissante, propre à faire des bordures de jardin.

Hypericum Burseri D C.

Soleil; sol profond.

Geranium cinereum Cas.

Sol léger, un peu tourbeux, bien drainé; exposition au soleil.

Geranium pyrenaicum L.

Erodium Manescavi Bub.

Oxytropis pyrenaica G. G.

Geum pyrenaicum Ram.

Potentilla fruticosa L.

pyrenaica Ram.

„ alchemilloides Lap. 


\section{$-206-$}

Potentilla nivalis Lap.

Sol léger, riche en humus: soleil.

Rosa pyrenaica Gouan.

Ombre, fraicheur; sol rocailleux, profond.

Umbilicus sedoides D G.

Sempervivum Boutygnianum Sch.

Anacampseros Borderi Jord.

Sec.

Saxifraga longitolia Lap.

Cette reine des Saxifrages demande à être placée verticalement dans les rocailles; elle devient fort belle dans les murs.

Saxifraga maedia Gouan.

" $\quad$ aretioides Lap.
" caleo-purpurea Lap.
" calyclora Lap.

Soleil; sol léger, bien drainé et peu profond. Ces espèces aiment la position verticale; il faut donc les planter en biais dans les rocailles.

Saxifraga retusa Gouan.

Sol tourbeux, peu profond et drainé; exposition mi-soleil.

Saxifraga umbrosa L.

hirsuta L.

Geum L.

"Geum L.

" $\quad$ var. polita.
" var. dentata.




\section{$-207-$}

Sol fertile, un peu humide, mi-soleil; ces plantes peuvent être utilisées pour confectionner des bordures dans les jardins.

Saxifraga serrata Walk.

" atropurpurea Gaud.

" caespitosa L.

"grœnlandica L.

* exarata Will.

" intricata Lap.

" nervosa Lap.

" ajugaefolia L.

" capitata $\mathrm{L}$.

" adscendens Wahl.

" geranioides $\mathrm{L}$.

" ladanifera Lap.

" pedatifida Smith.

" pentadactylis Lap.

"decipiens Ehrb.

" sedoides $\mathrm{L}$.

ఎ aquatica Lap.

Eryngium Bourgati Gouan

Bupleurum pyrenaeum Gouan

Meum pyrenaicum Gay

Gaya pyrenaica Gaud.

Sol profond, fertile; soleil.

Asperula hirta Ram.

Sol léger, sablonneux; soleil. 


\section{$-208-$}

Valerianu globulariaefolia Ram.

" pyrenaica L.

Sol rocailleux; exposition à mi-soleil.

Scabiosa pyrenaica D C.

Aster pyrenaeus D C.

Santolina pectinata Benth.

Achillea pyrenaica Sibth.

Campanula pyrenaica A. D C.

Sol rocailleux, proiond; mi-soleil.

Gentiana Burseri Lap.

Sol profond, riche en humus; soleil.

Gentiana pyrenaica L.

Sol léger, peu profond et bien drainé: mi-soleil.

Ramondia pyrenaica Rich.

Cette superbe plante devient très belle lorsqu'on la place dans un plan incliné et dans une position ombragée. Elle veut un sol tourbeux et spongieux.

Antirrhinum sempervirens Lap.

Sol riche en humus, peu profond; aime les fentes des rochers.

Linaria pyienaica D G.

- linifolia Koch.

Erinus hirsutus.

Veronica longifolia L.

- Ponae Gouan

„ nummularia Gouan 
Sol peu profond, rocailleux: fentes des rochers.

\section{Lavandula pyrenaica D C.}

Sol profond et nourrissant; soleil.

\section{Horminum pyrenaicum L.}

Sol riche en humus; ombre.

Teucrium pyrenaicum L.

Sol peu profond, léger; soleil.

Androsace pyrenaica Lam.

$\searrow \quad$ cylindrica D G.
$\triangleright \quad$ ciliata D C.

Sol léger, sablonneux et richement drainé; il est bon de planter en biais, entre les fentes des rochers afin d'éviter la pourriture.

Primula glaucescens Moret.

Sol riche en humus: mi-soleil.

Globularia nana Lam.

Sol léger, peu profond: soleil.

Iris xyphioides Ehrh

Narcissus minor L.

moschatus L.

„bicolor 1 .

- Bulbocodium L.

\ intermedius Lois.

v juncifolius Req.

Fritillaria pyrenaica L.

Lilium pyrenaicum Gouan 
Scilla umbellata Ram:

- Lilio-Hyacinthus L.

Hyacinthus amethystinus $\mathrm{L}$.

Allium Moly L.

Merendera Bulbocodium Ram.

Sol profond, fertile; soleil.

Cévennes et montagnes du midi de la France:

Rcemeria hybrida D C.

Alyssum spinosum L.

》) argenteum Witm.

Frankenia leavis L.

Dianthus Balbisii Ser.

- Seguieri Will.

D subacaulis Lois.

ఎ saxatilis Pers.

Erodium malachoides Willd.

Paronychica polygonitolia D C.

" argentea Lam.

„ serpyllifolia D C.

Sol léger, peu profond; exposition au soleil. Saxifraga Clusii Gouan

* hubescens D G.

Fraicheur et sol riche $\in \mathrm{n}$ humus.

Eryngium spino-alba Vill.

Campanula speciosa Pourr. 
Sol profond; soleil.

Lithospermum fiuticosum $\mathrm{L}$.

- prostratum Lois.

Sol profond, léger, plutôt rocailleux; soleil.

Antivrhinum Azarina L.

Cette superbe plante aime un terrain sec, rocailleux et peu profond; soleil.

Daphne Gnidium L.

Sol profond, rocailleux, bien drainé; soleil.

Lilium pomponium $\mathrm{L}$.

Allium grandiflorum All.

Sol profond et fertile.

Aphyllanthes monspeliensis L.

Sol léger; soleil.

Montaganes de la Corse, de la Sardaigne ET DES BALÉARES :

Viola heterophylla Bert.

Sol frais et nourrissant; mi-soleil.

Arenaria Balearica L.

Exige les fissures de roches au frais et craint les excès de sécheresse et d'humidité.

Hypericum hircinum L.

„Coris L.

Potentilla divaricata D C.

- crassinervia Viv.

Sedum corsicum Duby. 
Sol profond, léger; soleil.

Saxitraga cervicornis Viv.

Sol frais, léger et peu profond; mi-soleil.

Saxitraga corsica Ser.

Sol tourbeux et humide: soleil.

Scabiosa grandiflora Scop.

Sol fertile, peu profond; soleil.

Bellium bellioides L.

¿ nivale Req.

" crassifolium Moris.

Sol peu profond, léger; mi-soleil.

Artemisia coerulescens L.

Aronicum corsicum DG.

Sol profond; soleil.

Linaria hepaticaefolia Duby

- alsinaefolia Spreng.

- tristis Mill.

- pilosa $\mathrm{DG}$.

Plantes de murailles, aimant le soleil et les fissures des rochers.

\section{Mentha Requienii Benth.}

Ombre et fraîcneur, sol peu profond, plutôt gravier ; cette charmante plante craint une trop grande humidité.

\section{Armeria juncea De Gir.}

1) fasciculata Willd.

Sol léger; soleil. 
Sierra Nevada et moxtagnes d'Espagne:

Reseda complicata Bory.

Sol léger; soleil.

Iberis Gibraltarica L.

Sol fertile, nourrissant; position abritée et chaude.

Lychnis Lagasce Hook.

Dans les fentes des rochers, au soleil.

Saxifraga cuneata Willd.

\ latifolia Don.

- tridentata Don.

- trifurcata Schrad.

- cantabrica Boiss. \& Reut.

" coniferae.

- Gibraltarica Ser.

Sol frais et léger; mi-soleil.

Erica carnea L. var. occidentalis.

Terre de bruyère; soleil.

Gentiana Boryi Boiss.

Sol profond, riche en humus et bien drainé; mi-soleil.

Erimus hispanicus Boiss. et Reut.

Entre les fentes des rochers.

Linaria villosa $\mathrm{DG}$.

- glacialis Boiss.

„nivea Boiss. et Reut. 


\section{$-214-$}

Linaria delphinoides Gay. Armeria filicaulis Boiss.

- crespitosa Boiss.

, villosa De Gir.

ఎ Duriaei Boiss.

" splendens Boiss.

- allioides Boiss.

Sol léger, sablonneux; soleil.

\section{ApenNins :}

Anemone apennina L.

Sol léger; mi-soleil.

Iberis Tenoreana DG.

Dianthus Balbisii Ser.

„ furcatus Balb.

Saponaria bellidifolia Smith.

Potentilla apennina Ten.

1) Bocconi Nest.

Sol peu profond, léger; soleil.

Saxifraga australis Moric.

- marginata Sternb.

„ depressa Sternb.

Sol léger, bien drainé; fentes des rochers; misoleil. 
Globularia incanescens Viv.

Campanula vesula All.

Sol léger, profond: soleil.

Campanula Garganica Ten.

Linaria pallida Ten.

") linifolia Chav.

Cyclamen hederaefolium Willd.

Sol léger; ombre.

Lithospermum graminifolium Viv.

Armeria denticulata Bert.

Daphne collina Smith.

Sol riche en humus; soleil.

\section{CARPathes :}

Dianthus petraeus V. \& $\mathrm{K}$.

Antennaria carpathica Bl. \& Fing.

Campanula carpathica L.

Soleil.

Gentiana carpathica K.

Sol léger, peu profond, tourbeux; soleil.

Alpes de la Daluiatie, Transylyaxie

et Turquie D'Europe :

Anemone albana Stev.

Campanula muralis Port.

$\rightarrow$ turbinata Schott.

Edrayanthus Kitaibelii DG. 


\section{$-216-$}

Edrayanthus temuifolius DG.

\begin{tabular}{|c|c|}
\hline D. & dalmaticus DLi. \\
\hline 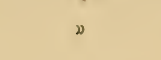 & serpyllifolius DG. \\
\hline & pumitio DG. \\
\hline Phyterma & globularicefolium Sternb. \& Hop \\
\hline D & persicefolium Hop. \\
\hline 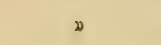 & tenuifolium A. DG. \\
\hline 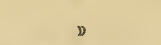 & canescens W. \& K. \\
\hline
\end{tabular}

Ces différentes Campanulacées se cultivent au sec, dans un sol bien drainé ou mieux, entre les fentes des rochers, au soleil. La Camp. turbinata seule fait exception et réussit dans le sol des jardins où elle est quelquefois cultivée en pleine terre.

\section{Lithospermum petraeum A. DG.}

Sol profond, fertile; soleil.

Janthe bugulifolia.

Sol profond, tourbeux; soleil.

Veronica Baumgartnerii Rœm. \& Schult. Armeria canescens Boiss.

Sol léger; soleil.

Cyclamen coum Mill.

Sol frais, riche en humus; mi-ombre.

Daphne Blagayana Frey.

Gette superbe plante demande un terrain léger, composé d'un tiers de terreau de feuilles, d'un tiers de terre de bruyère et d'un autre tiers 


\section{$-2217-$}

de morceaux de pierres calcaires et de sable. Il est bon de recouvrir ses longues tiges rampantes et trainantes avec de la mousse et des pierres.

Grèce et Iles de L'Archipel :

Anemone pusilla DC.

"biflora DC.

Aquilegia Olympica Boiss.

Papaver Heldreichii Boiss.

Draba Olympica Sibth.

Aubrietia deltoidea DG.

Dianthus leucopheeus Sibth. \& Sm.

- stricius Sibth. et Sm.

»Potentilla speciosa Will.

Eryngium multifidum Sibth.

, Athoum DG.

Umbilicus Samius DC.

Campanula pelviformis Lam.

$$
\text { Vanneri Rochel. }
$$

Phyteuma repandum Sm.

Veronica erinoïdes Boiss.

- Thessalica Benth.

1) caspitosa Boiss.

Armeria undulata Boiss.

Ir is reticulata Biet.

- tuberosa Vahl. 


\section{$-218-$}

Toutes ces plantes, sauf Campanula Vanneri et Potentilla speciosa qui aiment la position verticale entre les fenies des rochers, s'accommodent d'un sol léger, nourrissant et d'une posiau soleil.

\section{Caucase :}

Trollius caucasicus Stev.

Dianthus fragrans Bieb.

,

- caucasicus Sims.

) montanus Bieb.

- versicolor Fisch.

" capitatus DG.

Arenaria rotundifolia Bieb.

- imbricata Bieb.

Silene Schafta Gmel.

Astrantia Biebersteinii Trautr.

Eryngium planum Math.

Saxifraga Merkii Fisch.

Sedum involucratum Bieb.

" roseum Stev.

" oppositifolium Sims.

- pilosum Bieb.

„ spurium Bieb.

Doronicum caucasicum Bieb.

Campanula lamiifolia Bieb. 


\section{$-219-$}

Campanula ciliata Stv.

" sarmatica Ker.

Pytheuma pulchellum Fisch \& Mey.

Rhododendron cancasicum Pall.

Gentiana gelida M.Bieb.

Primula auriculata Lam.

Linaria rupestris G.A Mey.

„odora M. Bieb.

Veronica caucasica Bieb.

D peduncularis Bieb.

1) petroxa Stev.

- gentianoïdes Vahl.

Betonica grandiflora Willd.

Iris caucasica Bieb.

Tulipa tricolor Led.

Sol profond, léger, rocailleux.

Draba brunirefolia Stev.

Saxifraga cartilaginea Willd.

- laevis Bieb.

๖ juriperina Adams.

Umbilicus Sempervivum DC.

Niches petites, peu profondes, bien drainées; ou mieux encore fentes des rochers. Exposition au soleil.

\section{ORIENT ET LiBan :}

Aconitum Tauricum Rgl. 
Papaver pilosum S. \& Sm.

$>$ spicatum Boiss. \& Reut.

Draba pulchella Willd.

Aethionema cordifolia DG.

" ovalitolia Boiss.

Aubrietia macrostyla Boiss.

Arenaria rupestris Lab.

Cerastium Biebersteinii DG.

Dianthius multipunctatus Ser.

v Tymphresteus Held, et Sarb.

Saxitraga cymbalaric L.

- orientalis Jacq. (humidité et ombre).

Umbilicus Librnoticus DG.

- chrysanthus Boiss.

Phyteuma Sinaï DC.

" campanuloides Bieb.

\) lanceolatum Willd.

» amplexicaule Willd.

- Aucheri DC.

Primula Boveana Desc.

) crassifolia Lehm.

Cyclamen coum Mill.

Gregoria aretioides Duby

) ccespitosa Duby

Androsace odoratissima Schreb. 
Globularia trycosantha F. \& M.

Gentiana septemfida Pall.

Linaria corifolia Desf.

Veronica pectinata $\mathrm{L}$.

- polifolia Benth.

Acantholimon venustum Boiss.

1) glumaceum Boiss.

D roseum Boiss.

Cliionodoxa Lucilice Boiss.

Sol peu profond, léger, pierreux; soleil.

Omphatodes Lucilio Boiss.

Cette superbe Borraginée se cultive entre les fentes des pierres et des rochers exposés au soleil. Elle craint l'łıumidité.

Geum coccineum S. \& Sm.

Eryngium giganteum Bieb.

Campanula Damascena Lab.

Sol profond, fertile; soleil.

\section{Montagnes du Turkestan :}

Umbilicus Semenovii Herd.

Dracocephalum integrifolium Bnge.

Acantholimon alatavicum Bnge.

Colchicum luteum Baker.

Tulipa Greigi Rgl.

" Kolpakowstiana Rggl. 


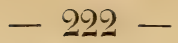

Iulipa Turkestanica Rgl.

Evemurus Olgae Rgl.

„ Turkestanicus Rgl.

Chaîne des Monts Himalaya:

Anemone vitifolia Buch.

Aquilegia fragrans Benth.

Saxifraga diversifolia Wall.

- Mooreroftiana Wall

" glandulosa Wall.

„ brachypoda Don.

- hispidula Don.

" ramulosa Wall.

» serrata Hook.

Campanula aristata Wall.

Mazus rugosus Lour.

Veronica cana Wall.

1) capitata Royle.

Omphalodes longiflora A. DC.

Gentiana depressa Don.

" venusta Wall.

Primula denticulata Sm.

D) involucrata Wall.

- purpurea Royle

1) capitata Hook.

"reticulata Wall.

- rosea Royle 
Androsace lanuginosa Wall.

¿ sarmentosa Wall.

Sol peu profond, riche en humus; soleil. Les Primula et les Androsaces préfèrent l'exposition du levant ou du couchant. Comme ces dernières sont très sarmenteuses et augmentent rapidement, il sera bon de les placer dans des endroits où elles puissent se développer et retomber en suspendant leurs branches le long des rochers.

Anemone rivularis Buch.

Aquilegia lutea Hort.

Meconopsis Nepalensis D.C.

Saxifraga ligulata Wall.

Sol profond, fertile; mi-soleil.

\section{Altaï :}

Aquilegia glandulosa Fisch.

- lactiflora Kar.

Trollius altaicus C.A. May.

Viola altaica Pall.

Papaver croceum Ledeb.

Sedum Asiaticum DC.

Campanula altaica DC.

Veronica incana L.

Dracocephalum grandiflorum $\mathrm{L}$.

- Altaïense Laxm. 


\section{$-224-$}

\section{Primula nivalis Pall.}

Sol profond, fertile; mi-soleil.

Sibérie, Daourie et Kaitschatia:

Atragene Sibirica Fisch.

Anemone dichotoma L.

D dahurica Fisch.

"patens L.

Adonis Wolgensis Stev.

Aquilegia arctica Hort.

i) atropurporea W. En.

- viridiflora Pall.

- ccerulea James

" formosa Fisch.

" fragrans Lindl.

" glauca Lindl.

" hybrida DG

, jucunda F. et M.

) leptoceras F. et M.

" Sibirica Lam.

Trollius asiaticus L.

„ dschungaricus Rgl.

Papaver nudicaule L.

Draba glacialis Adams.

Geranium Sibiricum 1.

Dianthus dentosus Fisch.

Silene Zawadskyi Herb. 
Umbilicus spinosus DG.

Sedum Aizoon L.

1) populifolium L.

" stenopetalum Pursch.

"Kamtschaticum Fisch. et Mey.

Saxifraga crassifolia L.

) cordifolia Haw.

„Kolenachiana Rgl.

Adenophora coronata A. DG.

, latifolia Fisch.

Mertensia sibirica G. Don

Dracocephahum grandiflorum $\mathrm{L}$

$\quad$ Argunense Fisch.

Gentiana macrophylla Pall.

Primula cortusoides $\mathrm{L}$.

Cortusa grandiflora $\mathrm{Rgl}$.

Allium azureum Ledeb.

Sol profond, riche en humus; mi-soleil.

Le Jardin alpin d'acclimatation a reçu de $\mathbf{M}$. le $\mathrm{D}^{\mathrm{r}} \mathrm{E}$. Regel, à Saint-Pétersbourg, une superbe et riche collection de graines provenant des contrées ci-dessus mentionnées. La plupart de ces semis ont bien réussi et viendront enrichir les collections alpines des amateurs. 


\section{Chine et Japon:}

Corydalis nobilis Pers.

Epimedium roseum Hort.

) niveum Hort.

») violaceum Morr. \& Dosne.

Campanula nobilis Lindl.

Primula japonica A. Gray.

Sol poreux et riche en humus. Exposition légèrement à l'ombre.

Saxitraga sarmentosa L.

๖ japonica Sieb.

Sedum sarmentosum Bge.

Plantes sarmenteuses, prenant un grand développement dans les rocailles; elles aiment la fraîcheur et un peu d'ombre.

Régions Scandinaves et Argtiques:

Draba borealis DG

- muricella Wahl.

1) alpina $\mathrm{L}$

- rupestris $\mathrm{Br}$.

- nivalis Willd.

1) Laponica Willd.

Arenaria arctica Stev.

Potentilla nivea L.

"nana Schlecht.




\section{$-227-$}

Saxifraga coespitosa L.

D spontemica Rgl.

$\rightarrow \quad$ arctica Ser.

hyperborea R. Br.

, rivularis $\mathrm{L}$.

" flagellaris Willd.

¿ elongella Ser.

" Siernbergi Rgl.

Sol profond, bien drainé, pierreux, mélangé de sable et d'humus; levant ou couchant.

Rubus arcticus $\mathrm{L}$.

Sol pierreux, tourbeux, contenant des pierres et du Sphagnum; soleil. Il a fleuri abondamment dans notre Jardin d'acclimatation.

\section{AMÉRIQUe BorÉale :}

Meconopsis diphylla DG.

Viola pedata L.

„ palmata L.

Potentilla tridentata Soland.

Tellima grandiflora Lindl.

Saxifraga bronchialis L.

* tricuspidata Retz.

- groënlandica L.

- fimbriata Don.

- pectinata Pursh. 


\section{$-228-$}

Empetrum rubrum A. DC.

Gentiana sceptrum Griseb.

Primula borealis Duby

Sol léger, bien drainé, mélangé de sable et d'humus; levant ou couchant.

Montagnes Rocheuses et Amérique Septentrionale:

Anemone virginiana $\mathrm{L}$. Aquilegia canadensis L.

1) Chrysantha A. Gray.

Delphinium medicaule Torr. \& Gray

Trollius americanus NI. \& G.

Dielytra formosa DG.

Stellaria elongata Nutt.

Dryas Drummondi Hook.

Geum triflorum Pursh.

Potentilla villosa Turth.

Waldsteinia fragarioides Tratt.

Saxifraga arguta Don.

- erosa Pursh.

» Fischeri Ser.

- Virginiensis Michx.

" Pensylvanica L.

Sedum pulchellum Michx.

Tiarella cordifolia L.

Mitella diphylla L. 
Mitella cordifolia Lam.

Heuchera americana L.

) villosa Michx.

Sedum pulchrum Michx.

„ ternatum Michx.

Erigeron glabellus Nutt.

Mertensia paniculata G. Don.

DVirginica D C.

Phlox canadensis Hort.

" glaberrima L.

- ovata L.

»Phlox procumbens Lehm.

1) pilosa L.

- reptans Michx.

" subulata L.

- ccespitosa Nutt.

"humilis Nutt.

Polemonium reptans. L.

Romanzoffia Sitchensis Gham.

Sol fertile; exposition au soleil.

Viola canadensis L.

Trillium grandiflorum Salisb.

Dodecatheon Meadia L.

D

Jeffrayanum Hort.

" integrifolium Michx.

Gentiana Andrewsi Griseb.

) Saponaria L. 


\section{$-230-$}

Gentiana affinis Griseb.

Asarum canadense L.

Erythronium americanum Ker.

¿ $\quad$ albidum Nutt.
grandiflorum Pursh.

Sol tourbeux, frais; mi-ombre.

Galax aphylla L.

Parnassia asarifolia Vent.

1) caroliniana Michx.

1) fimbriata Banks.

Cypripedium candidum W.

D) acaule Ait.

* spectabile $\mathrm{Sw}$.

1) montanum DougI.

" macranthum Sw.

- pubescens W.

Sarracenia purpurea L.

Voir aux cultures spéciales.

Andes de L'AMÉRIQUe DU

Aquilegia Skinneri Hook.

Calandrinia umbellata DC.

Saxifraga andicola H. B. \& Kunth.

, Pavoni Don.

- stellata Don.

Gentiana foliosa Kunth.

» hirculus Griseb.

Sol profond, riche en humus; soleil. 
Australie, Tasmanie, Nouvelle-Zélande:

Erpetion reniforme Spr.

Gentiana Diemensis Griseb.

Sol tourbeux; mi-ombre.

Mazus pumilio $\mathrm{Br}$.

Veronica nivea Lindl.

๖ Gunnii Benth.

Sol léger ; soleil.

\section{Montanges de l'Atlas:}

Viola Cornuta L.

"Munbyana Hort.

Saxifiaga globulifera Desf.

Sol frais: position légèrement ombragée.

On le voit, plus on s'éloigne des contrées exploitées et connues, moins le nombre des espèces introduites dans les cultures est considérable.

Il est des contrées montagneuses d'une grande richesse dont aucune espèce n'est encore cultivée. Les Andes de l'Amérique du Sud sont fort peu explorées; elle contiennent cependant une riche collection de Gentianes et de Saxifrages d'entre les plus belles. Il en est de même des montagnes de l'Océanie; là le genre Veronica est richement représenté et nous y retrourons aussi de fort jolies Gentianes. C'est un champ très 
vaste, ouvert à l'activité des voyageurs botanistes et des explorateurs horticoles.

Chez les espèces qui donnent de la graine on reproduit facilement la plante par le moyen du semis; malheureusement un grand nombre de celles qui appartiennent aux contrées lointaines restent stériles. Cela tient au fait que les insectes appelés à provoquer la fécondation chez ces espèces-là, manquent dans notre pays. Si on parvenait à les y introduire il est probable que les fleurs deviendraient immédiatement fertiles. Les insectes, comme aussi les vents, exercent une très grande influence sur la végétation. Ils sont les plus puissants auxilliaires de la nature dans la fécondation des fleurs. Schleicher, Darwin et d'autres naturalistes ont fait des découvertes remarqua. bles à ce sujet. Nul n'ignore que les oiseaux mouches sont les uniques causes qui provoquent la fécondation chez la plupart des orchidées épiphytes. Les papillons, les mouches, les abeilles et les bourdons sont nécessaires à la flore alpine et sans eux il est probable que bon nombre d'espèces ne produiraient pas de graines. On a souvent remarqué dans les jardins où se trouvent de grandes collections alpines la présence des papillons et d'insectes alpins. Il est donc permis de supposer qui si les entomologues pouvaient 
introduire chez nous les insectes des contrées lointaines dont ces plantes stériles sont originaires, on verrait celles - ci porter graines et se reproduire chez nous. Celles d'entre ces plantes qui ne se reproduisent pas par graines sont par contre très rameuses et drageonnantes et se multiplient facilement par boutures ou rejetons. Fiest le cas pour tous les Phlox américains, les Saxifrages, les Androsaces de l'Hymalaya, les Composées de la Sibérie et beaucoup d'autres encore.

\section{LES ROGAILLES.}

Leur apparition dans nos jardins. - Les rocailles du Jardin botanique de Genève. - Gelles de Valeyres. Emplacement à choisir. - Travaux préliminaires. Construction. - Sentiers. - Orientation. - Nature des matériaux à employer. - Formes à donner aux rocailles.

L'idée de cultiver les plantes de montagnes dans des rochers artificiels et d'utiliser ceux-ci pour la décoration des parcs et jardins, n'est pas très ancienne. Elle paraît nous être venue d'Angleterre où depuis fort longtemps on a l'habitude de ces con- 


\section{$-234-$}

structions rustiques et pittoresques. Ce n'est guère que depuis une quarantaine d'années que nous avons commencé ici à faire des rocailles $\in t$ je ne pense pas être éloigné de la vérité en attribuant à M. Ed. Boissier les premières tentatives de ce genre. Ciest bien lui, en tous cas, qui a commencé dans notre pays les cultures dans des rochers artificiels. Il n'y a pas vingt ans que Reuter, inspiré par celles de Valleyres, construisit la première rocaille au jardin botanique. Dans son rapport, lu en 1818 dans l'orangerie du jardin, M. de Candolle mentionne des plates bandes ombragées qu'il avait fait établir dans le but spécial d'acclimater et de cultiver les plantes de montagnes. On les cultivait alors à l'ombre, dans des endroits frais et sombres ce qui ne léur permettait pas de vivre bien longtemps.

Dans ces dernières années le goût des constructions rustiques et des rocailles s'est extrêmement développé chez nous; nous rencontrons maintenant peu de propriétés d'agrément qui n'aient des rochers artificiels. Deux causes différentes en provoquent la formation; tandis que pour les uns ces constructions rustiques n'ont qu'un but purement décoratif et ornemental, pour d'autres au contraire, elles ne sont que le cadre qui doit recevoir un tableau, 
le canevas sur lequel se brodera un tapis de fleurs. C'est à ce dernier point de vue seulement que nous allons en étudier la construction, les questions purement artistiques n'entrant dans notre sujet que d'une manière indirecte.

L'emplacement à choisir, lorsqu'on veut établir une rocaille, dépend beaucoup de la position du terrain, de la nature du pays et de celle de la température. Généralement on a l'habitude de placer ces constructions à l'ombre des arbres, à l'humidité; ou bien on les relègue dans une cour sombre et peu éclairée. C'est un tort; nous avons vu à la page 77 qu'il faut, pour ces cultures, le plus de lumière et d'air possible. Le voisinage des arbres offre en outre cet inconvénient que les racines des espèces arborescentes viennent s'infiltrer dans les rocailles dont elles absorbent le meilleur du terrain. Si l'on ne peut éviter ce voisinage, il faut alors intercepter les racines des arbres par un mur souterrain. Il faut chercher un endroit découvert, exposé à l'air et au soleil. Si un emplacement pareil se trouve près d'une pièce d'eau, c'est là qu'on placera de préférence sa construction. Les rocailles du jardin botanique de Genève se trouvenl précisément dans les plus mauvaises conditions possibles et dans un 
emplacement défavorable aux cultures alpines. Les grands arbres qui les entourent, l'humidité constante de cet endroit et le manque de circulation de l'air permettent le développement d'un grand nombre de mousses et de lychens qui tuent la végétation alpine. Les champignons s'y développent de toutes parts et mainte touffe de Saxifrage ou d'Androsace a déjà péri, étouffée par les parasites. Le voisinage si immédiat du kiosque rend impossible tout développement ultérieur de ces constructions et en condamne nécessairement l'existence. Il est fâcheux que le Conseil administratif de la ville de Genève n'ait pas cru devoir obtempérer aux désirs des amateurs de plantes alpines et développer la région des rocailles en lui consacrant la place que ce développement exigeait. Le peu d'intérêt qu'a témoigné ce Conseil pour les questions botaniques, autrefois si vénérées à Genève, a été mal accueilli du public éclairé de notre ville qui n'a pas attendu longtemps pour prouver son attachement aux rieilles traditions genevoises en fondant un jardin spécialement destiné aux cultures alpines. Là se construisênt dans de bonnes conditions des rocailles qui permettront de développer chez nous le gout et la connaissance de ces cultures. 


\section{$-237-$}

C'est à Valeyres, dans le jardin botanique de M. Boissier, qu'il faut aller pour trouver des rocailles bien construites et bien exposées. Pas un arbre, pas un arbuste n'interceptent les rayons du soleil qui, dans la plus grande partie du jardin, dardent sur les plantes, du matin jusqu'au soir. Les rochers forment trois terrasses différentes, superposées les unes aux autres et qui font involontairement songer à celles de Sémiramis. La première de ces terrasses est complètement entourée de murs, hauts de 3 mètres à peu près. Les autres sont plus ouvertes aux vents mais n'en sont pas moins exposées au soleil. Les plantes y réussissent admirablement et dans les mois d'avril, de mai et de juin les rochers y sont couverts des fleurs les plus diverses, appartenant aux zones les plus variées et aux montagnes les plus éloignées $\left({ }^{1}\right)$. Il va sans dire que les plantes d'Orient et d'Espagne y dominent puisque ce sont ces pays que le maître du lieu a explorés d'une manière particulière. Les Rhododendron, les Soldanelles fleurissent là côte à côte arec les plantes du Liban, de la Turquie, de l'Himalaya, de l'A mérique septentrionale et méridionale,

(1) J'ai vu là, il y quelques années, plusieurs papillons appartenant aux zones alpines, qui voltigeaient parmi les fleurs de montagnes. 
de la Tasmanie. Plusieurs d'entre elles se sont vulgarisées dans les environs de Valeyres et se retrouvent dans les murs ou les endroits rocheux de ce village.

Ainsi, en plein vignoble, au pied du Jura, dans l'une des parties les plus chaudes du canton de Vaud, nous constatons l'existence d'un jardin alpin en pleine prospérité et nous y voyons fleurir les espèces les plus délicates de nos Alpes comme celles des contrées plus chaudes. Quelquesuns s'en étonnent; mais pour ceux qui connaissent la situation de ce village, la chose est moins surprenante. Bien que situé au pied du Jura et sur du calcaire, le soleil n'est pas, dans cet endroit, aussi brûlant et desséchant qu'on pourrait le croire. Ici, comme dans les Alpes, une forte humidité est répandue dans l'air qui, tout en favorisant le développement des plantes et des fleurs, permet aux rayons du soleil d'exercer leur influence sans nuire aux organes délicats des espèces alpines. L'eau ruisselle de tous côtés et sature l'air a'humidité pendant une partie de l'année. C'est ce qui fait que, dans cette région chaude, richement ensoleillée, on ne rencontre pas la flore du Valais ou du midi de la France. Cette végétation grisâtre et rabougrie est remplacée ici par celles des contrées fertiles du centre 
européen. Les plantes alpines s'y trouvent chez elles et s'y développent merveilleusement bien. L'air sec est préjudiciable à ces plantes, aussi est-il toujours bon, lorsqu'on peut le faire, de placer les rocailles dans le voisinage des pièces d'eau ou d'établir dans la rocaille un système d'irrigation quelconque. C'est ce qu'a très bien compris l'habile inspecteur du jardin botanique de Zurich, M. Ortgies, qui a construit dans cet établissement de vastes et beaux rochers dans lesquels l'eau ruisselle de plusieurs côtés.

Après avoir choisi son emplacement, on creusera le sol sur lequel on doit établir la rocaille et on remplira le creux établi, de scories de coke (mûchefer) ou de toute autre matière sèche, qui permette à l'eau de s'écouler facilement et cons. stitue un bon drainage pour la rocaille. Cette opération a en outre l'avantage d'empêcher dans la rocaille, l'introduction des animaux rongeurs tels que rats, souris, taupes etc., qui y causent de grands dégats. On se procure le mâchefer dans toutes les usines qui brûlent du coke; les personnes qui font emploi de ce combustible et qui possèdent des jardins, feront bien d'en réserver tous les détritus, qui sont extrêmement utiles dans les cultures.

Une fois cette base bien établie on formera la 


\section{$-240-$}

carcasse de sa construction, c'est-à-dire qu'on fera avec des scories si l'on en possède assez, ou avec des détritus de pierres, de gravier, de plâtre, avec de la terre si l'on ne peut faire autrement, un amoncellement auquel on donnera à peu près la forme que devra revêtir la rocaille. Il faudra, dans tous les cas, que ce tas soit recouvert d'une couche de terre végétale assez épaisse pour que les plantes à racines très longues et pivotantes puisse y trouver leur subsistance. Il sera bon d'arroser beaucoup afin que le tout se tasse et se presse de façon à ne plus bouger une fois la rocaille terminée. Il est même nécessaire, pour les grandes constructions, de laisser la carcasse exposée à l'air et à la pluie, pendant un certain temps avant de commencer le cimentage. On commence alors par établir la base en entourant le pied de la montagne, d'une bordure de pierres, d'entre les plus grosses et les plus massives. Puis on élève sa construction en ayant soin d'établir dans le bas de la rocaille, les niches les plus grandes et les plus profondes. Le haut sera réservé pour les plantes saxatiles et renfermera nécessairement des niches plus petites et plus étroites. C'est là qu'il faut surtout réserver des fentes et de profondes fissures entre le blocs de pierres afin que les espèces des rochers puis- 
sent y vivre commodément. Les niches de la base seront réservées aux Gentianes, Soldanelles, Viola, Myosotis, Potentilles, Primevères et à toutes ces plantes qui garnissent les pâturages et les pentes herbeuses de nos montagnes. Dans la partie supérieure, on placera les Saxifrages à feuilles épaisses, les Joubarbes, les Sedum, les Androsaces, les Draba, l'Edelweiss, etc.

Il faut, lorsqu'on construit une rocaille, avoir soin de l'orienter de manière à ce que les deux faces qui sont le plus étendues regardent l'est et l'ouest, tandis que les plus étroites seront disposées au midi et au nord. Du côté du sud, on plantera les Joubarbes, Sedum, Opuntia, Paronichia, Calandrinia, Linaria pallida et hepaticaefolia, certaines Armoises (Artemisia) et Achillées, les Armeria et les Statice. Au nord, on placera les fougères, les Lycopodes, les mousses et les plantes demandant beaucoup d'ombre, telles que : Asa. rum europeum, Cardamine resedifolia, Circaea alpina, Viola biflora, Moehringia muscosa, Saxifraga cuneifolia, Hacquetia Epipactis. Mais la grande majorité des espèces alpines devra être placée sur les flancs est et ouest de la rocaille, exposées à la pleine lumière, mais préservées des rayons trop brûlants du soleil.

Le meilleur système à employer pour la cul- 
ture des plantes alpines est celui des petits rochers parsemés ici et là dans un jardin, posés de différentes manières et formés de pierres de diffé. rentes natures. M. W. Robinson, dans son ouvrage si important sur la confection des rocailles, recommande que les fentes que l'on établit entre les pierres soient toujours plus larges en haut qu'en bas et aillent en se rétrécissant vers le centre et en s'ouvrant vers la surface, ceci dans le but de former des crevasses dans lesquelles la terre puisse se tasser. Il arrive en effet fréquemment qu'on fabrique des rocailles dans les niches desquelles il est difficile de faire pénétrer de la terre parce que l'orifice est plus étroit que le fonds. L'auteur des "Alpine flowers " recommande en outre qu'on dispose les niches de manière qu'elles reçoivent la pluie, et que la pierre supérieure soit en retrait sur l'inférieure. Si la pierre supérieure, comme c'est souvent le cas, surplombe et recouvre la terre il arrivera naturellement que la plante se desséchera, parce qu'elle ne pourra être mise au bériéfice de l'humidité atmosphérique. Il est cependant quelques espèces de plantes qui demandent une pareille position; elles sont rares et ne rentrent pas positivement dans la catégorie des plantes alpines. Lorsqu'on construira une rocaille, on s'arran. 
gera donc toujours de manière à ce que la surface des niches et des fentes de rochers soit exposée à la pluie. Les niches de la base qui, comme je l'ai dit plus haut, seront les plus graniles et les plus larges, devront être plates et former de petites corbeilles de plantes alpines. Plus haut, les niches se rétrécissent et pourront prendre une position oblique; on $\mathrm{y}$ placera les espèces qui aiment le sec et demandent peu de terre. Plus haut viennent les fissures dans lesquelles on place les espèces purement saxatiles. Ces fissures devront être profondes et aussi nombreuses que possible. On les remplira d'un sol composé de débris de roches ou de cailloux, de terre franche, terreau de feuilles et de terre de bruyère. Les plantes saxatiles enfoncent leurs racines naturellement très profondément dans le roc, et il faut qu'elles puissent retrouver la facilité de le faire dans les rocailles artificielles.

Il est nécessaire, pour les grandes constructions, d'ètablir des sentiers qui parcourent la rocaille et permettent de la soigner et de l'arroser dans toutes ses parties. Ces sentiers auront une forme pittoresque et seront remplacés, dans les parties escarpées, par des escaliers formés avec les blocs naturels dont se compose 
la rocaille. Quant aux pierres à employer pour sa construction, il va sans dire que le calcaire est préférable dans la grande majorité des cas. J'ai supprimé l'an dernier, au Jardin Botanique, une des deux rocailles de granit qui se trouvaient dans le carré des plantes alpines, ces deux rochers n'offrant qu'une végétation pauvre et peu vigoureuse. Une fois le granit remplacé par le calcaire, on vit bientôt la végétation alpine se développer d'une manière surprenante et fleurir mieux qu'auparavant. La rocaille granitique qui a été conservée est spécialement réservée aux plantes de nature anti-calcaire. Les pierres de notre Salève, ou mieux encore celles de toute la chaine du Jura, sont particu. lièrement propres à la construction des rocailles. Leurs formes naturelles, leur aspect pittoresque donnent du charme et de l'élégance aux rochers alpins. Il faut éviter, autant que possible, la molasse et les grès qui n'offrent aucune prise à la végétation et lui sont peu favorables. Les granits, les ardoises, les schistes de différentes espèces trouveront leur place dans la rocaille afin d'y recevoir les plantes qui ont de l'affinité pour eux. Le tuf est lui-même très favorable à la végétation; sa nature sèche et poreuse offre cet avantage qu'il absorbe l'eau dans les temps de 


\section{$-245-$}

pluies et qu'il la rend petit à petit au terrain lorsque celui-ci en manque. Mais il a de grands inconvénients qui font qu'il n'est guère recommandable autrement qu'au point de vue décoratif et pittoresque. En effet, ses nombreuses fissures et ses innombrables trous se remplissent petit à petit d'herbes de toutes espèces qu'on ne peut détruire, parce que, pour les arracher avec leurs racines, il faudrait enlever le tuf; la mousse s'y met aussi très facilement. Il faut encore remarquer que le temps le noircit, et qu'au bout de peu d'années une grotte en tuf prend un aspect sombre et noirâtre qui négaye plus le paysage. On a fait des rochers artificiels en scories de coke agglomérées, mais ce système peu naturel n'est excusable que dans les pays où la pierre manque.

En général, ce qu'il faut chercher à obtenir lorsqu'on établit une rocaille, c'est une construction se rapprochant le plus possible de la nature. On peut utiliser dans ce but les pentes de terrain, les talus, les bords des massifs, les murs et les diverses sinuosités du sol dans les grands parcs.

Le cimentage d'une rocaille doit se faire de manière qu'on n'aperçoive pas le ciment; c'est une habitude qu'on acquiert par l'expérience. 
Le meilleur moment pour procéder à ces travaux est le printemps et l'automne jusqu'aux premiers jours de novembre, mais si l'on retardait trop et que le gel surprit une rocaille fraîchement construite on verrait celle-ci se fendre et le ciment se désagréger.

Quelcques amateurs ont reproduit en rochers. artificiels les montagnes du pays qu'ils habiient. Nous avons à Genève des monts Salèves en miniature dans certains jardins; on rencontre aussi la chaîne de Pithons et d'autres montagnes encore. Au Jardin Botanique d'Innsbrück, les rocailles forment huit groupes différents et sont disposées de façon à représenter, par leur forme et leur composition géologique, les huit massifs du Tyrol. La nature de leurs roches correspondant à celle des montagnes qu'elles représentent, on conçoit qu'il soit facile d'y cultiver la même flore. Cette disposition offre un grand avantage dans les jardins scientifiques exposés au public. Celui-ci peut, de prime abord, se faire une idée de la distribution géographique et géologique des plantes.

Les personnes qui voudraient construire elles-mêmes des rocailles feront bien de consulter l'ouvrage de M. Robinson, déjá mentionné 
ici et intitulé Alpine flower's $\left({ }^{1}\right)$. Cependant, étant donnée l'importance du bon établissement d'un rocher au point de vue des cultures, je crois devoir recommander aux personnes qui n'ont pas la pratique de la chose de s'adresser ì un constructeur spécial. Elles ont tout à gagner en portant leur attention sur ce point, car le manque de réussite des cultures alpines provient généralement des défectuosités d'une rocaille mal faite.

\section{JARDINS ALPINS}

Cultures alpines en plates-bandes, - à l'humidité, - au sec, - sous les arbres, - dans les gazons. - Fougeraies. - Plarites aquatiques et marécageuses. - Culture dans les vieux murs. - Traitement spécial à donner à quelques espèces.

Quelques amateurs de plantes alpines ont réussi dans leurs jardins une si grande quantité de ces plantes qu'ils en sont arrirés à avoir en plaine un véritable jardin alpin. Là, les végétaux des Alpes ne sont plus seulement confinés dans les rocailles, mais ils sont répandus dans

(1) Londres, librairie John Murray. 


\section{$-248$}

toute la campagne et disposés d'après leurs exigences. Les plantes des marécages bordent un ruisseau ou garnissent un petit marais artificiel, celles des parties ombrées sont dans les situations ombragées tandis que les plantes des régions sèches et ensoleillées garnissent les parlies sèches du terrain. Les plantes des Alpes peuvent être, en effet, disposées et utilisées de bien des manières différentes et il n'est pas toujours besoin d'avoir une rocaille pour les cultiver. J'ai fait en automne 1S83, au Jardin Botanique, un essai de culture en pleine terre lequel m'a parfaitement réussi. Dans une plate-bande exposée au soleil et dont le sol était formé d'un tiers de sable, un tiers de terreau de feuilles avec un autre tiers de terre naturelle qui formait la plate-bande, jai planté une collection très variée de plantes alpines appartenant surtout à la zone inférieure de toutes les parties des Alpes. Cette plate-bande a été recouverte avant l'hiver de branches de sapin, qui n'ont été enlevées que dans le mois de mars. Or, chacun a pu admirer la beauté de ces plantes qui ont fleuri plus richement et plus abondamment que dans les rochers du dit jardin, placés il est vrai dans une mauraise situation. Un grand nombre de plantes alpines, celles surtout qui appartiennent à 
la zone des pâturages, peuvent se cultiver de cette manière.

Avez-vous de grands cèdres ou des arbres dont les branches se trainent sur le sol? Le gazon y est rare et peu prospère; profitez-en pour y planter des espèces sauvages. Là les Pervenches, les Scilles, les Ciyclamens, les Dentsde-Chien vous donneront une belle floraison et vous n'aurez pas de peine à transporter vos visiteurs en imagination dans les bois et les taillis, à vingt lieues des villes et du bruit du monde. Vous possédez une pelouse bien verte, bien propre, très régulièrement fauchée et arrosée; c'est bien; laissez-la telle aux environs immédiats de votre habitation; mais, de grâce, donnezlui un peu de relief dans le reste de la campagne et animez-la de quelques fleurs. Faites descendre là, comme sous les arbres, la nature alpine et montagnarde; plantez-y des Narcisses, des Jonquilles, des Tulipes sauvages, des Perce-Neige et tant d'autres fleurs des champs qui vous égayeront la vie et vous parleront de paix et de simplicité. Ne craignez pas de placer là les Orchidées des prés, des pâturages et des pentes herbeuses. Les Ornithogales, les Fritillaires, les Campanules, les Ancolies, les Eillets sauvages, la Saxifrage bulbifère, les di- 


\section{$-250-$}

verses Primevères des champs, les Anémones du Midi aux brillantes couleurs; toutes ces plantes si diverses et si variées peuvent êtr ə placées dans les pelouses et s'y développent à merveille. Dans les endroits les plus frais ou sur le bord des ruisseaux on place la Menyanthes trifoliata (Trèfle d'eau), les diverses Line-Aigrettes, la Primula farinosa, le Trolle d'Europe, la grande Astrance, les Petasites, le Pavot de Sibérie, les Gcntiana pneumonanthe et asclepiadea, les Ramuculus aconitifolius et platanifolius, les Thatictrum, etc. Sur le bord des bosquets et des massifs d'arbres on plante le Lys martagon, l'Orchis bifolia, les fougères, si variées, de la région boisée et dans la partie fraiche d'un bosquet on sèmera la curieuse et ravissante Impatiens Noli Tangere L. Possédez-vous un endroit sec et aride, un terrain rocailleux et peu fertile? Vite garnissez-le des espèces les plus voraces appartenant à la zone montagneuse. Les Arabis alpina et autres, Alys sum spinosum, les Helianthèmes, certaines espèces de Stellaria et d'Arenaria, l'Anthylis montana, les diverses Herniaria et Paronychia, la Potentille argentée, celle des rochers, Epilobium rosmarinifolium, Crassula mbens, les diverses espèces de Sedum, de Sempervivum, Opuntia vulgaris, Pterocephalus Parnassi, les Santolines, plusieurs Achil- 


\section{$-251-$}

qees et Artémises, tous les Hieracium, Jasione montana, Campanula spicata, pusilla, Verbascum phoeniceum et Blattaria, Antirrtinum Azarina, etc., sont particulièrement propres à cet usage. Dans les endroits rocailleux, mais frais et ombragés, il faut placer les fougères, les Dentaria, le Delphinium elatum. Si vous aimez les fougères, et qui ne saurait les aimer, vous établirez une fougeraie et vous choisirez, à cet effet, un endroit frais, ombragé et un sol poreux, léger et pierreux. Il y a, à la Chaux-de-Fonds, chez un amateur rempli de goût et de talent, M. L. Landry, une admirable fougeraie placée entre une plan. tation de jeunes sapins et d'autres essences forestières. C'est un endroit humide et frais, sol fertile mais léger, puisque c'est celui de la montagne; là, les fougères deviennent superbes et revêtent des formes idéales. On fera bien d'établir sa fougeraie dans un endroit pittoresque et sauvage. On y ajoutera quelques blocs de rochers naturels et, si possible, des troncs darbres qui ne manqueront pas de donner au paysage un caractère pittoresque et naturel. Si le sol est lourd et glaiseux, on l'amendera avec du sable et du terreau de feuilles. Là on placera les nombreuses fougères des bois de notre centre européen, ainsi que celles de l'Amérique du 
Nord et de la Sibérie, et on ne leur donnera d'autres soins que d'arroser en été lorsqu'il fait. trop sec.

Enfin, on établira une pièce d'eau dans laquelle on placera les jolies plantes aquatiques qui garnissent les étangs et les mares de nos contrées. Il n'existe, à proprement parler, pas d'espèces aquatiques dans la flore des montagnes; mais le domaine des plantes sauvages est si rapproché de notre sujet qu'on ne peut le passer sous silence. Il y a, du reste, tant de différentes manières de construire un bassin que nous n'entrerons pas dans des détails à ce sujet. Qu'il soit seulement dit que le courant doit être régulier et l'écoulement facile. Quant à la profondeur, elle peut varier entre $0^{\mathrm{m}} 30$ jusqu'à 1 mètre et plus. Le fond du bassin doit être garni d'une couche de $0^{\mathrm{m}} 25$ à $0^{\mathrm{m}} 30$ de terre, afin de permettre aux racines des plantes de se développer. Certaines espèces, telles que. les Nénuphars, la Villarsia nymphoides, quelques Potamots, peuvent vivre dans une eau très profonde, les tiges de leurs feuilles pouvant atteindre une grande longueur. On assure que celles du Nénuphar arrivent à 5 mètres et que, dans les marécages du Sud de la Russie, ils sont encore plus longs. Mais un bassin convenablement 


\section{$-253-$}

établi n'aura guère plus d'un mètre de profondeur, car la mesure de $1^{\mathrm{m}}$, que je donne comme maximum, est déjà exagérée s'il s'agit d'y cultiver toutes les plantes aquatiques. On réunira dans ce bassin des pieds de Nénuphar blanc et jaune, le trèfle d'eau (Menyanthes trifoliata), la Villarsia nymphoides, Hottonia palustris, Sagitturia sagittcetolia, Hydrocharis Morsus Rane, Aponogeton dystachion, Butomus umbellatus, Vallisneria spiralis, Calla palustris, Saururus ceriuus, Scirpus lacustris, Sparganium ramosum et simplex, les divers Typha, Iris pseudo-Acorus, Acorus Calamus, etc. Quant aux plantes plus marécageuses qu'aquatiques, telles que les Sarracenia de l'Amérique du Nord, les Eryophorum (Line-Aigrette), la Parnassia des marais, les Grassètes, Myosotis palustris, Alisma Plantago et ramunculoides, Anagallis tenella, Saxifraga Hirculus, certains Carex, on les plante dans des pots qu'on place à fleur d'eau, afin quils soyent toujours entretenus dans une certaine humidité.

Enfin, et ceci est le plus joli mode d'emploi des plantes alpines, on peut cultiver les espèces saxatiles dans des murs. Les vieilles ruines, les remparts antiques, les anciennes murailles, sont généralement animés par une végétation intéressante et gracieuse, le plus souvent cryptogamique, mais où 


\section{$-254-$}

l'on rencontre aussi bon nombre d'espèces phanérogames qui s'y installent naturellement. I.es rochers les plus perpendiculaires renferment des touffes qui s'y développent à merveille, et c'est bien souvert dans ces conditions-là que les plantes fleurissent le plus richement et le plus brillamment. M. Ed ${ }^{d}$ Boissier, dans son admirable jardin botanique de Valeyres, est parvenu à tapisser un mur des plantes les plus variées et les plus intéressantes. La Saxifraga longifolia étale ses grandes rosaces argentées à côté du charmant Lychnis Lagasce, de la superbe Campamula Vanneri et d'une foule d'autres espèces toutes plus ravissantes, toutes plus prospères les unes que les autres. Et quelle vigueur chez ces plantes, quelle santé rayonne dans leurs touffes, quelle gaité, quelle animation dans le mélange de leurs mille couleurs! Aussi ce mur de Valleyres, que de jaloux n'a-t-il pas déjà faits et combien d'admirations n'a-t-il pas excitées! C'est un mur de soutènement; il est, par conséquent, plus humide qu'un mur ordinaire, ce qui ne veut pas dire qu'on ne puisse cultiver dans un mur exposé à l'air des deux côtés. J'ai moimême fait l'expérience que les plantes s'en trouvent fort bien, surtout si le mur est épais. Pas n'est besoin de se donner beaucoup de peine 


\section{$-255-$}

pour planter entre les pierres des murailles; on choisit les fissures qui se trouvent entre elles, on enlève une partie du mortier qui s'y trouve, puis on les remplit avec de la terre (terreau de feuilles mélangé de terre franche). On place sa plante dans une position perpendiculaire et on l'assujettit au moyen de petit cailloux que l'on cimente et que l'on maintient en place avec de la terre glaise ou toute autre chose.

Heureux propriétaires qui possédez de vieux murs, vous allez rapidement les transformer en un musée vivant et faire envie à tous vos voisins qui finiront peut-être par décrépir les leurs pour vous imiter. Les murs situés au bas des pentes de terrains et des vignes étant toujours sous l'influence de l'humidité, sont particulièrement propres à cela. On cultivera là, avec grand succès, les diverses fougères saxatiles, telles que: Ceterach officinarum, Polyporlium vulgare, P. Phegopteris, P. Dryopteris, P. Roberticnum, P. alpestie, Cystopteris fragilis, C. alpina, C. montana, Scolopendrium officinarum, Asplenium trychomanes, A. viride, A. Ruta-muraria, Adiantum Capillus Veneris. Cette dernière espèce, si admirable et si gracieuse, ne se montre que rarement en Suisse à l'état sauvage. Elle est abondante au Tessin, se trouve dans une grotte au bord du lac de 
Neuchâtel et dans un rocher au centre dù canton de Vaud. Elle exige une position chaude et humide. On remarquera que, comme c'est le cas chez les phanérogames, les fougères se divisent également en espèces purement terrestres. et en espèces saxatiles. Ce sont ces dernières que je viens d'énumérer et qui derront, dans une fougeraie, garnir un mur ou une rocaille.

Les fougères, plıs que tout autre végétal, recherchent l'humidité et la fraîcheur; on en pourrait douter lorsquion voit certaines espèces d'entre elles tapisser les murs exposés en plein soleil du midi et paraissant absolument secs. Mais si l'on se donne la peine de fouiller ces murs, on verra bientôt que les racines des plantes, dont les tiges sont brùlées par le plus ardent soleil, plongent dans une constante humidité. Qu'elles sont admirables ces ruines du vieux château de Heidelberg, chargées de gracieux Polypodes et de gais Capillaires! Cette végétation qui les recouvre si bien que par place on n'aperçoit plus le mur noirci par les siècles, semble vouloir protester contre la fragilité des choses humaines et parle de vie et d'espérance à l'âme impressionnée par la vue du colosse abattu. Les maitres du Palatinat ont passé, leur ouvrage et jusqu'à leur histoire passera, mais les petites 
plantes qui s'étaient nichées entre les blocs de leurs gigantesques remparts resteront comme pour dire à l'homme qui serait tenté de s'enorgueillir : "Tes œuvres, que sont-elles en présence de celles du Maitre!。

Il n'est pas nécessaire d'allonger et de donner davantage de détails au sujet de la manière dont on peut distribuer les plantes sauvages dans une campagne où l'on recherche le pittoresque et le naturel. Tous les vieux troncs, les pans de murs, les talus, les massifs des arbres, les parties herbeuses subiront cette influence artistique: pour peu qu'on s'en occupe d'une manière un peu suivie, on arrivera bientôt à obtenir en plaine et au centre de nos pays civilisés la nature sauvage et montagnarde. Quelquesuns l'ont déjà fait à Genève et ailleurs; espérons que ce mouvement gagnera tous les amateurs de la nature et se répandra de plus en plus autour de nous.

Il est une certaine quantité de plantes appartenant soit à la région alpine, soit à des zones plus inférieures, dont la culture exige des connaissances particulières et des soins spéciaux. Les espèces marécageuses, celles qui croissent dans les débris moussus que forment les bois de mélezes et de sapins, les plantes purement 
saxatiles dont les touffes sont formées d'une aggiomération de petites rosaces et exposées chez nous à la pourriture, se cultivent plus difficilement que celles dont nous nous sommes entretenus dans un précédent chapitre.

Une certaine catégorie d'entre elles veulent un terrain tourbeux, léger, poreux, afin que leurs longs stolons et leurs fines radicelles puissent se développer à leur aise et pomper l'air et l'humidité dont la plante a besoin. A cet effet, on se procure de la tourbe de montagne, qu'on expose à l'air pendant un certain temps après l'avoir concassée et déchirée le plus possible afin de lui faire perdre son acidité naturelle. On la mélange à du Sphagnum, du sable calcaire ou granitique, et, pour les espèces plus voraces, à une légère quantité de terreau de feuilles. Les plantes qui demandent le sol tourbeux veulent généralement le soleil et le grand air. Si on les cultive dans une rocaille, il faut avoir soin de les placer dans une grande niche, profonde et bien drainée, qui permette l'écoulement facile de l'eau et où l'on puisse les arroser souvent. On peut même placer un robinet qui inonde la niche et qu'on peut ouvrir de temps en temps. Les espèces propres à subir cette culture sont: Vacinium Oxycoccos, V. Vitis idcea, V. Bryrtillus, 
V. uliginosum, Arctostaphylos Alpina, A. Uva ursi, Swertia perennis, Empetrum nigrum, Galax aphylla, les Parnassia, les Sarracenia, les Cypripedium, Anagallis tenella et les Pinguicula. Les plantes appartenant à la famille des Ericacées se cultivent dans un mélange de tourbe et de terre de bruyère. Mais tandis que les Rhododendrons demandent peu de soleil et ne réussissent qu'au levant ou au couchant, les Erica, l'Azalea procumbens demandent le soleil. Cette dernière espèce exige un sol peu profond, bien drainé et mélangé d'un peu de poussière de coke. Il faut avoir soin d'enterrer légèrement ses longues tiges rampantes et d'arroser beaucoup pendant l'été. Dans ces conditions-là, cette plante fleurit assez facilement. Quant au Rhododendron, l'espèce à feuilles hérissées réussit généralement sans beaucoup de difficultés. Il n'en est pas de même du R. ferrugineux, qu'on a beaucoup de peine à faire fleurir chez nous. Nous avons déjà vu que, tandis que le premier croît sur le calcaire, l'autre demande le granit. Les pieds de Rhododendron transplantés de la montagne dans les plaines réussissent rarement. Il faut les semer ou bien emporter de très jeunes exemplaires qu'on élève en pots et qui, à la longue, donnent de forts beaux pieds. Le $R$. cha- 


\section{$-260$}

macistus est une superbe espèce tyrolienne dont la culture est assez facile. - Les Pirolacées, ces charmantes apparitions qui surgissent au fond des bois et dans les taillis les plus touffus, s'acclimatent dans des conditions à peu près analogues aux Vacciniées. Mais il faut éviter trop d'humidité. Prenez de la mousse, des aiguilles de sapin, de la terre de tourbe, du Sphagnum, du bois pourri; mélangez le tout et le placez dans un endroit passablement ombragé, pas trop humide. Là vous pourrez planter l'adorable Pyrola uniflora et ses congénères; la Linnoea borealis réussira dans les mêmes conditions. Dans un sol plus consistant, on plante la Trientalis europara. Quelques Daphne sont difficiles à maintenir dans les cultures; les exemplaires qui sont greffés réussissent général ement mieux que les autres. Le $D$. Cheorum et le D. striata veulent le calcaire, un sol mélangé de cailloux et l'exposition au soleil. Le Daphne alpina exige un peu d'ombre, mais demande d'être planté entre les fentes des rochers. Quant au D. Blagayana, la plus belle espèce de toutes, il aime un sol moussu, léger, tourbeux, mélangé de pierres et de morceaux de colie; il est bon d'enterrer ses longues branches ou de les recouvrir de mousse et de pierres. Les Androsace Helvetisa, imbricata, 


\section{$-261$}

Heerii, pubessens, demandent une position perpendiculaire et doivent être plantées entre les fentes des rochers calcaires ou granitiques, suivant les espèces. L'Androsace glacialis et l'Erytrichium nanum ne peuvent fleurir que si on les cultive dans un sol largement pourvu de poussière de coke et de gravier. Ils exigent une très faible quantité d'humus et une exposition au levant. Les Saxifraga Cernua et arachnoidea sont extrêmement difficiles à conserver dans les rocailles. J'ai réussi la $S$. Cernua dans un sol poreux, léger, tourieux, contenant beaucoup de gravier et un peu de poussière de coke. On m'assure que la $S$. arachnoidea doit réussir dans ces conditions-là. Les Gentianes des régions nivales, G. brachyphilla, G. pumila, G. Bavarica, G. Chusii, G. Frölichii, G. acaulis et ses variétés, fleurissent lorsqu'elles sont cultivées dans de bonnes conditions. Il est bon de les placer au levant ou au couchant, dans une niche bien drainée, dans un sol mélangé de terreau de feuilles, terre de bruyère ou de châtaigniers et tourbe. La Gentiana verna veut le soleil et un sol plus nourrissant.

Un certain nombre d'espèces non mentionnées ici sont à l'étude en ce moment au Jardin alpin, où elles subissent des essais d'acclimata- 
tion. Les résultats obtenus seront donnés dans des publications ultérieures.

Je tiens encore à insister sur ce fait c'est que, dans les cultures alpines, la question de la composition chimique et physique du sol est de toute importance. Faute de posséder le terreau qui convient aux plantes, bien des personnes perdent des espèces jolies et intéressantes, lesquelles eussent certainement prospéré si elles avaient re. trouvé un sol qui leur eût convenu. Les matières propres à amender le sol, énumérées dans le cours de cet ouvrage sont, il est vrai, souvent difficiles à se procurer, surtout pour les personnes qui ne les emploient qu'en petites quantités. C'est dans le but d'aider aux amateurs de cultures alpines et de favoriser le développement de ces cultures que la direction du Jardin d'acclimatation s'est mise en mesure de fournir ces choses en les détaillant. Si, par ce moyen là, le nouvel établissement peut rendre des services à la cause alpine et augmenter le nombre des cultivateurs de ces plantes, il n'en aura que plus de droits à la reconnaissance des alpinistes. 


\section{TABLE DES MATIÈRES}

\section{Pages.}

DÉDICACE. . . . . . . . . . . 3

PrÉFACE ................ 5

\section{Les Alpes et leur nature.}

Les différentes régions. - Le printemps dans les Alpes. - Le fœhn. - Les avalanches. - Les éboulements. - Les glaciers. - L'influence de ces différents phénomènes sur la végétation alpine.

\section{Forêts et déboisement.}

Importance de l'entretien des forêts au point de vue de l'exploitation et de leur bienfaisante influence sur le pays. - Mouvement descendant de la limite supérieure des forêts. - Les conséquences . . .

\section{La végétation dans les Alpes.}

Végétation arborescente. - Sous arbrisseaux. Garactères de la flore alpine. - Arrachages intempestifs. - Jardin alpin d'acclimatation. - Limites supérieures de la végétation dans les Alpes. .

31

IV. Origine de la flore alpine.

Les travaux du docteur Christ. -- Réflexions à ce sujet. - Opinion de M. John Ball . . . . . 48

V. Hapports de la flore alpine arec celle des autres montagues du globe.

\section{Conditions d'existence de Ia flore alpine.}

Chaleur - Lumière. - Humidité. - Sol, sa composition chimique et physique. - Cas d'albinisme chez les plantes. 
VII. Acclimatation et culfure des plantes alpines, leur multiplication et leur reproduction par semis.

Intérêt qu'offrent ces cultures. - Causes de non réussite. - Acclimatation. - Reproduction par semis. - Récolte des graines. - Bouturage et division des touffes. - Culture en rocailles. Terreau. - Culture en plates-bandes. - Culture en pots. . . . . . . . . . 109

VIII. Plantes des Alpes propres à être caltivées.

Ouvrages à consulter. - Liste des plantes alpines qui se cultivent. - Détails sur la manière de cultiver chacune de ces espèces. . . . . . . . 140

\section{Plantes des différentes régions nivales} du globe.

202

\section{Les rocailles.}

Leur apparition dans nos jardins - Les rocailles du Jardin botanique de Genève. - Celles de Valeyres. - Emplacements à choisir. - Travaux préliminaires. - Construction. - Sentiers. Orientation. - Nature des matériaux à employer. - Formes à donner aux rocailles . . . . .

233

\section{$\mathrm{X}$. Jardins alpins.}

Cultures alpines en pleine terre. - A l'humidité. $\mathrm{Au}$ sec. - Sous les arbres. - Dans les pelouses. - Fougreraies. - Plantes aquatiques et marécageuses. - Culture dans les vieux murs. - Cultures spéciales de quelques espèces. . . . . 


\section{JARDIN ALPIN D'ACCLIMATATION}

\section{Directeur: H. Correvon.}

Comité de surveillance: MM. Mare MIcheLI, CARdivalx, Pictet-de Seignecx, D ${ }^{r}$ H Goldet, J. Valley.

Principaux fondateurs: MM. C. de Candolle, A. de Candolle, A. Perrot-Turrettini, Gustave Pictet, Et. Brocher, Th. Audéoud. L. Naville, C. Martin, pasteur. Ant. Nartin, Jules Boissier, Gustare Revilliod. Ph. Plantamour, Naville-Saladin, E. Mittendorf, H. Lombard, $\mathrm{D}^{1}$ Colladon, $\mathrm{A}^{\mathrm{r}}$ Boissier, Ernest Favre, John Demole, C. Favre-de Seigneux, Isaac Demole, Ed. Boissier, H. Galopin, I. Machard, Mallet-de Blonay, $\mathrm{D}^{\mathrm{r}}$ Haltenhof, G. de Seigneux, M. de Seigneux, Paul Chapuy, Correvon-de Bechtold, E. Hess, Th. Morin, $\mathrm{D}^{\mathrm{r}}$ Long, O. Kolseth, etc., etc., et $\mathrm{M}^{\mathrm{m} \text { mes }}$ Wessel, Bizot D ${ }^{\mathrm{r}}$, Girod-Xartin, H. Lullin, Thomas et les membres du Comité.

Ce Jardin a pour but d'élever les plantes de montagnes et de les offrir au public à des prix avantageux; les fondateurs espèrent en faire un Jardin botanique destiné spécialement aux cultures alpines. La société botanique el le Club alpin trouveront là un établissement prêt à servir de laboratoire à ceux d'entre leurs membres qui voudront $y$ entreprendre des études. A part cela, le łardin fait le commerce des plantes horticoles et utilise dans ce but les serres qui se trouvent sur l'emplacement où il est situé. Il publie un catalogue de graines alpines et de plantes. 


\section{JARDIN ALPIN D'ACCLIMATATION}

situé au bout de la plaine de Plainpalais, à l'entrée du chemin Dancet, sur l'emplacement de l'ancien établissement horíicole Paris frères.

Plantes alpines et de rocailles: Plantes dippartements; Plantes aquatiques; Graiues de plantris alpines.

Le catalogue de` graines qui se publiera en Novembre 1881 ct celui de's plantes qui paraitra au printemps 1885 seront envoyés franco sur demande affranchie.

L'établissement est ourert au public tuus les jours de $6 \mathrm{~h}$. du matin à 8 h. du soir en été, et de 7 à 6 h. en hiver, sâuf le dimanche.

Le Jardin entrepremil la construction des rocailles; il se charge de la fuurniture des pierres, de la terre, du sable, des scories et de tout ce qui rentre dans le domaine des cultures alpines. Expédition de graines dans tous les pays.

Le Jardin alpin échange des plantes et des graines arec les Jardins botaniques ou les établissements qui peuvent lui oflrir des espèces qu'il ne possède pas encore.

\section{S'adresser au Directeur :}

2, chemin Dancet, Plainpalais, Genève. 


Correvon, Henry/Les plantes des Alpes

Tin 3 5185001338944 
